\title{
Technical-Economical Approach for PHB Production by Ralstonia Eutropha Strain Using Concentrated Vinasse as Carbon Source and Other Biotechnological Applications
}

\author{
Manuella Silverio ( $\nabla$ mso.silverio@gmail.com ) \\ USP: Universidade de Sao Paulo https://orcid.org/0000-0002-4964-0151 \\ Rosane Piccoli \\ Instituto de Pesquisas Tecnológicas do Estado de São Paulo \\ João Reis \\ Instituto de Pesquisas Tecnológicas do Estado de São Paulo \\ José Gregorio Gomez
}

Universidade de São Paulo

Antonio Baptista

Universidade de São Paulo

\section{Research}

Keywords: in natura vinasse, concentrated vinasse, amino acids, L-threonine, polyhydroxyalkanoates, P(3hydroxybutyrate), SuperPro Designer

Posted Date: October 5th, 2021

DOI: https://doi.org/10.21203/rs.3.rs-942291/v1

License: (c) (i) This work is licensed under a Creative Commons Attribution 4.0 International License.

Read Full License 
Title: Technical-economical approach for PHB production by Ralstonia eutropha strain using concentrated vinasse as carbon source and other biotechnological applications

Authors: Manuella Souza Silverio ${ }^{1,2^{*}}$, Rosane Aparecida Moniz Piccoli², João Lucas Maehara Said dos Reis², José Gregório Cabrera Gomez³, Antonio Sampaio Baptista ${ }^{1}$

1Escola Superior de Agricultura "Luiz de Queiroz", Universidade de São Paulo Av. Pádua Dias, 11, Piracicaba/São Paulo, Brazil

${ }^{2}$ Instituto de Pesquisas Tecnológicas do Estado de São Paulo - Av. Professor Almeida Prado, 532, São Paulo/São Paulo, Brazil ${ }^{3}$ Instituto de Ciências Biomédicas, Universidade de São Paulo - Av. Professor Lineu Prestes, 1374, São Paulo/São Paulo, Brazil “corresponding author: mso.silverio@usp.br 


\section{Abstract}

2 The Brazilian ethanol industry is one of the most important in the global market, however these 3 important industrial activities have been generating significant amounts of vinasse and its 4 management has become costly for distilleries. In this study, the aim was to evaluate concentrated and in natura vinasse as basal culture media for biotechnological processes.

6 Different bacteria and processes were assessed: L-threonine production by E. coli THR14, with 7 glucose as carbon source; PHB production by halophilic strain Halomonas sp. HG03, with sucrose 8 as carbon source; and PHB biosynthesis by $R$. eutropha L359PCJ, which used glycerol from vinasse as carbon source. Strains were evaluated firstly in shake flasks cultivations using vinassebased media. E. coli THR14 had no statistical difference for biomass and L-threonine concentrations among control and vinasse-based treatments (up to $50 \% \mathrm{v} \mathrm{v}^{-1}$ of in natura vinasse). Halomonas sp. HG03 and R. eutropha L359PCJ were cultivated in mineral media diluted by in natura ( $50 \%$ and $\left.75 \% \mathrm{v} \mathrm{v}^{-1}\right)$ and concentrated $\left(50 \%\right.$ and $\left.75 \% \mathrm{v} \mathrm{v}^{-1}\right)$ vinasses. Higher vinasse concentrations resulted in higher cellular growth rather than PHB accumulation for both bacteria. In vinasse-based treatments, Halomonas sp. HG03 had PHB content between 19.6 $75.2 \%$ and $R$. eutropha L359PCJ, $48.4-68.5 \% .50 \%\left(\mathrm{v} \mathrm{v}^{-1}\right)$ of concentrated vinasse was the most attractive condition for PHB production by both bacteria. Further experiments in CSTR bioreactors used this nutritional condition and R. eutropha L359PCJ had PHB content of $66.3 \%$, concentrations of residual cell dry weight $(\mathrm{rCDW})=9.4 \mathrm{~g} \mathrm{~L}^{-1}$ and $\mathrm{PHB}=18.6 \mathrm{~g} \mathrm{~L}^{-1}$, with $\mathrm{Y}_{\mathrm{X} / \mathrm{S}}=$ $0.16 \mathrm{~g} \mathrm{~g}_{\mathrm{GLYCEROL}}{ }^{-1}, \mathrm{YP}_{\mathrm{P} / \mathrm{S}}=0.32 \mathrm{~g} \mathrm{~g}_{\mathrm{GLYCEROL}}{ }^{-1}$ and $0.25 \mathrm{gPHB} \mathrm{Lh}^{-1}$. Halomonas sp. HG03 had PHB content of $45.7 \%, \mathrm{rCDW}=9.8 \mathrm{~g} \mathrm{~L}^{-1}, \mathrm{PHB}=8.3 \mathrm{~g} \mathrm{~L}^{-1}$ and $\mathrm{YX}_{\mathrm{X} / \mathrm{S}}=0.18 \mathrm{~g}_{\text {gSUCROSE}}{ }^{-1}, \mathrm{YP}_{\mathrm{S}}=0.16 \mathrm{~g}$ gSUCROSE $^{-1}$ and $0.12 \mathrm{gPHB}_{\mathrm{Lh}}{ }^{-1}$. Finally, cost reductions of PHB production by $R$. eutropha L359PCJ with concentrated vinasse-based medium were evaluated in silico by using SuperPro Designer. As a partial source of glycerol and other nutrients for PHB production by $R$. eutropha L359PCJ, vinasse reduced overall production costs by $13 \%$. Simulated processes that used concentrated vinasse-based media combined with improvements of PHB productivity and higher cellular densities had production costs between US\$ $3.9-7.5 / \mathrm{kg}$ PHB and $2.6-7.3$ years of payback time.

29 Keywords: in natura vinasse; concentrated vinasse; amino acids; L-threonine; polyhydroxyalkanoates; P(3-hydroxybutyrate); SuperPro Designer. 


\section{Introduction}

32 Global demand for green fuels has increased in recent years and it is expected to increase even

33 further. Bioethanol is one of the most important among these, along with biodiesel, biogas and others. Together, the United States and Brazil account for about $85 \%$ of the global ethanol supply. Brazil has a sucrose-based industry, established on sugarcane exploit by using juice, molasse and, more recently, lignocellulosic material as carbon source for alcoholic fermentation and other industrial systems make use of resources from sugarcane: sugar, bioenergy and derivatives (OECD, 2021; Salles-Filho et al., 2017).

Vinasse is the main wastewater produced by Sucroenergetic activities as it is the remaining fermented broth after distillation. All residual organic matter, metabolites and nutrients from fermented broth are found in vinasse, except for ethanol, which is efficiently recovered. About 10$15 \mathrm{~L}$ of vinasse are generated along with $1 \mathrm{~L}$ of ethanol, which implies an annual vinasse supply of over 300 billion L. Its composition is dependent on the ethanol process, so different sorts and quality of feedstocks, as well as process conditions and operations affect vinasse characteristics (Cortez, 2010). In general, vinasses have very high polluting potential (COD between $21,000-34,000 \mathrm{mgO}_{2} \mathrm{~L}^{-1}$ ) and they are a source of carbon compounds and salts: glycerol has been frequently described to be found in concentrations about 10,0 $\mathrm{g} \mathrm{L}^{-1}$ (Ortiz-Muniz et al., 2010; Souza et al., 2015); organic acids such as lactic acid and acetic acid have been reported in concentrations up to $7.0 \mathrm{~g} \mathrm{~L}^{-1}$ and

$502.2 \mathrm{~g} \mathrm{~L}^{-1}$, respectively (Dowd, Johansen \& Cantarella, 1994; Lopes et al., 2016); potassium, sodium and calcium salts, in concentrations of $13.0 \mathrm{~g} \mathrm{~L}^{-1}, 31.3 \mathrm{~g} \mathrm{~L}^{-1}$ and $5.2 \mathrm{~g} \mathrm{~L}^{-1}$, respectively

52 (Coelho et al., 2018; España-Gamboa et al., 2011; España-Gamboa et al., 2012; Ferreira et al.,

53 2011; Moraes, Zaiat \& Bonomi, 2015; Pedro-Escher, Maziviero \& Fontanetti, 2014; Souza et al., 54 2015).

55 Vinasses are frequently used as fertilizers in sugarcane crops, but such application has shown 56 limitations and concerns. Researchers have reported environmental issues such as soil 57 salinization; superficial and groundwaters contamination by sulphates, nitrates, metals; and 58 greenhouse gases emissions by degradation of carbon and nitrogen compounds found in vinasse 59 (Cassman et al., 2018; Pedro-Escher, Maziviero \& Fontanetti, 2014; Soto et al. 2015). 
Vinasse application as a fertilizer for sugarcane crops in Brazil emerged during the 80's, when a

61 governmental program favored the bioethanol industry in Brazil. By that time, the Brazilian

62 production increased by three fold in less than ten years, while vinasse generation is estimated

63 to have increased about three to five fold as well. However, technologies for vinasse treatment

64 did not receive the same investments as ethanol production did. Before the aforementioned 65 program, vinasses were disposed of in rivers and bodies of water. Thus, applying vinasse as a

66 soil fertilizer was an alternative and immediate solution for increasing volumes of wastewaters in

67 such a short period of time (Ribeiro, Novais \& Bahia-Filho 1983; UNICA, 2021).

68 Nowadays, the increasing ethanol production has made it necessary to find innovative solutions

69 for increasing volumes of vinasse. Such solutions may be integrated with value-added

70 bioproducts, bioenergy and biological waste treatment.

71 Amino acids are among the largest biocommodities markets. These bioproducts are largely used

72 in animal nutrition, in chemical and other bio-industries. Global market of amino acids is estimated

73 to reach about US\$29-35 billions between 2022 and 2024 (Grand View Research, 2015; Global

74 Industry Analysts Inc., 2018).

75 Poly(3-hydroxybutyrate) (PHB) is one of the main polyhydroxyalkanoates (PHAs), which are 76 precursors of bioplastics, a growing market that has received increasing investments as a result 77 of expanding policies on sustainability around the world. By 2025, global PHA market is expected 78 to grow about $14 \%$ and become one of the main sectors in bioplastics market, along with 79 polylactates (European Bioplastics, 2020; Sreedevi et al., 2014).

80 These bioproducts are synthesized by very robust microorganisms, which are advantageous for 81 bioprocesses because they have sets of molecular tools available for metabolic engineering, they

82 can metabolize a wide range of carbon sources and be cultured in low cost culture media.

83 In this study we aimed to evaluate technological applications for vinasse by cultivating bacterial 84 strains in vinasse-based culture media. We cultivated an E. coli L-threonine-producing strain in 85 mineral medium with volumetric dilutions of in natura vinasse. PHB-producing strains of $R$. 86 eutropha and Halomonas sp. were cultivated in concentrated and in natura vinasse-based media.

87 Vinasse was used as basal culture media and a source of water, salts and carbon. Shake flasks 88 and bioreactor fermentations were carried out and, finally, experimental data were used to 
simulate large scale bioprocesses in SuperPro Designer. Technical and economical feasibility were assessed and the potential of using vinasse as nutrients source was evaluated.

\section{Material and Methods}

\section{Vinasse}

94 Vinasse was obtained from a distillery in São Paulo State, Brazil, which produces ethanol from sugarcane molasses. In our laboratory, vinasse was concentrated to $34.4^{\circ} \mathrm{Brix}$ and kept at $4^{\circ} \mathrm{C}$. In order to apply vinasse in chemical analyses and experiments, the highly concentrated material was diluted in distilled water $\left(\mathrm{m} \mathrm{m}^{-1}\right)$ so final concentrations could be obtained. In this study, we named in natura vinasse the material diluted to $3.4^{\circ}$ Brix, simulating the concentration found in the output stream of bioethanol process.

100 Before all analytical procedures and shake flasks experiments, vinasses were filtered in vacuum

101 filtration system, which consisted of a Kitassato flask, Büchner funnel and qualitative paper filter.

102 Prior to all experiments, vinasses had pH set to $6.8<\mathrm{pH}<7.8$ with $\mathrm{NaOH} 10 \mathrm{M}$ or $\mathrm{NH}_{4} \mathrm{OH} 4 \mathrm{M}$

103 solutions, followed by autoclave sterilization, and then vinasses were added to sterile culture

104 media. In natura vinasse had pH = 4.3 and its chemical composition is presented in Table 1.

Table 1. In natura vinasse chemical composition (3.4ํㅜㄱix)

Microrganisms

109 For L-threonine production experiments, it was utilized the strain E. coli MG1655 $\Delta$ metJIQ $\Delta$ lysA 110 pBBR1MCS2::rhtC-thrB, a L-lysine auxotroph, which was conveniently named as E. coli THR14 111 in this study. For PHB production experiments, two strains were used. We employed the halophilic 112 strain Halomonas sp. HG03, which is derived from Halomonas HG01, a PHB-producing bacteria. 113 Halomonas sp. HG01 was first isolated from salines in Peru and it is naturally capable of 114 consuming glucose and sucrose. Halomonas sp. HG03 was submitted to evolutionary 115 engineering so a glycerol-consuming strain could be obtained (Moreno, 2015; Cardinali-Rezende 116 et al., 2016). An efficient glycerol-consuming strain was also employed for PHB production 117 experiments: Ralstonia eutropha PHB-4 LFM035-9 pBBR1MCS-2::phaPCJ, which was 118 conveniently named as $R$. eutropha L359PCJ in this study. 
119 All microorganisms were kept in glycerol solution $\left(20 \% \mathrm{v} \mathrm{v}^{-1}\right)$ at $-80^{\circ} \mathrm{C}$. Before experiments, they

120 were all cultivated in their respective solid culture media, kept at $30^{\circ} \mathrm{C}$ for $24-36 \mathrm{~h}$ and then a

121 loopful from a single colony was inoculated into fresh liquid medium for inoculum preparation.

123 Shake flasks fermentations

124 L-threonine production by E. coli THR14

\section{Culture conditions}

126 Luria-Bertani (LB) medium was used for E. coli THR14. Inoculum preparation was carried out by 127 inoculating a single colony into fresh liquid medium, followed by a $12 \mathrm{~h}$ incubation at $30^{\circ} \mathrm{C}$ and $128180 \mathrm{rpm}$. The culture was then used as inoculum for L-threonine biosynthesis. The mineral 129 medium $\mathrm{MM}_{E c}$ was adapted from Lee et al. (2006) (L-1): glucose, $25.0 \mathrm{~g}$; $\left(\mathrm{NH}_{4}\right)_{2} \mathrm{SO}_{4}, 5.0 \mathrm{~g}$; $130 \mathrm{KH}_{2} \mathrm{PO}_{4}, 8.5 \mathrm{~g} ; \mathrm{MgSO}_{4}, 1.0 \mathrm{~g}$; sodium citrate, $0.5 \mathrm{~g}$; L-lysine, $0.5 \mathrm{~g}$; $\mathrm{CaCO}_{3}, 10.0 \mathrm{~g}$; and trace 131 elements solution, $1.0 \mathrm{~mL}$, with the following composition $\left(\mathrm{L}^{-1}\right)-\mathrm{CaCl}_{2}, 13.2 \mathrm{~g}$; $\mathrm{FeSO}_{4}, 8.4 \mathrm{~g}$; $132 \mathrm{MnSO}_{4}, 2.4 \mathrm{~g} ; \mathrm{ZnSO}_{4}, 2.4 \mathrm{~g} ; \mathrm{CuSO}_{4}, 0.48 \mathrm{~g} ; \mathrm{CoCl}_{2}, 0.48 \mathrm{~g} ; \mathrm{Na}_{2} \mathrm{MoO}_{4}, 0.24 \mathrm{~g} ; \mathrm{K}_{2} \mathrm{~B}_{4} \mathrm{O}_{7}, 0.06 \mathrm{~g}$, 133 diluted in $\mathrm{HCl} 1 \mathrm{~N}$ and sterilized by ultrafiltration.

135 Evaluation of E. coli cellular growth and L-threonine biosynthesis in vinasse-based culture media 136 Vinasse-based culture media consisted of volumetric dilutions of in natura vinasse $\left(3.4^{\circ} \mathrm{Brix}\right)$ in

$137 \mathrm{MM}_{E c \text {. }}$ Four treatments were evaluated: $25 \%\left(\mathrm{v} \mathrm{v}^{-1}\right)$ of vinasse in $\mathrm{MM}_{E c}\left(\mathrm{MM}_{E c} \mathrm{~V} 253\right) ; 50 \%\left(\mathrm{v} \mathrm{v}^{-1}\right)$ 138 of vinasse in $\mathrm{MM}_{E C}\left(\mathrm{MM}_{E C} \mathrm{~V} 503\right)$; and $75 \%\left(\mathrm{v} \mathrm{V}^{-1}\right)$ of vinasse in $\mathrm{MM}_{E c}\left(\mathrm{MM}_{E C} \mathrm{~V} 753\right)$; control

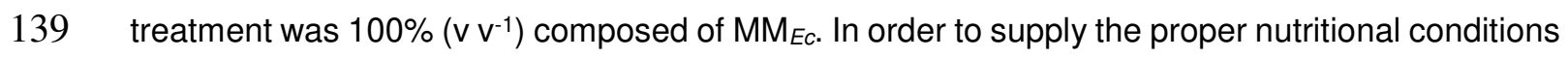
140 for E. coli THR14 growth, all treatments had carbon (glucose), nitrogen (ammonium sulphate), 141 phosphate $\left(\mathrm{KH}_{2} \mathrm{PO}_{4}\right)$ sources and L-lysine set to the same concentrations, as those described 142 above for $\mathrm{MM}_{E c}$, and $\mathrm{pH}$ was adjusted to $6.8<\mathrm{pH}<7.8$ with $\mathrm{NH}_{4} \mathrm{OH} 4 \mathrm{M}$. All treatments for L143 threonine production were carried on with inoculum ratio of $10 \% \mathrm{v} \mathrm{v}^{-1}, 50 \mathrm{~mL}$ of culture medium 144 in $250 \mathrm{~mL}$ flasks, kept at $30^{\circ} \mathrm{C}$, under agitation of $180 \mathrm{rpm}$ for $24 \mathrm{~h}$. All steps of E. coli THR14 145 cultivation had a final concentration of kanamycin sulphate $0.25 \mu \mathrm{g} \mathrm{L}^{-1}$.

146 Before cultivation started, culture media samples were collected for determination of initial 147 substrates concentration. By the end of $24 \mathrm{~h}$ incubation, final substrates concentrations were 148 quantified and cellular dry weight was determined by gravimetric method. 


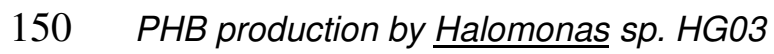

\section{Culture conditions}

152 Halophilic nutrient broth was used for Halomonas sp. HG03 culture in solid medium and for 153 inoculum preparation ( $\left.\mathrm{L}^{-1}\right)$ : beef extract, $3.0 \mathrm{~g}$; peptone, $5.0 \mathrm{~g} ; \mathrm{NaCl}, 100 \mathrm{~g}$. A single colony from 154 solid culture was inoculated into fresh liquid medium and kept at $30^{\circ} \mathrm{C}$, under $150 \mathrm{rpm}$ agitation 155 for $18 \mathrm{~h}$. Culture was then used as inoculum for experiments of PHB production in mineral medium $156\left(\mathrm{MM}_{\mathrm{Ha}}\right)$ adapted from Rocha et al. (2008) $\left(\mathrm{L}^{-1}\right)$ : sucrose, $15.0 \mathrm{~g} ; \mathrm{Na}_{2} \mathrm{HPO}_{4}, 3.5 \mathrm{~g} ; \mathrm{KH}_{2} \mathrm{HPO}_{4}, 1.5$ $157 \mathrm{~g} ;\left(\mathrm{NH}_{4}\right)_{2} \mathrm{SO}_{4}, 1.0 \mathrm{~g} ; \mathrm{MgSO}_{4} .7 \mathrm{H}_{2} \mathrm{O}, 0.2 \mathrm{~g} ; \mathrm{CaCl}_{2} .2 \mathrm{H}_{2} \mathrm{O}, 0.01 \mathrm{~g}$; ammonium ferric citrate, $0.06 \mathrm{~g}$; $158 \mathrm{NaCl}, 80.0 \mathrm{~g}$; and trace elements solution with the following composition $\left(\mathrm{L}^{-1}\right)-\mathrm{H}_{3} \mathrm{BO}_{3} 0.3 \mathrm{~g}$; $159 \mathrm{CoCl}_{2} .6 \mathrm{H}_{2} \mathrm{O}, 0.2 \mathrm{~g} ; \mathrm{ZnSO}_{4} .7 \mathrm{H}_{2} \mathrm{O}, 0.1 \mathrm{~g} ; \mathrm{MnCl}_{2} .4 \mathrm{H}_{2} \mathrm{O}, 0.03 \mathrm{~g} ; \mathrm{NaMoO}_{4} .2 \mathrm{H}_{2} \mathrm{O}, 0.03 \mathrm{~g} ; \mathrm{NiCl}_{2} .6 \mathrm{H}_{2} \mathrm{O}$, $160 \quad 0.02 \mathrm{~g} ; \mathrm{CuSO}_{4} .5 \mathrm{H}_{2} \mathrm{O}, 0.01 \mathrm{~g}$.

162 Evaluation of Halomonas sp. HG03 cellular growth and PHB biosynthesis in vinasse-based 163 culture media

164 Control treatment consisted of culture medium composed of $100 \%\left(\mathrm{v} \mathrm{v}^{-1}\right) \mathrm{MM}_{\mathrm{Ha}}$. Experiments with

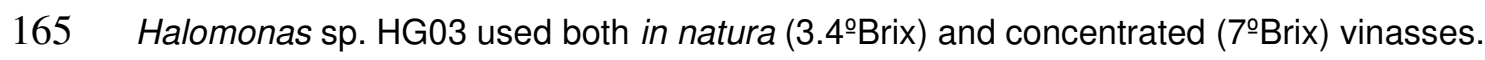

166 The following volumetric dilutions of vinasses were evaluated: $50 \%\left(\mathrm{v} \mathrm{v}^{-1}\right)$ of vinasse $3.4^{\circ}$ Brix in

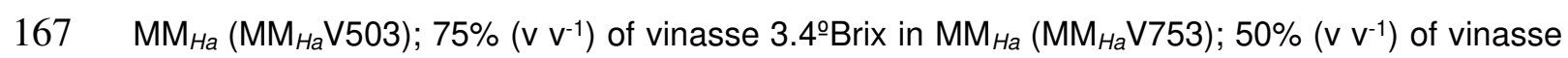
$1687^{\circ} \mathrm{B}$ Brix in $\mathrm{MM}_{\mathrm{Ha}}\left(\mathrm{MM}_{\mathrm{Ha}} \mathrm{V} 507\right)$; and $75 \%\left(\mathrm{v} \mathrm{v}^{-1}\right)$ of vinasse $7^{\circ}$ Brix in $\mathrm{MM}_{\mathrm{Ha}}\left(\mathrm{MM}_{\mathrm{Ha}} \mathrm{V} 757\right)$.

169 Carbon (sucrose), nitrogen (ammonium sulphate), phosphate $\left(\mathrm{Na}_{2} \mathrm{HPO}_{4}, \mathrm{KH}_{2} \mathrm{HPO}_{4}\right.$ ) sources and $170 \mathrm{NaCl}$ were set to the same concentrations for all treatments. Experiments were carried out with 171 initial $6.8<\mathrm{pH}<7.8$, adjusted with $\mathrm{NaOH} 10 \mathrm{M}$, inoculum ratio of $5 \%\left(\mathrm{v} \mathrm{v}^{-1}\right)$ in $125 \mathrm{~mL}$ flasks with $17225 \mathrm{~mL}$ of culture medium, incubated at $30^{\circ} \mathrm{C}$, under $150 \mathrm{rpm}$ agitation for $48 \mathrm{~h}$.

173 At time $\mathrm{t}=0 \mathrm{~h}$, culture media samples were collected in order to determine initial concentration of 174 substrates. By the end of $48 \mathrm{~h}$, processes were interrupted, cultures were submitted to 175 centrifugation at $4500 \mathrm{~g}, 15 \mathrm{~min}, 4^{\circ} \mathrm{C}$ and cells were separated from supernatant. Pellets with 176 cells were further used for determination of residual cell dry weight (rCDW) and PHB content (\% $177 \mathrm{~m} \mathrm{~m}^{-1}$ ); supernatant was used for quantification of residual substrates and residual concentration 178 of ammonium. 


\section{Culture conditions}

182 LB culture medium was used for $R$. eutropha L359PCJ culture in solid medium and for inoculum 183 preparation, which was carried with the same procedures described for Halomonas sp. HG03.

184 The mineral medium $\mathrm{MM}_{\text {Re }}$ was adapted from Rocha et al. (2008) and it had the same composition 185 as the medium used for Halomonas sp. HG03, except it did not have $\mathrm{NaCl}$ added and glycerol 186 was the carbon source $\left(15.0 \mathrm{~g} \mathrm{~L}^{-1}\right)$.

188 Evaluation of $R$. eutropha L359PCJ cellular growth and PHB biosynthesis in vinasse-based 189 culture media

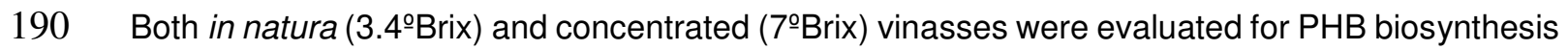
191 by $R$. eutropha L359PCJ. The control treatment consisted of $100 \%\left(\mathrm{v} \mathrm{v}^{-1}\right)$ mineral medium $\mathrm{MM}_{R e}$,

192 in which glycerol was fully provided by a concentrated sterile solution of $150 \mathrm{~g} \mathrm{~L}^{-1}$ glycerol.

193 Vinasse-based treatments had glycerol partially or fully provided by vinasse, according to the 194 volumetric dilutions: $50 \%\left(\mathrm{v} \mathrm{v}^{-1}\right)$ of vinasse $3.4^{\circ}$ Brix in $\mathrm{MM}_{R e}\left(\mathrm{MM}_{\mathrm{Re}} \mathrm{V} 503\right)$ had $2.5 \mathrm{~g} \mathrm{~L}^{-1}$ of glycerol;

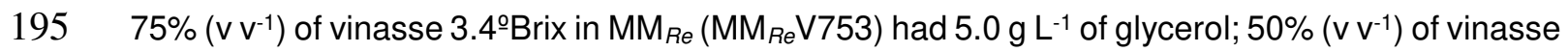
$1967^{\circ}$ Brix in $\mathrm{MM}_{R e}\left(\mathrm{MM}_{R e} \mathrm{~V} 507\right)$ had $7.5 \mathrm{~g} \mathrm{~L}^{-1}$ of glycerol; $75 \%\left(\mathrm{v} \mathrm{v}^{-1}\right)$ of vinasse $7^{\circ}$ Brix in $\mathrm{MM}_{R e}$ $197\left(\mathrm{MM}_{R e} \mathrm{V757}\right)$ had $15.0 \mathrm{~g} \mathrm{~L}^{-1}$ of glycerol. Finally, a concentrated glycerol solution $\left(150 \mathrm{~g} \mathrm{~L}^{-1}\right)$ was 198 used to supplement glycerol in vinasse-based treatments $\mathrm{MM}_{R e} \mathrm{~V} 503, \mathrm{MM}_{R e} \mathrm{V753}$ and $\mathrm{MM}_{R e} \mathrm{~V} 507$,

199 so all treatments were set to the same initial concentration of $15.0 \mathrm{~g} \mathrm{~L}^{-1}$ glycerol. No external 200 carbon source was added in $\mathrm{MM}_{R e} \mathrm{~V} 757$ treatment.

201 Carbon (glycerol), nitrogen (ammonium sulphate) and phosphate $\left(\mathrm{Na}_{2} \mathrm{HPO}_{4}\right.$ and $\left.\mathrm{KH}_{2} \mathrm{HPO}_{4}\right)$ 202 sources were set to the same concentrations in all treatments for $R$. eutropha L359PCJ 203 cultivations. All steps of $R$. eutropha L359PCJ cultivations had a final concentration of $0.25 \mu \mathrm{g} \mathrm{L}^{-}$ $204{ }^{1}$ of kanamycin sulphate.

205 Experiments were carried out at $30^{\circ} \mathrm{C}$, under $150 \mathrm{rpm}$ agitation for $48 \mathrm{~h}$, and both culture 206 conditions and samples treatment were the same as those described above for Halomonas sp. 207 HG03. 
209 All experiments in shake flasks had treatments conducted in triplicates and analytical procedures

210 were carried out in duplicates. Data were analyzed using ANOVA and means were compared

211 with Tukey's test (5\% probability), by using ExpDes.pt package in RStudio software (Ferreira,

212 Cavalcanti \& Nogueira 2014).

213

214 Bioreactor fermentations

215 PHB-producing strains R. eutropha L359PCJ and Halomonas HG03 were further cultivated in

216 CSTR bioreactors, model Biostat ${ }^{\circledR}$ Cplus, Sartorius Stedim Biotech, with a $15 \mathrm{~L}$ vessel.

217 Bioprocesses were carried on in consecutive batches: two initial batches had growth-inducing 218 conditions, followed by batches that induced nutritional conditions for PHB accumulation. The aim 219 was to achieve higher concentration of $\mathrm{rCDW}$ before imposing nitrogen limitation for PHB 220 accumulation. Besides, we aimed to minimize any osmotic stress in growth phases that could be 221 a result of higher concentrations of carbon source, salts and vinasse.

222 Inoculum preparation followed the same procedures described above for shake flasks 223 fermentations. Both R. eutropha L359PCJ and Halomonas HG03 strains were cultivated with 224 initial volume of $6 \mathrm{~L}$, inoculum ratio of $10 \%\left(\mathrm{v} \mathrm{v}^{-1}\right)$ and nutritional conditions from $\mathrm{MM}_{R e} \mathrm{~V} 507$ and $225 \mathrm{MM}_{\mathrm{Ha}} \mathrm{V} 507$ treatments were chosen for PHB production in bioreactors.

226 Bacteria were cultivated in culture media composed of mineral medium MMB, adapted from 227 Rocha et al. (2008), and a volumetric dilution of $50 \%$ of concentrated vinasse ( $7^{\circ}$ Brix) was used 228 (Table 2).

230 Table 2. Culture medium composition for bioprocesses of PHB production in CSTR 231 bioreactors.

233 Similarly to flask cultivations with $R$. eutropha L359PCJ, glycerol was partially provided by vinasse

234 (7.5 $\left.\mathrm{g} \mathrm{L}^{-1}\right)$, and a concentrated solution of pure glycerol $\left(300 \mathrm{~g} \mathrm{~L}^{-1}\right)$ was used to set a final 235 concentration of $15 \mathrm{~g} \mathrm{~L}^{-1}$ in all batch cultivations. 
236 Once the carbon source reached limiting concentration, below $5 \mathrm{~g} \mathrm{~L}^{-1}$, the first batch was 237 considered finished. The second batch was initiated by adding a concentrated solution $(0.7 \mathrm{~L})$, so

238 nutrients from mineral medium could be set to concentrations described in Table 2. A 239 concentrated solution of pure glycerol and highly concentrated vinasse (34.4ำix) provided the 240 final concentration of $15 \mathrm{~g} \mathrm{~L}^{-1}$ of glycerol (1:1). Finally, working volume was $6.7 \mathrm{~L}$.

241 Once carbon source in the second batch became limiting, further batches aiming to PHB 242 accumulation were initiated by adding concentrated vinasse ( $34.4^{\circ}$ Brix) and pure glycerol solution $243\left(300 \mathrm{~g} \mathrm{~L}^{-1}\right)$ as the sole nutrients source. These materials were added in variable volumes, so the 244 final concentrations of glycerol from vinasse $\left(7.5 \mathrm{~g} \mathrm{~L}^{-1}\right)$ and pure glycerol $\left(7.5 \mathrm{~g} \mathrm{~L}^{-1}\right)$ were kept the 245 same for all batches. PHB accumulation phase was ceased once the culture reached stationary 246 growth phase.

247 Halomonas sp. HG03 used sucrose as carbon source, which was fully provided by adding a 248 concentrated solution $\left(600 \mathrm{~g} \mathrm{~L}^{-1}\right)$ so final concentration could be set to $15 \mathrm{~g} \mathrm{~L}^{-1}$.

249 Once sucrose reached limiting concentration, below $5 \mathrm{~g} \mathrm{~L}^{-1}$, the first batch was finished and the 250 second batch was carried on similarly to the procedure described for $R$. eutropha L359PCJ. A 251 concentrated solution ( $0.7 \mathrm{~L}$ ) containing nutrients from mineral medium (Table 2 ), a concentrated 252 solution of sucrose $\left(600 \mathrm{~g} \mathrm{~L}^{-1}\right)$ and highly concentrated vinasse $\left(34.4^{\circ}\right.$ Brix $)$ were added. Glycerol 253 from vinasse was not the preferable carbon source of Halomonas sp. HG03, but its concentration 254 in culture medium $\left(7.5 \mathrm{~g} \mathrm{~L}^{-1}\right)$ was efficiently used as an indicator of vinasse dilution in bioreactor, 255 so the volumetric dilution of $50 \%$ could be kept the same for all batches.

256 After the second batch was finished, further batches aiming to PHB accumulation were initiated

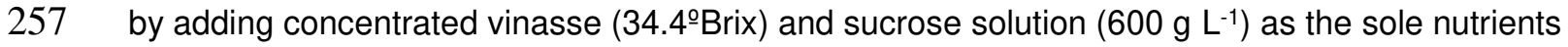
258 source, aiming to keep the volumetric dilution of $50 \%\left(\mathrm{v} \mathrm{v}^{-1}\right)$ of concentrated vinasse and $15 \mathrm{~g} \mathrm{~L}^{-1}$ 259 of sucrose for all batches. Consecutive batches with Halomonas sp. HG03 were carried on until 260 stationary growth phase was observed.

261 Bioprocesses with both $R$. eutropha L359PCJ and Halomonas sp. HG03 were carried on at 30C 262 and $\mathrm{pH}$ was automatically controlled at $6.8<\mathrm{pH}<7.8$ by addition of $\mathrm{H}_{2} \mathrm{SO}_{4} 1 \mathrm{M}$ and $\mathrm{NaOH} 2 \mathrm{M}$ 263 solutions. The air inflow was set to $3 \mathrm{Lpm}(0.5 \mathrm{vvm})$ and agitation speed was initially set to 300 
264 rpm. Bioreactors were set to keep saturation of dissolved oxygen at $40 \%$ by controlling both air 265 inflow and agitation.

266 Bioprocess data were further used for calculation of instantaneous velocities $\left(\mathrm{g} \mathrm{Lh}^{-1}\right)$ of product 267 formation $\left(r_{P}\right)$ and cellular growth $\left(r_{x}\right)$ :

$$
r_{P}=\frac{\mathrm{d}\left(P_{f}-P_{i}\right)}{\mathrm{d}\left(t_{f}-t_{i}\right)}
$$

269

270

271

$$
r_{X}=\frac{\mathrm{d}\left(X_{f}-X_{i}\right)}{\mathrm{d}\left(t_{f}-t_{i}\right)}
$$

272

273

274 Specific velocities of residual biomass formation $\left(\mu_{x} \mathrm{~h}^{-1}\right)$ and product formation $\left(\mu_{P} g \mathrm{gh}^{-1}\right)$ were 275 also determined:

$$
\mu_{P}=\frac{1}{\mathrm{X}} \cdot r_{P}
$$

277

278

279

$$
\mu_{X}=\frac{1}{\mathrm{X}} \cdot r_{X}
$$

280

eq. (4)

281

282 Maximum growth velocity $\left(\mu_{\max } \mathrm{h}^{-1}\right)$ was determined using $\mathrm{rCDW}$ concentration, as described by

283 the equation below:

$$
\ln \frac{X_{f}}{X_{i}}=\mu \max \cdot\left(t_{f}-t_{i}\right)
$$

287 PHB productivity $\left(\mathrm{Pp}_{P H B} \mathrm{~g} \mathrm{Lh}^{-1}\right)$ was calculated for a given variation of product concentration within 288 a time range: 


$$
P_{P p h b}=\frac{\left(P_{f}-P_{i}\right)}{\left(t_{f}-t_{i}\right)}
$$

291 Finally, product $\left(\mathrm{Y}_{P / S} \mathrm{~g} \mathrm{~g}^{-1}\right)$ and biomass $(\mathrm{rCDW})\left(\mathrm{Y}_{X / S} \mathrm{~g} \mathrm{~g}^{-1}\right)$ yields were determined for a variation

292 of product and biomass concentrations given the substrate consumption:

$$
Y_{X / S}=\frac{\left(X_{f}-X_{i}\right)}{\left(S_{i}-S_{f}\right)}
$$

$$
Y_{P / S}=\frac{\left(P_{f}-P_{i}\right)}{\left(S_{i}-S_{f}\right)}
$$

298 Analytical methods

299 Vinasse refractive index was determined as Brix Degrees (午Brix), by using digital refractometer.

300 Organic acids (acetic acid, lactic acid) and carbohydrates (glucose, fructose, sucrose, glycerol) 301 were analyzed by liquid chromatography (HPLC) in a Dionex® system (Ultimate 3000 , Thermo

302 Fisher Scientific Inc, Waltham, MA, USA) with Aminex HPX-87H Bio-Rad column and

303 RefractoMax 520 detector. lonic forms of calcium, potassium, sodium and ammonium in vinasse

304 were determined by ionic chromatography using Metrohm 930 Compact system, with Metrosep

305 C4 250/4.0 column. Amino acids were quantified by using the Phenomenex "EZ: Faast ( ${ }^{\mathrm{TM}}$ ) Family

306 of Amino Acids Analysis Kit”, for GC-FID determination (Badawy, 2012).

307 In E. coli THR14 cultures, cell dry weight was determined by gravimetric method. Culture media

308 were centrifuged at $10,000 \mathrm{~g}$, for 10 minutes, at $10^{\circ} \mathrm{C}$. Pellets were then resuspended in distilled

309 water, cells were harvested with filtration membranes $(0.22 \mu \mathrm{m})$, and finally submitted to $105^{\circ} \mathrm{C}$

310 until constant dry weight (Quillaguamán et al., 2007).

311 Residual ammonium concentration in PHB production experiments was determined by using

312 Orion $^{\mathrm{TM}}$ Ion-Specific Electrode kit for ammonia analysis (Thermo Fisher Scientific Inc, Waltham,

313 MA, USA). Sample volumes of 3,0 mL were used and $\mathrm{NaOH} 10 \mathrm{M}$ solution was used to alkalize 314 samples and make ammonium available for detection, as procedure recommended by the 315 manufacturer. 
316 In Halomonas sp. HG03 and R. eutropha L359PCJ cultivations, cell dry weight was determined

317 by lyophilization of cells, so PHB extraction could be performed next. Sample volumes of $10 \mathrm{~mL}$

318 were centrifuged, resuspended in saline solution $\left(0.85 \% \mathrm{~m} \mathrm{v}^{-1}\right)$, next washed in the same solution

319 and centrifuged. Remaining pellets were then submitted to lyophilization overnight. Resulting dry

320 mass was measured and cell dry weight was calculated in order to determine total biomass

321 concentration (CDW g L-1).

322 The same dry mass was used for PHB extraction method by propanolysis (Riis \& Mai, 1988).

323 Propyl esters were next quantified by gas chromatography Agilent 7890A with HP-5 column (5\%

324 diphenyl-95\%-dimethyl-polisiloxane, $30 \mathrm{~m}, 320 \mathrm{~mm}, 0.25 \mu \mathrm{m}$ film thickness). Volume samples of

$3251.0 \mu \mathrm{L}$ were analyzed after split injection (1:20), using a flame-ionization detector. Injector and

326 detector temperatures were, respectively, $250^{\circ} \mathrm{C}$ and $300^{\circ} \mathrm{C}$. Helium $\left(0.8 \mathrm{~mL} \mathrm{~min}^{-1}\right)$ was the carrier

327 gas and a quantification program was set to $100^{\circ} \mathrm{C} 1^{\prime}, 210^{\circ} \mathrm{C} 15^{\prime}$ ( $\left(8^{\circ} \mathrm{C} \mathrm{min}^{-1}\right)$, up to $240^{\circ} \mathrm{C} 1^{\prime}$.

328 Benzoic acid $\left(40 \mathrm{mg} \mathrm{mL}^{-1}\right)$ was used as internal standard.

329 PHB cellular content was determined as the ratio of PHB concentration in total CDW. Residual

330 cell dry weight concentration ( $\mathrm{rCDW}$ ) was then obtained by subtracting PHB mass from CDW.

331 Even though vinasses were previously filtrated, specific analyses were performed in order to

332 make sure that vinasse would not overestimate dry weight measures, due to any insoluble solids

333 from vinasse. Before bacterial inoculation all vinasse-based culture media were submitted to dry

334 cell weight analyses, following the same procedures described above. Vinasse-based culture

335 media were analyzed in triplicates, the resulting dry mass was determined and next subtracted

336 from dry cell weight measures in samples from bioprocesses.

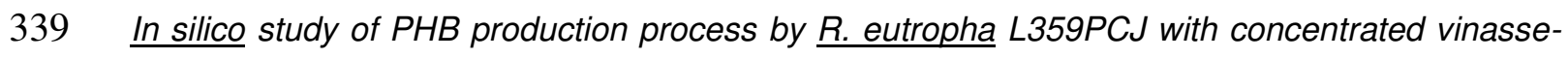

340 based medium

342 In silico analyses were performed with SuperPro Designer software, v. 9.5 (Intelligen, Inc., Scotch

343 Palins, NJ, USA). The software was used in all technical and economical evaluations in this study.

344 A base scenario was designed and named SC1. The bioprocess flowsheet is detailed in Figure 3451. 
347 Figure 1. Bioprocess of PHB production by R. eutropha L359PCJ in SuperPro Designer v.

$348 \quad 9.5$.

350 The stoichiometric model for simulation of PHB bioprocess was designed based on process

351 conditions previously reported in literature and in silico analyses were performed according to

352 methods described elsewhere (Akiyama et al., 2003; Canizales et al., 2020; Choi \& Lee, 1997;

353 Homenschuh et al., 2014; Leong et al., 2017; Petrides, 2015).

354 Economical evaluations aimed to estimate production costs that could be reduced by using

355 vinasse as a partial source of glycerol and salts for PHB production by R. eutropha L359PCJ.

356 Technical-economical scenarios were simulated in order to analyze how PHB productivity and

357 cell density might impact on production costs and profitability indicators.

358 Experimental data were previously converted into input data for SuperPro Designer simulation 359 model as described below.

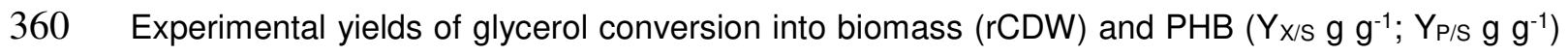

361 were used in global stoichiometric equations used in both unit procedures seed fermenter SFR-

362101 (R1) and production bioreactor FR-101 (R2). All mineral medium components were 363 normalized to glycerol (Table 3).

365 Table 3. Global stoichiometric equations used in base scenario SC1.

367 PHB productivities were estimated from experimental data. Simulated global productivities ( $\left.\mathrm{Pp} \mathrm{si}_{i}\right)$

368 aimed to simulate PHB production by high cell density cultures. Time ranges for growth phase $\left(\mathrm{t}_{x}\right.$ -

$\left.369 s_{i}\right)$ and PHB accumulation phase ( tPHB-Si $)$ were calculated. 
370 Equation 5 was used to calculate the term $\left(\mathrm{t}_{f}-\mathrm{t}_{i}\right)$. Experimental data of $\mu_{\max }\left(\mathrm{h}^{-1}\right)$ and $\mathrm{X}_{i}\left(\mathrm{~g} \mathrm{~L}^{-1}\right)$

371 were used. The term $\mathrm{t}_{i}$ was set to $\mathrm{t}=0 \mathrm{~h}$; the term $\mathrm{X}_{f}$ simulated high cell densities, named as $\mathrm{X}_{f-}$

372 Si. Scenario $\mathrm{SC} 1$ used $\mathrm{X}_{f-S i}=30 \mathrm{~g} \mathrm{~L}^{-1}$. Finally, $\mathrm{t}_{f}=\mathrm{t}_{X-S i}$, the time range required for high cell density.

373 Equation 3 was used to calculate the term $d\left(t_{f}-t_{i}\right)$ and finally to calculate the time range required

374 for PHB accumulation phase and the resulting PHB titer. Experimental data of $\mu_{\mathrm{P}}\left(\mathrm{g} \mathrm{gh}^{-1}\right)$ was

375 used; $X=X_{f-S i}$ and $t_{i}$ was set to $t=0 \mathrm{~h}$. The term $d\left(P_{f}-P_{i}\right)$ was calculated based on experimental

376 data of PHB content $\left(\% \mathrm{~m} \mathrm{~m}^{-1}\right)$. The term PHBcontent $i$ was the experimental data of PHB content

377 at the end of the growth phase. The term $\mathrm{P}_{i}$ was the calculated PHB titer at the end of growth

378 phase for a high cell density culture $\left(\mathrm{X}_{\left.f-S_{i}\right)}\right)$. Thus, the term PHBcontent $f$ was the PHB content

379 experimentally determined at the end of the accumulation phase and $\mathrm{P}_{f}$ was consequently the

380 calculated PHB titer:

381

$$
P_{i-S i}\left(\mathrm{~g} \mathrm{~L}^{-1}\right)=\frac{X_{f-S i}}{1-\left(\text { PHBcontent }_{i} / 100\right)}
$$

383

$$
P_{f-S i}\left(\mathrm{~g} \mathrm{~L}^{-1}\right)=\frac{X_{f-S i}}{1-\left(\text { PHBcontent }_{f} / 100\right)}
$$

The term $\mathrm{t}_{f}=\mathrm{t}_{P H B-S i}$.

Finally, the simulated global productivities $\left(\mathrm{Pp}_{s i} \mathrm{~g} \mathrm{Lh}^{-1}\right)$ were calculated as it follows:

$$
P_{p S i}=\frac{P_{f-S i}}{t_{X-S i}+t_{P H B-S i}}
$$

392 The base scenario SC1 was designed by considering specificities of integrating the PHB

393 bioprocess with ethanol bioprocess. The aim was to reproduce the main nutritional conditions of

394 PHB production by $R$. eutropha L359PCJ in concentrated vinasse-based medium $\left(50 \% \mathrm{v} \mathrm{v}^{-1}\right.$ of vinasse $7^{\circ}$ Brix). 
396 Firstly, the annual production capacity was 10,000 tons of PHB. By taking into consideration that 397 vinasse would provide $50 \%$ of carbon source, such production capacity would be compatible to 398 vinasse production by a distillery that produces $295,245-443,000 \mathrm{~m}^{3}$ of ethanol annually $(10-15$ $399 \mathrm{~L}$ of vinasse for $1 \mathrm{~L}$ of ethanol), providing 44,300 tons of glycerol annually (in natura vinasse with $40010 \mathrm{~g} \mathrm{~L}^{-1}$ of glycerol, Table 1).

401 Secondly, the annual campaign had 5760 operating hours, which is compatible to the operating 402 hours in bioethanol campaign and sugarcane harvest (240 days year $\left.{ }^{-1}\right)$ so vinasse supply would 403 be guaranteed.

404 These two requirements defined major aspects of model design, however the base scenario SC1 405 did not include vinasse use as nutrients source and such factor was assessed in scenarios of 406 technical-economical evaluation, as detailed further. The scenario SC1 used medium composition

407 from Rocha et al. (2008) (Table 2), which means that nutrients for culture medium would need to 408 be completely purchased from external suppliers.

409 The simulation model was set to batch mode and it consisted of three sections: Upstream, 410 Bioprocess and Downstream (Figure 1). The Upstream section included culture medium 411 preparation and seed fermentation for inoculum production.

412 A blending tank was set to be charged with medium components, followed by in situ sterilization.

413 Afterwards, sterile medium was split between SFR-101 and FR-101 (1:9). Inoculum preparation 414 was set to take place in a $40 \mathrm{~m}^{3}$ seed fermenter, operated at $30^{\circ} \mathrm{C}, 13 \mathrm{~h}$.

415 The Bioprocess section consisted of the biotransformation process in production reactors FR-101 $416\left(315 \mathrm{~m}^{3}\right)$. Six units of production reactors were set to be charged with culture medium and 417 inoculum from SFR-101. Biotransformation was ruled by the global stoichiometric reaction R2 and 418 the base scenario SC1 simulated a calculated time reaction $\left(\mathrm{t}_{X-S i}+\mathrm{t}_{P H B-S_{i}}\right)$ of $51.7 \mathrm{~h}, \mathrm{X}_{\mathrm{f}-S_{i}}=30 \mathrm{~g} \mathrm{~L}$ $419{ }^{1}, \mathrm{P}_{f-\mathrm{Si}}=59 \mathrm{~g} \mathrm{~L}^{-1}$ and $\mathrm{Ppsi}=1.1 \mathrm{~g} \mathrm{Lh}^{-1}$. Finally, PHB-rich medium was set to be transferred out to 420 a storage tank and downstream process could be initiated.

421 The Downstream section was based on operations described by Akiyama et al., 2003; Choi \& 422 Lee, 1997; and Leong et al., 2017. According to these authors, recovery of PHB by surfactant- 
423 hypochlorite digestion is economically interesting and it has low environmental impacts in 424 comparison to other PHB extraction methods.

425 Cells are separated from broth by centrifugation, next they are collected in a storage tank where 426 surfactant solution $\left(1 \% \mathrm{~m} \mathrm{v}^{-1}\right)$ is charged and the mixture is kept at $25^{\circ} \mathrm{C}, 1 \mathrm{~h}$. Hypochlorite 427 digestion is performed with addition of hypochlorite solution $\left(30 \% \mathrm{~m} \mathrm{v}^{-1}\right)$ in flow-through manner. 428 Aqueous phase with residual cell debris and PHB are separated by centrifugation, washed with 429 water (1:1), concentrated by centrifugation and finally spray-dried to a final form of $\geq 99 \%\left(\mathrm{~m} \mathrm{~m}^{-}\right.$ 430 1) PHB and $\leq 1 \%\left(\mathrm{~m} \mathrm{~m}^{-1}\right)$ water. As described by Akiyama et al., 2003; Choi \& Lee, 1997; and 431 Leong et al., 2017, the overall yield of downstream process for recovering PHB was set to 95\%.

432 Economical evaluations were performed for a 15-year period at an annual interest rate of $6 \%$ and selling price of US $\$ 10 \mathrm{kgPHB}^{-1}$. SuperPro Designer was used in all calculations of capital costs,

434 production costs, annual operating costs and profitability analyses. Prices configurations were: $435\left(\mathrm{US} \$\right.$ ton $\left.^{-1}\right)$ - glycerol, 400; $\left(\mathrm{NH}_{4}\right)_{2} \mathrm{SO}_{4}, 107 ; \mathrm{KH}_{2} \mathrm{PO}_{4}, 980 ; \mathrm{MgSO}_{4}, 120 ; \mathrm{CaCl}_{2}, 130 ;$ ammonium 436 iron citrate, 285; $\mathrm{H}_{3} \mathrm{BO}_{3}, 780 ; \mathrm{CoCl}_{2}, 10,000 ; \mathrm{ZnSO}_{4}, 560 ; \mathrm{MnSO}_{4}, 1,900 ; \mathrm{Na}_{2} \mathrm{MoO}_{4}, 9,750 ; \mathrm{NiCl}_{2}$, 437 4,700; $\mathrm{CuSO}_{4}$, 3,800; surfactant, 800; $\mathrm{NaOCl}, 200 ;\left(U S \$ \mathrm{MT}^{-1}\right)$ - steam, 12; high pressure steam, 438 20; chilled water, 0.5; (US\$ kW- $\left.\mathrm{h}^{-1}\right)$ power, 0.07.

\section{$440 \quad$ Sensitivity analyses}

441 Firstly, the base scenario SC1 was evaluated for variations of glycerol prices and reduction of 442 production costs due to vinasse as a partial source of nutrients for culture medium. According to 443 Stracke et al. (2018), crude glycerol from biodiesel processes in Brazil might have prices ranging 444 from US\$ 200 - 400 ton $^{-1}$, depending on location, purity and other factors. Thus, three scenarios 445 simulated glycerol prices at US\$ 400 ton $^{-1}$ (SC1), US\$ 300 ton $^{-1}$ (SC2) and US\$ 200 ton $^{-1}$ (SC3). 446 Next, each glycerol price was evaluated combined with cost reductions by vinasse. Since vinasse 447 contributed with $50 \%$ of carbon source in our experiments, scenarios SC4, SC5 and SC6 448 simulated, respectively, glycerol prices of US $\$ 400$ ton $^{-1}$, US $\$ 300$ ton $^{-1}$ and US $\$ 200$ ton $^{-1}$ as well, 449 however, due to vinasse use, their final cost with glycerol in culture media were, respectively, 450 US $\$ 200$ ton $^{-1}$, US\$ 150 ton $^{-1}$ and US $\$ 100$ ton $^{-1}$. 
451 Due to vinasse use, scenarios SC4, SC5 and SC6 also had reduction costs with other nutrients

452 in culture medium. In silico, we reproduced the experimental conditions of fully supplementing

453 phosphate and nitrogen sources, while other mineral nutrients in medium were diluted by vinasse.

454 Thus, these scenarios had their costs with mineral nutrients reduced by $50 \%$, except for $\mathrm{KH}_{2} \mathrm{PO}_{4}$

455 and $\left(\mathrm{NH}_{4}\right)_{2} \mathrm{SO}_{4}$.

456 A second set of analyses investigated bioprocesses with high cell densities and improvements in

457 PHB productivity. All scenarios considered vinasse as a partial source of nutrients. Glycerol price

458 was set to US $\$ 400$ ton $^{-1}$, but its final cost in culture medium was US $\$ 200$ ton $^{-1}$ and other mineral

459 nutrients had costs reduced by $50 \%$, except for $\mathrm{KH}_{2} \mathrm{PO}_{4}$ and $\left(\mathrm{NH}_{4}\right)_{2} \mathrm{SO}_{4}$.

460 Three cell densities were evaluated, $\mathrm{X}_{f-S_{i}}=30 \mathrm{~g} \mathrm{~L}^{-1}, \mathrm{X}_{f-S_{i}}=40 \mathrm{~g} \mathrm{~L}^{-1}$ and $\mathrm{X}_{f-S_{i}}=50 \mathrm{~g} \mathrm{~L}^{-1}$. Each value

461 of $X_{f-S i}$ was combined with three experimental values of $\mu_{\mathrm{p}}\left(\mathrm{g} \mathrm{gh}^{-1}\right)$. Thus, different values of

462 simulated PHB productivity were calculated. Scenarios SC7-SC15 were characterized as

463 optimistic, realistic and pessimistic according to values of $\mu_{\mathrm{P}}$ and their resulting PHB productivity

464 (Table 4). All scenarios kept the same glycerol conversion into PHB (YP/s $\mathrm{g} \mathrm{g}^{-1}$ ), biomass (rCDW)

$465\left(\mathrm{Y}_{\mathrm{x} / \mathrm{s} \mathrm{g} \mathrm{g}} \mathrm{g}^{-1}\right)$ and PHB contents $\left(\% \mathrm{~m} \mathrm{~m}^{-1}\right)$.

466

467

Table 4. Technical-economical scenarios for evaluation of high cell density cultures and PHB productivities.

Results and Discussion

473 E. coli THR14 had cellular growth in all vinasse based conditions we evaluated in this study.

474 Volumetric dilutions of $25 \%$ and $50 \%$ of in natura vinasse in mineral medium increased biomass

475 concentration by $15 \%$ and $30 \%$ in comparison to control treatment, with a maximum value of 10.7

$476 \pm 2.1 \mathrm{~g} \mathrm{~L}^{-1}\left(\mathrm{MM}_{E C} \mathrm{~V} 503\right)$, although no statistical difference was found. Vinasse dilution of $75 \%$ ( $\mathrm{V}$

$477 \mathrm{v}^{-1}$ ) resulted in the least satisfactory cellular growth, which was $4.9 \pm 0.5 \mathrm{~g} \mathrm{~L}^{-1}$, statistically the

478 lowest biomass concentration (Figure 2). 
480 Figure 2. CDW, L-threonine and acetic acid concentrations by E. coli THR14 in control and 481 vinasse-based treatments after $\mathbf{2 4} \mathrm{h}$ incubation in shake flasks.

482

483 Culture medium acidification is highly associated with $E$. coli glucose metabolism, so acetic acid 484 concentration was determined after processes were interrupted. Although CDW concentrations in $\mathrm{MM}_{E c}, \mathrm{MM}_{E c} \mathrm{~V} 253$ and $\mathrm{MM}_{E C} \mathrm{~V} 503$ showed no significant difference, acetic acid concentrations in $\mathrm{MM}_{E c} \mathrm{~V} 253\left(0.6 \pm 0.1 \mathrm{~g} \mathrm{~L}^{-1}\right)$ and $\mathrm{MM}_{E c} \mathrm{~V} 503\left(0.5 \pm 0.2 \mathrm{~g} \mathrm{~L}^{-1}\right)$ were significantly lower than those in $\mathrm{MM}_{E c}\left(2.3 \pm 0.8 \mathrm{~g} \mathrm{~L}^{-1}\right)$ and $\mathrm{MM}_{E c} \mathrm{~V} 753\left(1.9 \pm 0.04 \mathrm{~g} \mathrm{~L}^{-1}\right)$. In $\mathrm{MM}_{E C} \mathrm{~V} 253$ and $\mathrm{MM}_{E C} \mathrm{~V} 503$, E. coli THR14 synthesized $1.2( \pm 0.7) \mathrm{g} \mathrm{L}^{-1}$ and $1.2( \pm 0.1) \mathrm{g} \mathrm{L}^{-1}$ of 489 L-threonine, respectively. No statistical difference was found between L-threonine production among these vinasse-based treatments and control treatment $\mathrm{MM}_{E c}$, which had $0.8( \pm 1.1) \mathrm{g} \mathrm{L}^{-1}$ of $\mathrm{L}$-threonine. No detectable L-threonine production was determined in $\mathrm{MM}_{E C} \mathrm{~V} 753$.

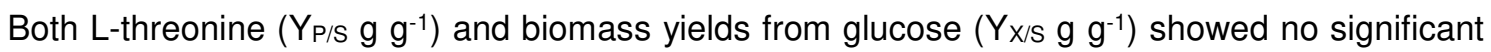
difference between $M_{E c}, M_{E C} V 253$ and $M_{E C} V 503$. $M_{E C} V 753$ showed the lowest biomass production, but glucose consumption was consistently low (9.7 $\mathrm{g} \mathrm{L}^{-1}$ of residual glucose) and resulting biomass yield did not differ from those in other treatments (Table 5).

Table 5. Biomass and L-threonine yields from glucose by E. coli THR14

498

499 Amino acids are primary bioproducts, meaning their biosynthesis is growth related. For that

500 reason, biomass yields are fundamentally important for amino acid bioprocesses (Li et al., 2017;

501 Hermann, 2003).

502 E. coli THR14 cellular growth was limited by low oxygen transfer and the batch operation mode

503 but CDW concentrations were consistent with those described by previous studies. Chen et al.

504 (2009) cultivated an E. coli L-threonine producing strain. After $48 \mathrm{~h}$ incubation the authors reported biomass concentration of $7.5 \mathrm{~g} \mathrm{~L}^{-1}$. 
506 In this study, biomass yields were consistent with those previously reported on E. coli yield on 507 glucose (0.5 gbiomass gglucose $\left.^{-1}\right)$ (Shiloach \& Fas, 2005), and no statistical difference was found 508 among treatments. Furthermore, $\mathrm{MM}_{E c} \mathrm{~V} 253$ and $\mathrm{MM}_{E c} \mathrm{~V} 503$ treatments had significantly lower 509 acetic acid production than control, which made these vinasse-based treatments interesting for 510 E. coli THR14 cultivation.

511 In bioprocesses with E. coli strains using glucose as carbon source, acetic acid synthesis may 512 lead to longer processes and consequently lower productivities. Glucose is assimilated and 513 catabolized into acetyl-CoA. Conditions such as oxygen limitation and glucose concentration 514 above saturation constant may shift acetyl-coa flux from tricarboxylic acid cycle towards ethanol, 515 lactate and/or acetate fermentation. These pathways are advantageous because they contribute 516 for ATP balance and once favorable conditions are restored, acetic acid might be re-assimilated 517 whether glucose becomes limiting (Soini, Ukkonen \& Neubauer 2008).

518 There is a large concern about acetate production in bioprocesses by E. coli strains. In our study, 519 acetic acid production was expected and the final acetic acid concentration of $2.3 \pm 0.8 \mathrm{~g} \mathrm{~L}^{-1}$ in $520 \mathrm{MM}_{E c}$ was acceptable, meaning a production of 0.3 gacetate $_{\text {gbiomass }}{ }^{-1}$. Ying et al. (2014) described

5210.95 gacetate gbiomass $^{-1}$ (biomass concentration was $7.1 \mathrm{~g} \mathrm{~L}^{-1}$ ) in fed-batch bioprocesses. The final 522 acetic acid concentrations in vinasse based treatments $\mathrm{MM}_{E c} \mathrm{~V} 253\left(0.6 \pm 0.2 \mathrm{~g} \mathrm{~L}^{-1}\right)$ and $\mathrm{MM}_{E c} \mathrm{~V} 503$ $523\left(0.5 \pm 0.2 \mathrm{~g} \mathrm{~L}^{-1}\right)$ were, respectively, $75 \%$ and $79 \%$ lower than that in control treatment. These 524 results indicate that those treatments provided balanced nutritional conditions for E. coli THR14 525 metabolism.

526 As for $M_{E C} V 753$ treatment, results indicate that low efficiency was most likely due to nutritional 527 limitation rather than inhibition. As stated in Material and Methods section, our experiments aimed 528 to supply all macronutrients that are known to limit cellular growth. However, micronutrients from 529 the mineral medium were diluted by vinasse.

530 Since biomass yield in $M_{E C} V 753$ treatment was satisfactory, it is possible that as long as cells 531 had favorable nutritional conditions for growth, they were able to consume glucose for biomass 532 production. Once the culture reached some possible nutritional limitation, cellular growth ceased 533 and L-threonine was not favored. Acetic acid concentration in $\mathrm{MM}_{E c} \mathrm{~V} 753$ supports the hypothesis 534 of limitation rather than inhibition. In $M_{E C} V 753$ treatment, glucose uptake by E. coli THR14 did 
535 occur and acetyl-CoA was synthesized and driven to acetic acid pathway. The metabolic switch 536 from cellular growth to acetic acid synthesis might have occurred once nutritional conditions 537 started to limit biomass synthesis due to lacking (micro) nutrients, so available acetyl-CoA was 538 driven towards acetic acid pathway.

539 In this study, L-threonine production was below some results described by other authors. In 540 literature, E. coli producing strains have been reported to achieve production yields ranging from 5410.33 to $0.57 \mathrm{gL}_{\text {Lthreonine }} \mathrm{gGLUCOSE}^{-1}$, and final concentrations between 9.7 and $17 \mathrm{~g} \mathrm{~L}^{-1}$ in shake flasks 542 (Wang et al., 2019; Zhao et al., 2018).

543 Ours results indicate that much can improved in the L-threonine-producing strain E. coli THR14.

544 Previous studies have described L-threonine production by E. coli strains around $34.06-42.25$ $545 \mathrm{mg} \mathrm{L}^{-1}$ and further approaches in order to improve production rates required multiple strategies 546 (Lee et al., 2009).

547 This study, however, aimed to investigate the potential of using vinasse for L-threonine

548 production. To our knowledge, there is no available study about amino acids production using 549 vinasse-based culture media, or E. coli strains cultivation in sugarcane vinasse aiming to 550 bioproducts synthesis.

551 Suhaili et al. (2018) used vinasse from sugar beet processes to evaluate an E. coli BL21 strain.

552 The authors evaluated cellular growth and biosynthesis of CV2025 $\omega$-transaminase, an enzyme 553 that is widely used in pharmaceutical industry. Ethanol process from sugar beet molasse yielded 554 a very different composition of vinasse (glycerol, $183.6-187.6 \mathrm{~g} \mathrm{~L}^{-1}$; acetic acid, 1.7- $7.2 \mathrm{~g} \mathrm{~L}^{-1}$; 555 residual sugars, $\left.20 \mathrm{~g} \mathrm{~L}^{-1}\right)$. The authors evaluated volumetric dilutions of vinasse and results of 556 both CDW concentration and enzyme specific activity were comparable to those obtained in 557 control treatment (without vinasse addition). Finally, authors reported sugar beet vinasse as a fit 558 feedstock for E. coli BL21 cultivation and its potential for CV2025 $\omega$-transaminase production was 559 very attractive.

560 In L-threonine production by E. coli THR14, vinasse was a source of water and mineral salts, 561 such as the ionic forms of calcium, sodium and potassium salts. Besides, vinasse contributed 562 with low amounts of amino acids that might have been assimilated either as nitrogen sources or 563 building blocks. 
564 No previous literature was found about vinasse composition of amino acids. Most likely, the main 565 source of amino acids in vinasse are yeast cells that lyse along the fermentation process,

566 releasing cellular components in culture medium. L-threonine is a L-aspartate derived product 567 and interestingly, in our analyses L-aspartate was the most important amino acid in vinasse (Table

568 1). By the end of processes by E. coli THR14, L-aspartate concentrations had been depleted in 569 all treatments.

570 As for glycerol, E. coli MG1655 strains are capable of using it as carbon source. However, in the presence of highly available glucose, glycerol was neglected by E. coli THR14, similarly to results reported by Suhaili et al. (2018).

PHB production in vinasse-based culture media by $\underline{\text { Halomonas } s p . ~ H G 03 ~ a n d ~} \underline{R}$. eutropha L359PCJ

576 Increasing volumetric dilutions of both in natura and concentrated vinasse had a positive effect 577 on bacteria cellular growth.

578 In Halomonas sp. HG03 cultivations, rDW concentration in $\mathrm{MM}_{\mathrm{Ha}} \mathrm{V} 503\left(1.1 \pm 0.2 \mathrm{~g} \mathrm{~L}^{-1}\right)$ did not 579 differ from that in control treatment $\left(\mathrm{MM}_{\mathrm{Ha}}\right)\left(0.74 \pm 0.1 \mathrm{~g} \mathrm{~L}^{-1}\right)$. By increasing vinasse in culture

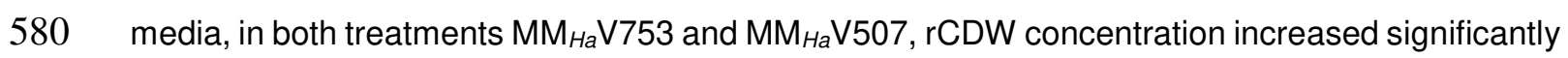
581 by three fold, with final values of $2.2 \pm 0.1 \mathrm{~g} \mathrm{~L}^{-1}$ and $2.3 \pm 0.4 \mathrm{~g} \mathrm{~L}^{-1}$, respectively. In $\mathrm{MM}_{\mathrm{Ha}} \mathrm{V} 757 \mathrm{a}$

582 further significant increase was achieved and residual biomass concentration improved by four 583 fold $\left(3.0 \pm 0.6 \mathrm{~g} \mathrm{~L}^{-1}\right)$ (Figure 3$)$.

Figure 3. Halomonas sp. HG03 cellular growth and PHB biosynthesis in mineral medium, in natura and concentrated vinasse-based treatments, after $48 \mathrm{~h}$ incubation.

In R. eutropha L359PCJ cultivations, all vinasse-based treatments showed a significant increase in cellular growth. In natura vinasse-based treatments $\mathrm{MM}_{R e} \mathrm{~V} 503$ and $\mathrm{MM}_{R e} \mathrm{~V} 753$ had rCDW 
concentrations of $2.2 \pm 0.3 \mathrm{~g} \mathrm{~L}^{-1}$ and $2.3 \pm 0.1 \mathrm{~g} \mathrm{~L}^{-1}$, respectively, which were statistically different

591 from control treatment $\left(1.1 \pm 0.2 \mathrm{~g} \mathrm{~L}^{-1}\right)$ (Figure 4).

592

593 Figure 4. R. eutropha L359PCJ cellular growth and PHB biosynthesis in mineral medium, in natura and concentrated vinasse-based treatments, after $48 \mathrm{~h}$ incubation.

596 The use of concentrated vinasse in $\mathrm{MM}_{R e} \mathrm{~V} 507$ treatment did not contribute significantly to 597 increase $\mathrm{rCDW}\left(2.7 \pm 0.4 \mathrm{~g} \mathrm{~L}^{-1}\right)$ in comparison to in natura vinasse treatments. $\mathrm{MM}_{\mathrm{Re}} \mathrm{V757}$, however, resulted in the statistically highest concentration of rCDW, $4.1 \pm 0.2 \mathrm{~g} \mathrm{~L}^{-1}$.

599 Quantification of residual ammonium showed that no detectable concentration was found in any

600 treatment. Both Halomonas sp. HG03 and R. eutropha L359PCJ depleted the main nitrogen 601 source in control and vinasse-based treatments, so unbalanced nutritional conditions for PHB 602 accumulation were met.

603 PHB cellular content decreased as vinasse concentration in culture media increased.

604 In Halomonas sp. HG03 cultures, the highest PHB cellular content, $81.7 \pm 3.8 \%$ of CDW, and final 605 PHB concentration of $3.45 \pm 0.3 \mathrm{~g} \mathrm{~L}^{-1}$ were determined in control treatment $\mathrm{MM}_{\mathrm{Ha}}$. $\mathrm{MM}_{\mathrm{Ha}} \mathrm{V} 503$ 606 treatment showed the best PHB production by Halomonas sp. HG03 among vinasse-based 607 treatments: PHB content $(75.2 \pm 2.7 \%$ of $\mathrm{CDW})$ and final PHB concentration $\left(3.5 \pm 0.4 \mathrm{~g} \mathrm{~L}^{-1}\right)$ were 608 comparable to those in control treatment. PHB production decreased significantly in $\mathrm{MM}_{\mathrm{Ha}} \mathrm{V753}$ : 609 cellular content dropped to $56.3 \pm 3.1 \%$ of CDW and PHB final concentration of $2.9 \pm 0.3 \mathrm{~g} \mathrm{~L}^{-1}$.

610 In R. eutropha L359PCJ cultivations, PHB cellular content in control treatment $\mathrm{MM}_{R e}(84.1 \pm 3.6 \%)$ 611 was significantly higher than both volumetric dilutions of in natura vinasse $\mathrm{MM}_{R e} \mathrm{~V} 503(68.5 \pm$ $6124.9 \%)$ and $\mathrm{MM}_{R e} \mathrm{~V} 753(65.1 \pm 2.3 \%)$. Consequently, PHB final concentration in $\mathrm{MM}_{R e} \mathrm{~V} 503$ (4.8 \pm $\left.6130.6 \mathrm{~g} \mathrm{~L}^{-1}\right)$ dropped $21 \%$ in comparison to $\mathrm{MM}_{R e}\left(5.8 \pm 0.3 \mathrm{~g} \mathrm{~L}^{-1}\right)$, and $\mathrm{MM}_{R e} \mathrm{V753}\left(4.4 \pm 0.4 \mathrm{~g} \mathrm{~L}^{-1}\right)$, $61433 \%$.

615 The use of concentrated vinasse resulted in further decrease of PHB cellular content. Halomonas

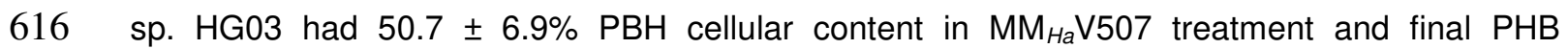


617 concentration $\left(2.3 \pm 0.2 \mathrm{~g} \mathrm{~L}^{-1}\right)$ dropped significantly. $\mathrm{MM}_{\mathrm{Ha}} \mathrm{V} 757$ had PHB content as low as 19.6

$618 \pm 3.7 \%$ and its PHB final concentration was statically the lowest among Halomonas sp. HG03

619 treatments $\left(0.8 \pm 0.3 \mathrm{~g} \mathrm{~L}^{-1}\right)$.

620 Our results for PHB cellular content in treatments $\mathrm{MM}_{\mathrm{Ha}}, \mathrm{MM}_{\mathrm{Ha}} \mathrm{V} 503, \mathrm{MM}_{\mathrm{Ha}} \mathrm{V} 753$ and $\mathrm{MM}_{\mathrm{Ha}} \mathrm{V} 507$

621 were consistent to those reported by other authors for Halomonas sp. strains. According to 622 literature, different culture conditions and carbon sources might result in PHB cellular contents 623 between 44 - 90\% by Halomonas sp. PHA-producing strains (Kucera et al., 2018; Quillaguamán 624 et al., 2007; Rivera-Terceros et al., 2015).

625 Other authors have cultivated Halomonas sp. strains in shake flasks with sucrose as carbon 626 source. PHB contents between $44-75 \%$ and rCDW concentrations between $1.1-1.6 \mathrm{~g} \mathrm{~L}^{-1}$ have 627 been described (Kucera et al., 2018; Rathi et al., 2012; Stanley et al., 2017). In our study, in

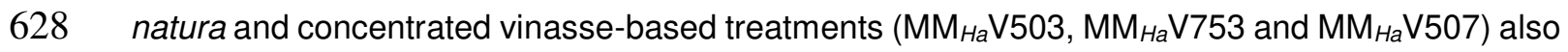
629 had PHB content comparable to those found in literature, but residual biomass values were 630 notably higher than those reported elsewhere.

631 Similarly, PHB cellular content in R. eutropha L359PCJ dropped significantly in concentrated 632 vinasse treatments in comparison to control. In $\mathrm{MM}_{R e} \mathrm{~V} 507$, PHB cellular content $(60.8 \pm 4.0 \%)$ 633 differed from control treatment and $\mathrm{MM}_{R e} \mathrm{~V} 503$, but it was comparable to that in $\mathrm{MM}_{R e} \mathrm{V753}$. The 634 same was observed for its final PHB concentration $\left(4.2 \pm 0.3 \mathrm{~g} \mathrm{~L}^{-1}\right)$. In $\mathrm{MM}_{R e} V 757$, PHB cellular 635 content $(48.4 \pm 1.3 \%)$ was statistically the lowest among $R$. eutropha L359PCJ treatments. 636 However, higher rCDW concentration in $\mathrm{MM}_{R e} \mathrm{~V} 757$ contributed to its final PHB concentration (3.9 $637 \pm 0.3 \mathrm{~g} \mathrm{~L}^{-1}$ ), which differed only from control treatment and $\mathrm{MM}_{R e} \mathrm{~V} 503$.

638 In shake flasks cultures, using glycerol as carbon source, R. eutropha strains were described by 639 other authors with residual biomass production between $0.66-2.2 \mathrm{~g} \mathrm{~L}^{-1}$, and PHB cellular content 640 from 57\% to 65\% (Fukui et al., 2014; Cavalheiro et al., 2009; Volova et al., 2018). Similarly to our 641 results with Halomonas sp. HG03, increasing vinasse in culture media improved $R$. eutropha 642 L359PCJ cellular growth and rCDW concentrations were higher than those reported by other 643 authors. 
644 Since PHB biosynthesis is not growth related, as substrate conversion into biomass increased, 645 substrate conversion into product decreased. Table 6 presents conversion yields of sucrose into 646 rCDW and PHB by Halomonas sp. HG03.

647

Table 6. Biomass and PHB yields from sucrose by Halomonas sp. HG03.

649

$650 \mathrm{MM}_{\mathrm{Ha}} \mathrm{V753}$ treatment had the best PHB production among vinasse-based treatments with 651 Halomonas sp. HG03. Biomass and PHB yields in both treatments $\mathrm{MM}_{\mathrm{Ha}} \mathrm{V} 753$ and $\mathrm{MM}_{\mathrm{Ha}} \mathrm{V} 507$ 652 were interestingly balanced, indicating that such conditions have good potential for high cell 653 density cultures for PHB production. $\mathrm{MM}_{\mathrm{Ha}} \mathrm{V757}$, on the other hand, did not show a satisfactory 654 PHB yield, which dropped $72 \%$ in comparison to control treatment.

655 Table 7 presents conversion yields of glycerol into PHB and biomass (rCDW) by R. eutropha 656 L359PCJ. Biomass yield in $\mathrm{MM}_{R e} \mathrm{~V} 503$ treatment was over twice higher than that in control 657 treatment $\mathrm{MM}_{R e}$. As vinasse concentration in culture media increased, biomass yields increased 658 as well, with significant difference in treatments that used concentrated vinasse. Biomass yield in $659 \mathrm{MM}_{\mathrm{Re}} \mathrm{V757}$ was over four times higher than biomass yield in control treatment.

660 In $\mathrm{MM}_{\mathrm{Re}} \mathrm{V757}$ product yield dropped $34.5 \%$ when compared to control treatment. Lower vinasse 661 concentrations in $\mathrm{MM}_{R e} \mathrm{~V} 503, \mathrm{MM}_{R e} \mathrm{~V} 753$ and $\mathrm{MM}_{R e} \mathrm{~V} 507$ treatments decreased product yields in $66211.4-18.2 \%$.

663 Even though PHB biosynthesis is not growth related, high cellular densities are very important for

664 large volumetric production. Considering vinasse-based treatments, it was particularly interesting 665 that in natura vinasse and concentrated vinasse at $50 \%\left(\mathrm{v} \mathrm{v}^{-1}\right)$ improved biomass production for 666 both Halomonas sp. HG03 and R. eutropha L359PCJ cultivations, while keeping PHB cellular 667 content competitive with those obtained in mineral media, as well as those reported by other 668 authors.

669 Concerning treatments with $75 \%\left(\mathrm{v} \mathrm{v}^{-1}\right)$ of concentrated vinasse, the unsatisfactory results for 670 PHB production suggest that nutritional conditions favored cellular growth and they were not 
671 unbalanced enough for PHB accumulation, instead, these treatments provided the most efficient 672 cellular growth conditions in our study.

673 Similarly to L-threonine production by E. coli THR14, processes with Halomonas sp. HG03 exploited vinasse mostly as a source of water, salts, residual amino acids and an external carbon source had to be supplemented.

676 Other authors have investigated the combined use of vinasses and molasses in culture media for 677 polyhydroxyalkanoates production. Paula et al. (2021) cultivated Burkholderia gluma MA13 in 678 shake flasks with basal mineral medium; they evaluated volumetric dilutions of $25 \%$ and $50 \%$ of 679 in natura vinasse and sugarcane molasse was used as carbon source $\left(20 \mathrm{~g} \mathrm{~L}^{-1}\right)$. PHA cellular 680 content was between $14.07-29.4 \%$ and $\mathrm{rCDW}$ concentrations between $0.52-1.31 \mathrm{~g} \mathrm{~L}^{-1}$ were 681 determined. Acosta-Cárdenas, Alcaraz-Zapata \& Cardona-Betancur (2018) cultivated $R$. 682 eutropha ATCC17699 in culture medium with a volumetric ratio of sugarcane molasse/vinasse of 683 25/75. They determined final PHA concentrations between $1.9-3.8 \mathrm{~g} \mathrm{~L}^{-1}$ and product yields 684 ranged from $0.13-0.21 \mathrm{~g} \mathrm{~g}^{-1}$.

685 Cheaper carbon sources are a major interest in large scale bioprocesses in general. 686 Biotechnological processes might have carbon sources accounting for up to $50 \%$ of total 687 operational costs (Eggeling \& Bott, 2015; Poltronieri \& Kumar, 2017). Zanfonatto et al. (2018), 688 Bhattacharyya et al. (2012) and Pramanik et al. (2012) have investigated PHAs production by 689 Cupriavidus necator DSM545, Haloferax mediterranei and Haloarcula marismortuii MTCC 1596, 690 respectively, by using vinasse as carbon source.

691 Bhattacharyya et al. (2012) used mineral medium with $50 \%\left(\mathrm{v} \mathrm{v}^{-1}\right)$ vinasse and described the 692 production of $17.4 \mathrm{~g} \mathrm{~L}^{-1}$ of $\mathrm{P}(3 \mathrm{HB}-\mathrm{co}-\mathrm{HV})(14.09 \mathrm{~mol} \% \mathrm{HV})$ after $120 \mathrm{~h}$ cultivation. Pramanik et 693 al. (2012) cultivated Haloarcula marismortuii MTCC1596 in culture medium composed of 100\% 694 vinasse and total biomass concentration was $15 \mathrm{~g} \mathrm{~L}^{-1}$, with $30 \%$ of $\mathrm{PHB}$, after $216 \mathrm{~h}$ cultivation. 695 Zanfonatto et al. (2018) used in natura vinasse as glycerol source $\left(4.5 \mathrm{~g} \mathrm{~L}^{-1}\right)$ for cultivating $C$. 696 necator DSM545. Final concentrations of rCDW and PHB were, respectively, $3.7 \mathrm{~g} \mathrm{~L}^{-1}$ and $1.3 \mathrm{~g}$ $697 \quad \mathrm{~L}^{-1}$ (PHB cellular content of $\left.26 \%\right)$.

698 In our study we also had interest on vinasse as carbon source, so the glycerol-consuming $R$. 699 eutropha L359PCJ was cultivated. As vinasse concentration in culture media increased, demand 
700 for external glycerol supplementation decreased, and $\mathrm{MM}_{R e} \mathrm{~V} 757$ finally had glycerol fully 701 provided by concentrated vinasse $\left(15 \mathrm{~g} \mathrm{~L}^{-1}\right)$.

702 Despite lower PHB production by $R$. eutropha L359PCJ in $\mathrm{MM}_{R e} \mathrm{~V} 757$ treatment, it is important to 703 emphasize that such process had zero cost with carbon source acquisition. $\mathrm{MM}_{\mathrm{Re}} \mathrm{V} 507$ was

704 particularly interest because PHB production was competitive with those in our control treatment 705 and those reported by previous studies. Besides, costs with carbon source were reduced in half, 706 since vinasse supplied $7.5 \mathrm{~g} \mathrm{~L}^{-1}$ of glycerol. To our knowledge, no previous study described the 707 use of concentrated vinasse as carbon source for PHB bioprocesses.

708

\section{Bioreactor fermentations}

710 Because Halomonas sp. HG03 and $R$. eutropha L359PCJ had satisfactory cellular growth and 711 product bionsynthesis in vinasse-based treatments, these strains were chosen for further 712 investigation of vinasse as basal medium in bioreactor bioprocesses.

713 Both bacteria showed satisfactory cellular growth in bioreactor cultivations. $R$. eutropha L359PCJ 714 had a lag phase of $13 \mathrm{~h}$, while lag phase in Halomonas sp. HG03 cultivation lasted $37 \mathrm{~h}$, which 715 suggests that inoculum adaptation to concentrated vinasse-based medium could be necessary, especially for Halomonas sp. HG03.

$717 R$. eutropha L359PCJ showed consistent cellular growth for $74 \mathrm{~h}$, according to optical density 718 monitoring during cultivation $\left(\mathrm{OD}_{600}\right)$. Maximum growth velocity $\mu_{\max }=0.255 \mathrm{~h}^{-1}$ was observed 719 between $\mathrm{t}=0 \mathrm{~h}$ and $\mathrm{t}=7.15 \mathrm{~h}$ and exponential growth phase was observed until $\mathrm{t}=30 \mathrm{~h}$. At $\mathrm{t}=$ $72055 \mathrm{~h}$ the culture reached stationary growth phase.

721 At $\mathrm{t}=26 \mathrm{~h}$ the second batch was initiated, which supplied all nutrients from culture medium and 722 at $\mathrm{t}=32 \mathrm{~h}$ the batch was finished. At $\mathrm{t}=34 \mathrm{~h}$ the third batch supplied pure glycerol and 723 concentrated vinasse $\left(34.4^{\circ}\right.$ Brix $)$ as the sole nutrients source, which initiated the PHB 724 accumulation phase. In total, seven batches were carried on with concentrated vinasse, including 725 the initial batch (Figure 5). 
727 Figure 5. Cellular growth by $\boldsymbol{R}$. eutropha L359PCJ in bioprocess operated by consecutive

728 batches mode in bioreactor with concentrated vinasse-based medium. (-_): start of the

729 second batch. (_): start of third to seventh batches.

730

731 Halomonas sp. HG03 was cultivated for $67 \mathrm{~h}$, with increasing optical density $\left(\mathrm{OD}_{600}\right)$ until $\mathrm{t}=53$

732 h. Maximum growth velocity was $\mu_{\max }=0.091 \mathrm{~h}^{-1}$, observed between $\mathrm{t}=20 \mathrm{~h}$ and $\mathrm{t}=26.7 \mathrm{~h}$. The

733 culture reached stationary growth phase at $\mathrm{t}=44 \mathrm{~h}$ (Figure 6).

734

735

Figure 6. Cellular growth by Halomonas sp. HG03 in bioprocess operated by consecutive

736 batches mode in bioreactor with concentrated vinasse-based medium. (--_): start of the second batch. (—): start of third to sixth batches.

738

739 At $\mathrm{t}=20 \mathrm{~h}$ the second batch providing all nutrients to Halomonas sp. HG03 was initiated. At $\mathrm{t}=$

$74026 \mathrm{~h}$ the third batch initiated the cultivation providing sucrose and concentrated vinasse as the

741 sole nutrients source. Despite the fact that after $\mathrm{t}=20 \mathrm{~h}$ no specific nitrogen source was supplied

$742\left(\left(\mathrm{NH}_{4}\right)_{2} \mathrm{SO}_{4}\right)$, Halomonas sp. $\mathrm{HG} 03$ showed increasing concentration of $\mathrm{rCDW}$ until $\mathrm{t}=44 \mathrm{~h}$, which

743 suggests that amino acids from vinasse might have been used as building blocks and enabled

744 Halomonas sp. HG03 to grow. In total, Halomonas sp. HG03 cultivation had six batches, including

745 the initial batch.

746 By using vinasse as a partial source of glycerol, $R$. eutropha L359PCJ showed maximum specific 747 growth velocity $\left(\mu_{\max }\right)$ higher than those previously reported by other authors that cultivated $R$.

748 eutropha strains with residual sources of glycerol. Cavalheiro et al. (2009) and Volova et al. (2019)

749 described $\mu_{\max }$ values between 0.11 and $0.15 \mathrm{~h}^{-1}$ for cultivations with crude glycerol as carbon

750 source. Zanfonatto et al. (2018) evaluated the PHB production by Cupriavidus necator (also

751 known as $R$. eutropha) DSM 545 with in natura vinasse as glycerol source $\left(4.5 \mathrm{~g} \mathrm{~L}^{-1}\right)$, and $\mu_{\max }=$

$752 \quad 0.21 \mathrm{~h}^{-1}$ was determined. 
753 Halomonas sp. HG03 maximum specific growth velocity was not satisfactory, which might have 754 been negatively affected by the prolonged lag phase. Moreno (2015) had previously cultivated 755 the parental strain Halomonas sp. HG01 in glucose and described $\mu_{\max }=0.16 \mathrm{~h}^{-1}$.

756 Both bioprocesses were thoroughly monitored by their process conditions. In $R$. eutropha 757 L359PCJ cultivation, nitrogen source as in the form of $\mathrm{NH}_{4}{ }^{+}$had been depleted at $\mathrm{t}=34 \mathrm{~h}$. Glycerol 758 was consumed by bacteria and dissolved oxygen was efficiently kept at a saturation value around $75940 \%$ as well. In order to keep the established oxygen saturation, agitation speed and air inflow 760 were highly responsive to batches durations, which are represented in Figure 7 by glycerol 761 content $\left(\mathrm{g} \mathrm{L}^{-1}\right)$.

762

Figure 7. R. eutropha L359PCJ cultivation in bioreactor with concentrated vinasse-based culture medium: monitoring of agitation speed, dissolved oxygen, aeration, glycerol and ammonium concentrations.

766

767 Agitation speed was gradually increasing during first and second batches. From the third batch 768 on, which had only pure glycerol and vinasse as the sole nutrients source, air inflow was also 769 increasing so the minimum saturation of dissolved oxygen could be kept. Altogether, these data 770 suggested that $R$. eutropha L359PCJ could efficiently consume glycerol in order to have cellular 771 growth and PHB biosynthesis in concentrated vinasse-based medium throughout the entire 772 process and no inhibitory effects were observed.

773 In Halomonas sp. HG03 cultivation, despite the increasing concentration of rCDW until $\mathrm{t}=44 \mathrm{~h}$

774 (Figure 6), nitrogen as in the form of $\mathrm{NH}_{4}+$ had been depleted in culture medium at $\mathrm{t}=33 \mathrm{~h}$.

775 Sucrose was satisfactorily consumed until $\mathrm{t}=48 \mathrm{~h}$, but sucrose accumulation was observed later.

776 Still, it was expected that glycerol would not be significantly consumed by Halomonas sp. HG03

777 (Figure 8). 

culture medium: monitoring of agitation speed, dissolved oxygen, aeration, glycerol and ammonium concentrations.

782

783 Saturation of dissolved oxygen was efficiently kept around $40 \%$ during the entire process, although agitation speed and air inflow responses were remarkably different from those observed in $R$. eutropha L359PCJ cultivation. Agitation speed was increasing during first and second batches, in which all nutrients from culture medium were provided. From the third batch on, agitation speed showed short responses, associated to batches initiation. Air inflow, on its turn, was mostly constant during the process. These data suggest that microbial respiration was relatively low and short periods of time with increasing agitation could easily keep dissolved oxygen around $40 \%$.

791 Since the third to sixth batches had concentrated vinasse and sucrose as the sole nutrients 792 source, it is unlikely that sucrose concentrations were related to the little increase in microbial 793 respiration at the beginning of batches because total sugars eventually accumulated in bioreactor.

794 On the other hand, vinasse partially replaced minerals in all vinasse-based treatments we 795 evaluated in this study. Thus, it is possible that concentrated vinasse carried limiting nutrients for 796 Halomonas sp. HG03: once batches were initiated with sucrose and concentrated vinasse supply, 797 microbial respiration increased and higher agitation speed was needed in order to keep dissolved 798 saturation around 40\%. Possibly, once mineral nutrients from vinasse reached limiting 799 concentrations, microbial respiration decreased, as well agitation speed, and sucrose was not 800 efficiently metabolized. Further studies with detailed investigation on Halomonas sp. HG03 801 nutritional requirements are necessary, but such hypothesis would be consistent with the results 802 we obtained in shake flasks cultivations that showed increasing concentrations of vinasse in 803 culture media being related to increasing cellular growth.

804 Regarding PHB content, $R$. eutropha L359PCJ showed little PHB accumulation during the first 805 two batches, which supplied nitrogen source $\left(\left(\mathrm{NH}_{4}\right)_{2} \mathrm{SO}_{4}\right)$ and other nutrients from mineral 806 medium. By the end of the second batch, at $\mathrm{t}=32 \mathrm{~h}, \mathrm{PHB}$ content reached $21.4 \%\left(\mathrm{~m} \mathrm{~m}^{-1}\right)$. 807 Previous studies also reported PHB content around $20 \%$ by $R$. eutropha strains at the end of 
808 growth phases (Kim et al., 1994). Finally, at $\mathrm{t}=74 \mathrm{~h}$, $R$. eutropha L359PCJ reached PHB content 809 of $66.3 \%\left(\mathrm{~m} \mathrm{~m}^{-1}\right)$ and CDW concentration was $28.0 \mathrm{~g} \mathrm{~L}^{-1}$ (Figure 9).

810

811 Figure 9. $R$. eutropha L359PCJ cultivation in bioreactor with concentrated vinasse-based 812 culture medium: volume variation, PHB content, CDW, rCDW, consumed glycerol and PHB 813 concentrations.

814

815 Cavalheiro et al. (2009) obtained PHB contents between $38-62 \%$ by cultivating C. necator DSM 816545 in bioreactors with crude glycerol as carbon source. Bormann \& Roth (1999) cultivated $R$. 817 eutropha DSM 11348 with pure glycerol and PHB content of $42-65 \%$ was reported. As for in 818 natura vinasse as glycerol source, Zanfonatto et al. (2018) described PHB content of $26 \%$ by C. 819 necator DSM 545.

820 By the end of the growing phase $(t=32 h)$, conversion yield of glycerol into $\mathrm{CCDW}$ was $\mathrm{Y}_{\mathrm{x} / \mathrm{s}}=0.52$ $821 \mathrm{~g} \mathrm{~g}^{-1}$, and into PHB, YP/S $=0.14 \mathrm{~g} \mathrm{~g}^{-1}$. At the end of the seventh batch the global yields were $\mathrm{Y} / \mathrm{S}$ $822=0.16 \mathrm{~g} \mathrm{~g}^{-1}, \mathrm{YP}_{\mathrm{P} / \mathrm{S}}=0.32 \mathrm{~g} \mathrm{~g}^{-1}$ and the final concentration of $18.6 \mathrm{~g} \mathrm{~L}^{-1} \mathrm{PHB}$ was reached after 74 $823 \mathrm{~h}$, which resulted into PHB productivity of $0.25 \mathrm{~g} \mathrm{Lh}^{-1}$.

824 Shake flasks cultivations of $R$. eutropha L359PCJ had PHB content of $60.6 \pm 4.0 \%$ and global 825 conversion yields were $\mathrm{Y}_{\mathrm{X} / \mathrm{S}}=0.23 \pm 0.05 \mathrm{~g} \mathrm{~g}^{-1}$ and $\mathrm{Y}_{\mathrm{P} / \mathrm{S}}=0.34 \pm 0.03 \mathrm{~g} \mathrm{~g}^{-1}\left(\mathrm{MM}_{R e} \mathrm{~V} 507\right.$ treatment).

826 Thus, the PHB production by $R$. eutropha L359PCJ with concentrated vinasse-based medium in 827 bioreactor had conversion yields consistent with those determined in shake flasks fermentations 828 and PHB content satisfactorily improved.

829 The production results were also consistent with those described by other authors with glycerol 830 as carbon source, which supports the use of concentrated vinasse as glycerol source for PHB 831 biosynthesis. Sharma et al. (2021) described values between $2.1-11.3 \mathrm{~g} \mathrm{~L}^{-1}$ of CDW and 6.7 $83213.1 \mathrm{~g} \mathrm{~L}^{-1}$ of PHB in bioprocesses with C. necator DSM 545 and pure glycerol as carbon source. 833 Productivities ranged from 0.16 to $0.27 \mathrm{~g} \mathrm{Lh}^{-1}$. Kachrimanidou et al. (2014) reported productivity 834 of $0.31 \mathrm{~g} \mathrm{Lh}^{-1}$, concentrations of CDW $=24.6 \mathrm{~g} \mathrm{~L}^{-1}$ and PHB $=7.6 \mathrm{~g} \mathrm{~L}^{-1}$, with conversion yield YP/S $835=0.30 \mathrm{~g} \mathrm{~g}^{-1}$ by $C$. necator DSM 7237 with purified crude glycerol as carbon source. Cavalheiro et 
836 al. (2009) described a fed-batch bioprocess with C. necator DSM 545 and crude glycerol was 837 evaluated as carbon source. The authors obtained a PHB productivity of $0.84 \mathrm{~g} \mathrm{Lh}^{-1}$ in a high cell 838 density culture, with final rCDW concentration of $42.8 \mathrm{~g} \mathrm{~L}^{-1}$ and PHB content of $38 \%$, which 839 resulted in PHB concentration of $26 \mathrm{~g} \mathrm{~L}^{-1}$. Conversion yields were $\mathrm{Y}_{\mathrm{X} / \mathrm{S}}=0.45 \mathrm{~g} \mathrm{~g}^{-1}$ and $\mathrm{Y}_{\mathrm{P} / \mathrm{S}}=0.34$ $840 \mathrm{~g} \mathrm{~g}^{-1}$

841 PHB content during growth phase in Halomonas sp. HG03 cultivation was more important than

842 that observed for $R$. eutropha L359PCJ. During the first batch, at $\mathrm{t}=17.7 \mathrm{~h}, \mathrm{PHB}$ content was 843 determined at $28.5 \%$, and it showed little variation until the end of the second batch at $\mathrm{t}=26 \mathrm{~h}$, 844 with $28.8 \%$. By the end of the sixth batch, at $t=67 \mathrm{~h}, \mathrm{PHB}$ content finally reached $45.7 \%$ and $845 \mathrm{CDW}$ concentration was $18.1 \mathrm{~g} \mathrm{~L}^{-1}$, meaning a final concentration of $\mathrm{PHB}=8.3 \mathrm{~g} \mathrm{~L}^{-1}$. Globally, 846 conversion yields of sucrose into PHB and $\mathrm{rCDW}$ were, respectively, $\mathrm{YP} / \mathrm{S}=0.16 \mathrm{~g} \mathrm{~g}^{-1}$ and $\mathrm{YX/S}=$ $8470.18 \mathrm{~g} \mathrm{~g}^{-1}$, and PHB productivity was $0.12 \mathrm{~g} \mathrm{Lh}^{-1}$ (Figure 10).

849 Figure 10. Halomonas sp. HG03 cultivation in bioreactor with concentrated vinasse-based 850 culture medium: volume variation, PHB content, CDW, rCDW, consumed total sugars and 851 PHB concentrations.

852

853 In comparison to results obtained in shake flasks ( $\mathrm{MM}_{\mathrm{Ha}} \mathrm{V} 507$ treatment), the consecutive batches 854 operation mode was not successful in achieving higher PHB content by Halomonas sp. HG03, 855 which had been $50.7 \pm 6.9 \%$. As mentioned above, further investigation on Halomonas sp. HG03 856 nutritional requirement is needed and such information could be valuable for improving 857 bioprocess strategies for PHB production in bioreactors with concentrated-vinasse medium.

858 PHB production by Halomonas sp. HG03 indeed was less attractive than that showed by $R$. 859 eutropha L359PCJ, however, it was still consistent with results reported by other authors for 860 Halomonas sp. strains cultivated in bioreactors.

861 Ortiz-Veizán et al. (2020) reported PHB content of 52\% by Halomonas boliviensis DSM 15516 in 862 bioprocess with glucose $\left(5 \mathrm{~g} \mathrm{~L}^{-1}\right)$ and molasse $\left(15 \mathrm{~g} \mathrm{~L}^{-1}\right)$ as carbon sources. Quillaguamán et al. 863 (2006) described a batch process in bioreactor with Halomonas boliviensis $\mathrm{LC}^{\top}{ }^{\top}$ with sucrose as 
864 carbon source. PHB content was 55\% and final concentrations were rCDW $=0.54 \mathrm{~g} \mathrm{~L}^{-1}$ and PHB

$865=0.66 \mathrm{~g} \mathrm{~L}^{-1}$. In further studies, Quillaguamán et al. (2007) described PHB production H. boliviensis

$866 \mathrm{LC}^{\top}$ with sucrose in bioreactors and productivities were between $0.14-0.16 \mathrm{~g} \mathrm{Lh}^{-1}, \mathrm{PHB}$ content

867 was $52 \%$ and final concentrations were $\mathrm{rCDW}=6.9 \mathrm{~g} \mathrm{~L}^{-1}$ and $\mathrm{PHB}=7.5 \mathrm{~g} \mathrm{~L}^{-1}$.

868 Other authors have also reported relatively important PHB production by Halomonas sp. strains

869 during growth phases. Besides, in bioprocesses that used complex media, such as hydrolysates,

870 the authors have also described that rCDW continued to increase despite the depletion of the

871 main nitrogen source (Rivera-Terceros et al., 2015). Quillaguamán et al. (2008) have

872 demonstrated that amino acids such as L-aspartate, L-glutamate and L-glycine have, individually,

873 an important effect on Halomonas boliviensis cellular growh and PHB biosynthesis.

874 Halomonas sp. strains are highly attractive for bioprocesses that aim to biocommodities

875 manufacturing, especially because they grow in cheap culture media and non-sterile conditions.

876 For this reason an important set of strains and bioprocesses have been studied in recent years

877 (Kshirsagat et al., 2012; Quillaguamán et al., 2005; Van-Thuoc et al., 2007; Yue et al., 2014).

878 As strategies that aimed to improve PHB production by Halomonas sp. strains, limitation by

879 oxygen and controlled supply of inorganic and/or complex nitrogen sources have been previously

880 evaluated by other authors and could be as well applied in bioprocesses with vinasse-based

881 media (Kshirsagar et al., 2012; Quillaguamán et al., 2007; Quillaguamán et al., 2008).

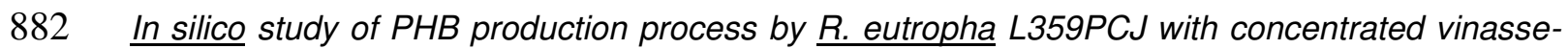

883 based culture medium

884

885 The model process considered a seed fermenter with reaction described reation R1 (Table 3) and

886 the glycerol conversion yields determined experimentally during growth phase were used $\left(\mathrm{Y}_{\mathrm{X} / \mathrm{s}}=\right.$ $\left.887 \quad 0.52 \mathrm{~g} \mathrm{~g}^{-1} ; \mathrm{YP}_{\mathrm{P} / \mathrm{S}}=0.14 \mathrm{~g} \mathrm{~g}^{-1}\right)$.

888 Settings in the production bioreactor considered initial biomass ( $\mathrm{rCDW}$ ) of $0.3 \mathrm{~g} \mathrm{~L}^{-1}$; $\mathrm{PHB}$ 889 accumulation phase would require the increase from $21.4 \% \mathrm{PHB}$ up to $66.3 \%\left(\mathrm{~m} \mathrm{~m}^{-1}\right)$; and

890 glycerol conversion yields applied in $R 2$ (Table 3) were $Y_{x / s}=0.16 \mathrm{~g} \mathrm{~g}^{-1}$ and $Y_{p / S}=0.32 \mathrm{~g} \mathrm{~g}^{-1}$, as

891 obtained experimentally. In order to determine the time needed for growth phase and PHB 
893 used. These assumptions about growth phase and PHB accumulation phase were considered

894 during calculations of simulation parameters, however, settings in SuperPro Designer treated 895 these parameters globally, as detailed in Table 8.

896

897 Table 8. Simulation parameters in base scenario SC1 - input, output data and settings in 898 SuperPro Designer model.

899

900 The model had batch time of $78.3 \mathrm{~h}$ and the reaction in Bioprocess was the bottleneck procedure,

901 which had duration of $52.3 \mathrm{~h}$, including bioreactor chargings and reaction times. The bioreactor

902 occupancy time is directly affected by PHB productivity, so improving productivity would reduce

903 the minimum cycle time and optimize equipment usage (Figure 11).

904

905

Figure 11. Gantt chart of base scenario SC1: Unit procedure (P-) / equipment - operation.

906

(苂) Bottleneck unit procedure. (*) Operations in bottleneck unit procedure.

907

908

Leong et al. (2017) also analyzed in silico the PHB production process with pure glycerol as the

909 carbon source. The authors did not specifically relate the study to experimental data and the

910 simulated process was described by PHB productivity of $2.86 \mathrm{~g} \mathrm{Lh}^{-1}$. Some simulation parameters

911 used by Leong et al. (2017) are compared to those applied in this study, as detailed in Table 9.

912

913 Table 9. Simulation parameters and output data - Base scenario SC1 (this study) and

914 Leong et al. (2017).

915

916 Experimentally, using pure and crude glycerol from biodiesel process, high cell density cultures

917 were described by Cavalheiro et al. (2009) ( $\mathrm{rCDW}=31 \mathrm{~g} \mathrm{~L}^{-1}$ and $\mathrm{rCDW}=42.8 \mathrm{~g} \mathrm{~L}^{-1}$, respectively). 
918 The authors achieved maximum PHB content of $62 \%$, which resulted in PHB titer of $51.1 \mathrm{~g} \mathrm{~L}^{-1}$

919 and productivities ranged from 0.84 to $1.5 \mathrm{~g} \mathrm{Lh}^{-1}$.

920 In comparison to the study described by Leong et al. (2009), the simulated productivity we

921 calculated in this study, $\mathrm{Pp}_{s_{i}}=1.1 \mathrm{~g} \mathrm{Lh}^{-1}$ was low, although comparable to those experimentally

922 described by Cavalheiro et al. (2009) that used glycerol from agroindustrial wastes as carbon 923 source.

924 In regards to facility use in this study, putting as an objective the integration of PHB and bioethanol

925 bioprocesses through vinasse imposed an additional challenge. A shorter annual campaign was

926 considered (5760 operating hours) so PHB process would be synchronized to sugarcane

927 harvesting period in Brazil. Consequently, facility use becomes more important, inefficient or sub-

928 optimal use could be limiting and add to production costs.

929 Because PHB productivity simulated by Leong et al. (2009) was higher than $\mathrm{Pp}_{S i}$ we calculated

930 in this study, the PHB production per batch (ton batch ${ }^{-1}$ ) was lower and the number of batches

931 per year was larger. The authors described an effective and optimized use of facility, especially

932 regarding bioreactors occupancy. Due to higher productivity, bioprocess duration is shorter and

933 less production units are needed to achieve an annual demand of PHB production. As a result, a

934 smaller number of bioreactor units operate in a larger number of batches during the annual

935 campaign.

936 As detailed in Table 9, scenario SC1 had lower production costs related to raw materials (37.4\%).

937 However, facility-dependent production costs and investments were very important (56.9\%) and

938 remarkably disadvantageous in comparison to simulated results by Leong et al. (2017). As a

939 consequence, despite lower costs with raw material, unit production cost in SC1 (US\$ $6.2 \mathrm{kgPHB}^{-}$

$940{ }^{1}$ ) was not more competitive than that described by Leong et al. (2017) (US\$ $6.1 \mathrm{kgPHB}^{-1}$ ) (US\$

941500 ton $\left.^{-1}\right)$. Moreover, SC1 had higher investments on direct fixed capital, which made financial

942 indicators ROI, IRR, NPV and payback less attractive.

943 Production costs were also analyzed by process section. The Upstream section, which included

944 culture medium and inoculum preparation, had the most important share in costs, $39.5 \%$. Next,

945 Bioprocess accounted for $37.6 \%$, which included mostly the operation of FR-101 units. Lastly, the

946 Downstream section accounted for $22.9 \%$ of total production costs. These results implyed that 
947 optimizing bioreactor use was imperative for reduction of production costs, but cheaper culture

948 medium were also needed.

949 Firstly, different prices of glycerol were evaluated, as well as the use of vinasse as a partial source

950 of nutrients for culture medium. As expected, higher costs with glycerol resulted in higher

951 production costs in general. Scenarios that did not consider the use of vinasse (SC1, SC2 and

952 SC3) had annual production costs reduced by $6 \%$ due to the lower glycerol prices. In scenarios

953 SC4, SC5 and SC6, the higher the glycerol price, more important were production costs due to

954 vinasse use as nutrients source. Both scenarios SC1 and SC4 had glycerol price at US\$ 400 ton- $^{-}$

$955{ }^{1}$, and costs in SC4 were 13.1\% lower. As for SC2 and SC5 (glycerol at US\$ 300 ton $^{-1}$ ), SC5 had

956 production costs reduced by $10.8 \%$; between SC3 and SC6 (glycerol at US $\$ 200$ ton $^{-1}$ ), costs in

957 SC6 were $8.2 \%$ lower (Figure 12).

958 These results suggest that economical scenarios with more expensive carbon source, or possible

959 increase of prices, could have lower impact on production costs by using vinasse as a partial

960 source of carbon source and making operation less vulnerable to such external factors.

961

962 Figure 12. Unit production costs and annual production costs discriminated by raw

963 materials, facility and others in scenarios with mineral medium (SC1, SC2, SC3) and

964 scenarios with concentrated vinasse as partial source of nutrients in culture medium (SC4,

965 sc5, SC6).

966

967 Vinasse was also a partial source of mineral components in culture medium. Considering final 968 costs with glycerol in culture medium, scenario SC3 had the same costs with external carbon

969 source as SC4 because the later used vinasse as a partial source of carbon source. However,

970 due to reduced costs with mineral components for medium, total production costs in SC4 were

$9712 \%$, or US\$ $972,825.00$ year $^{-1}$, lower than those in SC3. That was about the annual cost with

972 utilities (US\$ 951,802.00 year $^{-1}$ ).

973 The decrease of glycerol price from US $\$ 400$ ton $^{-1}$ (SC1) to US\$ 200 ton $^{-1}$ (SC3) reduced unit

974 production cost from US\$ $6.2 \mathrm{kgPHB}^{-1}$ to US $\$ 5.5 \mathrm{kgPHB}^{-1}$. Scenarios that combined decrease of 
975 glycerol price with the use of vinasse had unit production costs of US\$5.4 $\mathrm{kgPHB}^{-1}$ (SC4, US $\$ 400$

976 ton $^{-1}$ ) and US $\$ 5.1 \mathrm{kgPHB}^{-1}\left(\mathrm{SC} 6\right.$, US $\$ 200$ ton $\left.^{-1}\right)$.

977 Despite reduction of production costs by decreasing costs with culture medium, facility-dependent 978 costs were significant and invariable (Figure 12). So in order to decrease process costs even

979 further, improvements in productivity are needed.

980 The second set of in silico analyses aimed to investigate bioprocess improvements on productivity

981 and cell density, and evaluate their impacts on production costs and profitability indicators.

982 As detailed in the Material and Methods section, experimental values of specific velocity of 983 product biosynthesis $\left(\mu_{\mathrm{P}}\right)$ were used to simulate productivities $\left(\mathrm{Pp}_{s_{i}}\right)$. The highest $\mu_{\mathrm{P}}$ value was

$9840.09 \mathrm{~g} \mathrm{gh}^{-1}$ at $\mathrm{t}=39 \mathrm{~h}$. So $\mu \mathrm{p}$ values determined between $\mathrm{t}=55 \mathrm{~h}$ and $\mathrm{t}=74 \mathrm{~h}$ were further used 985 in simulations of optimistic $\left(\mu_{\mathrm{P}}=0.07 \mathrm{~g} \mathrm{gh}^{-1}\right)$, realistic $\left(\mu_{\mathrm{P}}=0.05 \mathrm{~g} \mathrm{gh}^{-1}\right)$ and pessimistic $\left(\mu_{\mathrm{P}}=0.02\right.$ $986 \mathrm{~g} \mathrm{gh}^{-1}$ ) scenarios (Figure 13).

987

988

Figure 13. R. eutropha L359PCJ cultivation in bioreactor with concentrated vinasse-based culture medium: specific velocities of product biosynthesis $\left(\mu_{\mathrm{p}} \mathbf{g} \mathbf{g h}^{-1}\right) .\left({ }_{--}\right)$: start of the second batch. (_): start of third to seventh batches.

991

992 Table 10 presents calculated productivities for each scenario of optimistic, realistic or pessimistic 993 values of $\mu_{p}$.

994

995

Table 10. Optimistic, realistic and pessimistic scenarios for simulation of productivities, cell density and PHB titers.

997

998 Previous studies described growth phases that lasted between $20 \mathrm{~h}$ to $26 \mathrm{~h}$ in high cell density 999 bioprocesses that produced PHA from glycerol (Cavalheiro et al., 2009; Volova et al., 2018). As 1000 for PHB accumulation phase duration, bacterial bioprocesses are very rarely described with 1001 accumulation phases longer than $50 \mathrm{~h}$, which would be more compatible with archaeal 
1002 bioprocesses (Bhattacharyya et al., 2012; Pramanik et al., 2012). Thus, our calculated process

1003 times between $88.2 \mathrm{~h}$ and $90.3 \mathrm{~h}$ were appropriately pessimistic.

1004 The realistic scenarios had total process times consistent with those experimentally described by

1005 other authors (Acosta-Cárdenas et al., 2018; Bormann \& Roth, 1999; lenczak et al., 2011;

1006 Kachrimanidou et al., 2014; Rodríguez-Contreras et al., 2015). These authors described

1007 bioprocesses with $R$. eutropha strains that used glycerol as carbon source and fermentation times

1008 ranged from $45 \mathrm{~h}$ to $60 \mathrm{~h}$. Thus, high cell density bioprocess with duration times below $45 \mathrm{~h}$ could

1009 indeed be considered optimistic scenarios.

1010 All simulated scenarios considered PHB content of $66.3 \%$, as we determined experimentally, so

1011 cell densities $\left(\mathrm{X}_{\mathrm{f}-\mathrm{S} i}\right)$ of $30 \mathrm{~g} \mathrm{~L}^{-1}, 40 \mathrm{~g} \mathrm{~L}^{-1}$ and $50 \mathrm{~g} \mathrm{~L}^{-1}$ resulted in estimated CDW concentrations of

$101289 \mathrm{~g} \mathrm{~L}^{-1}, 118.7 \mathrm{~g} \mathrm{~L}^{-1}$ and $148.4 \mathrm{~g} \mathrm{~L}^{-1}$, respectively. Estimated PHB titers $\left(\mathrm{P}_{f-S_{i}}\right)$ are presented in

1013 Table 10. Finally, the simulated productivities $\left(\mathrm{Pp}_{s_{i}}\right)$ ranged between $0.7-2.3 \mathrm{~g} \mathrm{Lh}^{-1}$, which were

1014 consistent with those experimentally described elsewhere (Blunt et al., 2018; Cavalheiro et al.,

1015 2009; Volova et al., 2018).

1016 Scenarios from SC7 to SC15 were firstly analyzed by facility-dependent costs. Figure 14 depicts

1017 total annual production costs specifically related to glycerol and facility-dependent costs. The

1018 remaining production costs such as other raw materials, utilities, labor, etc., were generally

1019 treated as "Other production costs".

1020

1021 Figure 14. Total annual production costs. (o) optimistic scenarios; (r) realistic scenarios;

1022 (p) pessimistic scenarios; (30) $\mathrm{X}_{f-S i}=30 \mathrm{~g} \mathrm{~L}^{-1}$; 30) $\mathrm{X}_{f-S i}=40 \mathrm{~g} \mathrm{~L}^{-1}$; 30) $\mathrm{X}_{f-S i}=50 \mathrm{~g} \mathrm{~L}^{-1}$.

1023

1024 In comparison to scenario SC1, optimistic and realistic scenarios for all cell densities had lower

1025 production costs. Among pessimistic scenarios, SC9 had production costs $13.4 \%$ higher than

1026 those in SC1, but in scenarios SC12 and SC15 these costs were, respectively, $3.4 \%$ and $13 \%$

1027 lower.

1028 In order to reduce production costs, results in Figure 14 indicated that both productivity and PHB

1029 titers were important. The later was a result of cell density, given that PHB content was invariable 
1030 among scenarios. As stated above, higher cell densities became especially important in scenarios

1031 for pessimistic productivities.

1032 Higher cell densities also had greater impact on reduction of facility-dependent costs once

1033 productivity was improved. Comparing to pessimistic productivities, realistic scenarios decreased

1034 facility-dependent costs by $56.5 \%, 55.6 \%$ and $63.2 \%$ for $\mathrm{X}_{f-S i}=30 \mathrm{~g} \mathrm{~L}^{-1}, \mathrm{X}_{f-S i}=40 \mathrm{~g} \mathrm{~L}^{-1}$ and $\mathrm{X}_{f-S i}=$

$103550 \mathrm{~g} \mathrm{~L}^{-1}$, respectively. By comparing realistic and optimistic scenarios, these reduction costs were

$10365.3 \%$ for $\mathrm{X}_{f-S i}=30 \mathrm{~g} \mathrm{~L}^{-1}, 19.6 \%$ and $19.4 \%$ for $\mathrm{X}_{f-S i}=40 \mathrm{~g} \mathrm{~L}^{-1}$, and $\mathrm{X}_{f-S i}=50 \mathrm{~g} \mathrm{~L}^{-1}$, respectively.

1037 According to these results, efforts and resources dedicated to achieving higher cell densities are

1038 justifiable in order to optimize PHB bioprocesses. Even though our study estimated growth phase

1039 two hours longer in order to increase $\mathrm{X}_{f-S i}=30 \mathrm{~g} \mathrm{~L}^{-1}$ up to $\mathrm{X}_{f-S i}=50 \mathrm{~g} \mathrm{~L}^{-1}$, production costs were

1040 not negatively affected. Improving cell density and consequently PHB titers would also be an

1041 strategy for optimizing facility occupancy and the PHB production (tons PHB batch ${ }^{-1}$ ) could be met

1042 by a lower number of bioreactor units (Figure 15A and B).

1043 Higher productivities were expected to reduce unit production costs. Scenarios from SC7 to SC15

1044 evaluated improvements on productivity and PHB titers combined with the use of vinasse as a

1045 partial source of nutrients and unit production costs ranged from US\$3.9 $\mathrm{kgPHB}^{-1}$ to US\$7.5 $\mathrm{kgPHB}^{-}$

$1046{ }^{1}$ (Figure 15C).

1047

1048 Figure 15. Effect of productivity on production costs. A. Number of units of production

1049 bioreactor. B. PHB production as tons per batch. C. Unit production cost.

1050

1051 Unit production costs determined in pessimistic scenarios were less competitive than those

1052 determined in SC1 (US\$ $6.2 \mathrm{kgPHB}^{-1}$ ) and by Leong et al. (2017) (US\$ $6.1 \mathrm{~kg}_{\mathrm{PHB}^{-1}}{ }^{-1}$. On the other

1053 hand, all realistic and optimistic scenarios had more competitive unit production costs and

1054 profitability indicators ROI, IRR, NPV and payback as well.

1055 Unit production costs determined in scenarios from SC1 to SC15, that ranged between US\$ 3.9 $1056 \mathrm{kgPHB}^{-1}$ and US $\$ 7.5 \mathrm{~kg}_{\mathrm{PHB}^{-1}}$ were consistent with previous studies. Many factors might affect PHB 1057 production costs, such as microbial strain, PHB content, type, quality and location of carbon 
sources, production capacity, and others. Feedstocks such as sucrose, waste glycerol, whey, methane, soy oil and others have been previously evaluated by other authors and unit production

1060 costs between US\$ $1.9 \mathrm{kgPHB}^{-1}$ and US\$ $18.7 \mathrm{kgPHB}^{-1}$ were determined, and studies most 1061 commonly estimated costs between US\$ $4.1 \mathrm{kgPHB}^{-1}$ and US\$ $6.8 \mathrm{kgPHB}^{-1}$ (Akiyama et al., 2003;

1062 Choi \& Lee, 1997; Koller et al., 2013; Leong et al., 2017; Levett et al., 2016; Listewnik et al., 2007;

1063 Mudliar et al., 2008; Posada et al., 2011; Van-Wegen et al., 1998). According to our study,

1064 sugarcane vinasse has great potential as feedstock for PHB bioproduction.

1065 The best results were determined for scenario SC13, which had $\mathrm{X}_{f-S i}=50 \mathrm{~g} \mathrm{~L}^{-1}$, PHB productivity 1066 of $2.3 \mathrm{~g} \mathrm{Lh}^{-1}$, PHB titer of $98.4 \mathrm{~g} \mathrm{~L}^{-1}$ and bioprocess time of $42.8 \mathrm{~h}$. The unit production cost was 1067 US\$ $3.9 \mathrm{kgPHB}^{-1}$ and payback time was 2.6 years (Table 11).

1068

1069 Table 11. Unit production costs and profitability indicators in scenarios of optimistic, realistic and pessimistic productivities.

1071

1072 Indicators of economical feasibility and profitability are highly variable among projects, depending

1073 on their technical specificities, geographic location and markets they aim to. The payback time is

1074 one of the most general indicators and, at some level, allows comparison among a variety of 1075 projects. Considering bioprocesses that aimed to exploit agroindustrial wastes for biocommodities 1076 manufacturing, other authors have applied the SuperPro Designer software to estimate payback 1077 times of $3-5.5$ years for valorization of whey wastes and syrups by food products (Gómez et al., 1078 2020). The biotechnological process of L-lysine synthesis from sugarcane molasses was 1079 estimated to have payback time of 3.8 years (Anaya-Reza \& Lopez-Arenas, 2017). And the 1080 integration of Brazilian sugar mills to single cell oil production had estimated payback times 1081 between $5.4-13.1$ years (Vieira et al., 2016). The payback times determined for scenarios SC7 1082 to SC15 ranged from $2.6-7.3$ years and may be considered competitive with other bioprocesses 1083 of agroindustrial wastes valorization. 
1084 Our results were obtained while assuming glycerol price of US\$ 400 ton $^{-1}$, which could be 1085 considered as an expensive price in Brazil (Stracke et al., 2018). Evaluating lower prices could

1086 result in more attractive scenarios for any of the conditions presented in this study.

1087 Scenarios SC9 and SC13, which had respectively the worst and best unit production costs and 1088 profitability indicators, were further analyzed for glycerol price of US $\$ 200$ ton $^{-1}$. Scenario SC9 1089 had production cost reduced to US $\$ 7.2 \mathrm{kgPHB}^{-1}$ and profitability indicators were $\mathrm{ROI}=14.3 \%$, IRR $10907.6 \%, \mathrm{NPV}=\mathrm{US} \$ 32$ million and payback time of 7.0 years. As for SC13, unit production cost 1091 was US $\$ 3.6 \mathrm{kgPHB}^{-1}$ and ROI, IRR, NPV were respectively $40.8 \%, 31 \%$ and US $\$ 258.5$ million, 1092 with a payback time of 2.5 years.

1093 In this study, despite the proposal of integrating bioethanol and PHB processes, our simulation 1094 model in SuperPro Designer considered a production facility entirely dedicated to the PHB 1095 process. No facility sharing between processes was simulated in this study. Including facility 1096 sharing between PHB and bioethanol process would require very specific information from the 1097 Brazilian sugarcane mills to be inserted into our simulation model. Because this study employed 1098 a theoretical approach, it was decided not to assume such reduction costs due to facility sharing. 1099 However, with future perspectives for such integration, these factors should be considered and 1100 initial investments could become more attractive.

1101

\section{Conclusion}

1103 In this study we were able to demonstrate that vinasse has potential for cultivating E. coli THR14,

1104 Halomonas sp. HG03 and R. eutropha L359PCJ.

1105 L-threonine is a growth-related bioproduct and its biosynthesis by $E$. coli THR14 was not 1106 negatively affected in vinasse-based media with in natura vinasse up to $50 \%\left(\mathrm{v} \mathrm{v}^{-1}\right)$. Further 1107 improvements in L-threonine production rates by E. coli THR14 could bring perspectives for use 1108 vinasse application as water and mineral source for culture medium.

1109 As for PHB biosynthesis by Halomonas sp. HG03 and R. eutropha L359PCJ, both in natura and 1110 concentrated forms of vinasse provided results comparable to those previously reported in 
1111 literature, for shake flasks and bioreactors fermentations. That makes vinasse a competitive

1112 feedstock for PHB production processes, especially for glycerol-consuming strains.

1113 R. eutropha L359PHB could efficiently consume glycerol from vinasse and biosynthesize PHB.

1114 No inhibitory effects were observed in CSTR bioreactor cultivation, production yields, PHB

1115 content and final titer were comparable to those reported for PHB production from other glycerol

1116 sources.

1117 Moreover, in silico analyses were determinant for assessing the potential of using vinasse in large

1118 scale bioprocesses. Important reductions of production costs could be possible due to vinasse as

1119 a partial source of glycerol and other mineral components in culture medium

1120

\section{Abbreviations}

1122 PHB: poly(3-hydroxybutyrate)

1123 PHA: polyhydroxyalkanoate

1124 COD: Chemical Oxygen Demand

1125 CDW: Cell Dry Weight

1126 rCDW: residual Cell Dry Weight

1127

\section{Declarations}

\section{Ethics approval and consent to participate}

1130 Not applicable.

\section{Consent for publication}

1132 Not applicable.

\section{Availability of data and materials}

1134 All the needed data are provided in the manuscript. 


\section{Competing interests}

1136 The authors declare they have no competing interests.

\section{Funding}

1138 This study was financed by the Coordenação de Aperfeiçoamento de Pessoal de Nível Superior

1139 - Brasil (CAPES), Finance Code 001.

\section{Author's Contributions}

1141 MSS, experimental execution, formal analysis, data curation, writing; RAMP, conceptualization,

1142 supervision of the study, manuscript review; JLMSR, experimental execution; JGCG,

1143 conceptualization, manuscript review; ASB, conceptualization, manuscript review. All authors

1144 approved the final manuscript.

1145 Corresponding author: Correspondence to Manuella Souza Silverio.

1146

\section{References}

1148 Acosta-Cárdenas A, Alcaraz-Zapata W, Cardona-Betancur M (2018) Sugarcane molasses and 1149 vinasse as a substrate for polyhydroxyalkanoates (PHA) production. Dyna. 85:220-225. doi: $1150 \quad 10.15446 /$ dyna.v85n206.68279.

1151 Akiyama M, Tsuge T, Doi Y (2003) Environmental life cycle comparison of polyhydroxyalkanoates

1152 produced from renewable carbon resources by bacterial fermentation. Polymer Degradation and 1153 Stability, 80:183-194. doi: 10.1016/S0141-3910(02)00400-7.

1154 Anaya-Reza O, Lopez-Arenas T (2017) Comprehensive assessment of the I-lysine production 1155 process from fermentation of sugarcane molasses. Bioprocess and Biosystems Engineering, 1156 40:7. doi: 10.1007/s00449-017-1766-2.

1157 Badawy AAB (2012) The EZ:Faast family of amino acids analysis kits: application of the GC-FID 1158 kit for rapid determination of plasma tryptophan and other amino acids. Methods Mol Biol. 1159 828:153-164. doi: 10.1007/978-1-61779-445-2_14. 
1160 Bhattacharyya A, Pramanik A, Maji SK, Haldar S, Mukhopadhyay UK, Mukherjee J (2012)

1161 Utilization of vinasse for production of poly-3-(hydroxybutyrate-co-hydroxyvalerate) by Haloferax

1162 mediterranei. Dig AMB Express. doi: 10.1186/2191-0855-2-34.

1163 Blunt W, Levin D, Cicek N (2018) Bioreactor Operating Strategies for Improved

1164 Polyhydroxyalkanoate (PHA) Productivity. Polymers, 10:11. doi: 10.3390/polym10111197.

1165 Bormann EJ, Roth M (1999) The production of polyhydroxybutyrate by Methylobacterium

1166 rhodesianum and Ralstonia eutropha in media containing glycerol and casein hydrolysates.

1167 Biotechnology Letters, 21:1059-1063.

1168 Canizales L, Rojas F, Pizarro CA, Caicedo-Ortega NH, Villegas-Torres MF (2020) SuperPro

1169 Designer®, User-Oriented Software Used for Analyzing the Techno-Economic Feasibility of

1170 Electrical Energy Generation from Sugarcane Vinasse in Colombia. Processes, 8:9. doi:

$1171 \quad 10.3390 /$ pr8091180.

1172 Cardinali-Rezende J, Nahat RATPS, Moreno CWG, Farfán CRC, Silva LF, Taciro MK, Gomez

1173 JGC (2016) Draft Genome Sequence of Halomonas sp. HG01, a Polyhydroxyalkanoate-

1174 Accumulating Strain Isolate from Peru. Dig Genome Announcements.

1175 doi:10.1128/genomeA.01598-15.

1176 Cassman NA, Lourenço KS, Carmo JB, Cantarella H, Kuramae EE (2018) Genome-resolved

1177 metagenomics of sugarcane vinasse bacteria. Bioenergy for Biofuels. 11:48. doi:10.1186/s13068-

1178 018-1036-9.

1179 Cavalheiro, JMBT, Almeida MCMD, Grandfils C, Fonseca MMR (2009) Poly(3-hydroxybutyrate)

1180 production by Cupriavidus necator using waste glycerol. Process Biochemistry. 44:509-515. doi:

$1181 \quad$ 10.1016/j.procbio.2009.01.008.

1182 Chen N, Huang J, Feng ZB, Yu L, Xu QY, Wen TY (2009) Optimization of Fermentation

1183 Conditions for the Biosynthesis of L-Threonine by Escherichia coli. Appl Biochem Biotechnol.

1184 158:595-604. doi: 10.1007/s12010-008-8385-y. 
1185 Choi J, Lee SY (1997) Process analysis and economic evaluation for Poly(3-hydroxybutyrate)

1186 production by fermentation. Bioprocess Engineering, 17:6. doi: 10.1007/s004490050394.

1187 Coelho MPM, Correia JE, Vasques LI, Marcato ACC, Guedes TA, Soto MA, Basso JB, Kiang C,

1188 Fontanetti CS (2018) Toxicity evaluation of leached of sugarcane vinasse: Histopathology and

1189 immunostaining of cellular stress protein. Ecology and Environmental Safety. 165:367-375.

1190 doi:10.1016/j.ecoenv.2018.08.099.

1191 Cortez LAB (2010) Sugarcane Bioethanol: R\&D for productivity and sustainability. Editora Edgard

1192 Blucher Ltda., São Paulo. ISBN-10: 8521205309.

1193 Dowd MK, Johansen SL, Cantarella L (1994) Low molecular weight organic composition of 1194 ethanol stillage from sugarcane molasses, citrus waste, and sweet whey. J. Agri. Food Chem. 1195 42:283-288. doi:10.1021/jf00038a011.

1196 Eggeling L, Bott M (2015) A giant Market and a powerful metabolism: L-lysine provided by 1197 Corynebacterium glutamicum. Appl Microbiol Biotechnol. 99:3387-3394. doi: 10.1007/s00253$1198 \quad 015-6508-2$

1199 España-Gamboa E, Mijangos-Cortes J, Barahona-Perez L, Dominguez-Maldonado J, 1200 Hernández-Zarate G, Alzate-Gaviria L (2011) Vinasses: characterization and treatments. Waste 1201 Management and Research. 29:1235-1250. doi:10.1177/0734242X10387313.

1202 España-Gamboa E, Mijangos-Cortes J, Hernández-Zarate G, Dominguez-Maldonado J, Alzate1203 Gaviria L (2012) Methane production by treating vinasses from hydrous ethanol using a modified 1204 UASB reactor. Biotechnology for Biofuels. 5:82-90. doi:10.1186/1754-6834-5-82.

1205 European Bioplastics (2020) Dynamic growth: global production capacities of bioplastics 202012062025. https://docs.european-

1207 bioplastics.org/conference/Report_Bioplastics_Market_Data_2020_short_version.pdf. Accessed 120824 May 2021.

1209 Ferreira LFR, Aguiar MM, Messias TG.; Pompeu GB, Lopez AMQ, Sila DP, Monteiro RT (2011) 1210 Evaluation of sugar-cane vinasse treated with Pleurotus sajor-caju utilizing aquatic organisms as 
1211 toxicological indicators. Ecotoxicology and Environmental Safety. 74:132-137.

1212 doi:10.1016/j.ecoenv.2010.08.042.

1213 Ferreira E, Cavalcanti P, Nogueira D (2014) ExpDes: Na R Package for ANOVA and Experimental

1214 Designs. Applied Mathematics. 5:2952-2958. doi:10.4236/am.2014.519280.

1215 Fukui T, Mukoyama M, Orita I, Nakamura S (2014) Enhancement of glycerol utilization ability of

1216 Ralstonia eutropha $\mathrm{H} 16$ for production of polyhydroxyalkanoates. Appl Microbiol Biotechnol.

1217 98:7559-7568. doi: 10.1007/s00253-014-5831-3.

1218 Global Industry Analysts Inc. (2018) Healthy Market for meat and nutraceuticals drive the global

1219 amino acids market. 2018. https://www.strategyr.com/MarketResearch/market-report-

1220 infographic-amino-acids-forecasts-global-industry-analysts-inc.asp. Accessed 22 Feb 2020.

1221 Gómez JA, Sánchez ÓJ, Correa LF (2020) Techno-economic and Environmental Evaluation of

1222 Cheesemaking Waste Valorization Through Process Simulation Using SuperPro Designer. Waste

1223 and Biomass Valorization, 11:11. doi: 10.1007/s12649-019-00833-4.

1224 Grand View Research (2015) Amino Acids Market Analysis By Product (L-Glutamate, Lysine,

1225 Methionine, Threonine, Tryptophan, Leucine, Iso-Leucine, Valine, Glutamine, Arginine, Glycine,

1226 Phenylalanine, Tyrosine, Citrulline, Creatine, Proline, Serine), By Source (Plant-Based \& Animal-

1227 Based), By Application (Animal Feed, Food \& Dietary Supplements \& Pharmaceuticals) And

1228 Segment Forecasts To 2022. https://www.grandviewresearch.com/industry-analysis/amino-

1229 acids-market. Accessed 22 Feb 2020.

1230 Hermann (2003) Industrial production of amino acids by coryneform bacteria Journal of 1231 Biotechnology. 104:155-172. doi: 10.1016/S0168-1656(03)00149-4.

1232 Hohenschuh W, Kumar D, Murthy GS (2014) Economic and cradle-to-gate life cycle assessment 1233 of poly-3-hydroxybutyrate production from plastic producing, genetically modified hybrid poplar 1234 leaves. Journal of Renewable and Sustainable Energy, 6:6. doi: 10.1063/1.4901870. 
1235 lenczak JL, Quines LK, Melo AA, Brandellero M, Mendes CR, Schmidell W, Aragão GMF (2011)

1236 High cell density strategy for poly(3-hydroxybutyrate) production by Cupriavidus necator. Brazilian

1237 Journal of Chemical Engineering, 28:4. doi: 10.1590/S0104-66322011000400004.

1238 Kachrimanidou V, Kopsahelis N, Papanikolaou S, Kookos IK, Bruyn M, Clark JH, Koutinas AA

1239 (2014) Sunflower-based biorefinery: Poly(3-hydroxybutyrate) and poly(3-hydroxybutyrate-co-3-

1240 hydroxyvalerate) production from crude glycerol, sunflower meal and levulinic acid. Bioresource

1241 Technology, 172:121-130. doi: 10.1016/j.biortech.2014.08.044.

1242 Kim BS, Lee SC, Lee SY, Chang HN, Chang YK, Woo, SI (1994) Production of poly(3-

1243 hydroxybutyric acid) by fed-batch culture of Alcaligenes eutrophus with glucose concentration

1244 control. Biotechnology and Bioengineering, 43:9. doi: 10.1002/bit.260430908.

1245 Koller M, Niebelschütz H, Braunegg G (2013) Strategies for recovery and purification of poly[( $R$

1246 )-3-hydroxyalkanoates] (PHA) biopolyesters from surrounding biomass. Engineering in Life

1247 Sciences 13:6. doi: 10.1002/elsc.201300021.

1248 Kshirsagar P, Suttar R, Nilegaonkar S, Kulkarni S, Kanekar P (2012) Scale up production of 1249 polyhydroxyalkanoate (PHA) at different aeration, agitation and controlled dissolved oxygen 1250 levels in fermenter using Halomonas campisalis MCM B-1027. J Biochem Tech, 41:512-517.

1251 Kucera D, Pernicová I, Kovalcik A, Koller M, Mullerova L, Sedlacek P, Mravec F, Nebesarova J,

1252 Kalina M, Marova I, Krzyzanek V, Obruca S (2018) Characterization of the promising poly(31253 hydroxybutyrate) producing halophilic bacterium Halomonas halophila. Bioresource Technology.

1254 256:552-556. doi: 10.1016/j.biortech.2018.02.062.

1255 Lee MH, Lee HW, Park JH, Ahn JO, Jung JK, Hwang YI (2006) Improved L-Threonine Production

1256 of Escherichia coli Mutant by Optimization of Culture Conditions. Journal of Bioscience and 1257 Bioengineering. 101:127-130. doi: 10.1263/jbb.101.127.

1258 Lee JH, Sung BH, Kim MS, Blattner FR, Yoon BH, Kim JH, Kim SC (2009) Metabolic engineering 1259 of a reduced-genome strain of Escherichia coli for L-threonine production. Dig Microbial Cell 1260 Factories. doi: 10.1186/1475-2859-8-2. 
1261 Leong YK, Show PL, Lan JCW, Loh HS, Lam HL, Ling TC (2017) Economic and environmental

1262 analysis of PHAs production process. Clean Technologies and Environmental Policy, 19:19411263 1953. doi: $10.1007 / \mathrm{s} 10098-017-1377-2$.

1264 Levett I, Birkett G, Davies N, Bell A, Langford A, Laycock B, Lant P, Pratt S (2016) Techno1265 economic assessment of poly-3-hydroxybutyrate (PHB) production from methane-The case for 1266 thermophilic bioprocessing. Journal of Environmental Chemical Engineering 4:4. doi: 1267 10.1016/j.jece.2016.07.033.

1268 Li Y, Wei H, Wang T, Xu Q, Zhang C, Fan X, Ma Q, Chen N, Xie X (2017) Current status on 1269 metabolic engineering for the production of L-aspartate family amino acids and derivatives. 1270 Bioresource Technology. 245:1588-1602. doi: 10.1016/j.biortech.2017.05.145.

1271 Listewnik HF, Wendlandt KD, Jechorek M, Mirschel G (2007) Process Design for the Microbial 1272 Synthesis of Poly- $\beta$-hydroxybutyrate (PHB) from Natural Gas. Engineering in Life Sciences 7:3. 1273 doi: 10.1002/elsc.200620193.

1274 Lopes ML., Paulillo SCL, Godoy A, Cherubin RA, Lorenzi MS, Giometti FHC (2016) Ethanol 1275 production in Brazil: a bridge between science and industry. Brazilian Journal of Microbiology. $1276 \quad$ 47:64-76. doi:10.1016/j.bjm.2016.10.003.

1277 Moraes B. S, Zaiat M, Bonomi A (2015) Anaerobic digestion of vinasse from sugarcane ethanol 1278 production in Brazil: Challenges and perspectives. Renewable and Sustainable Energy Reviews. 1279 44:888-903. doi:10.1016/j.rser.2015.01.023.

1280 Moreno CWG (2015) Produção de Polihidroxialcanoatos (PHA) por Halomonas sp. HG01. 1281 Dissertation, University of São Paulo.

1282 Mudliar SN, Vaidya AN, Suresh Kumar M, Dahikar S, Chakrabarti T (2008) Techno-economic 1283 evaluation of PHB production from activated sludge. Clean Technologies and Environmental 1284 Policy 10:3. doi: 10.1007/s10098-007-0100-0.

1285 OECD/FAO. (2021) OECD-FAO Agricultural Outlook 2021-2030. OECD Publishing, Paris. 1286 doi.org/10.1787/19428846-en. 
1287 Ortiz-Muniz B, Carvajal-Zarrabal O, Torrestiana-Sanchez B, Aguilar-Uscanga MG (2010) Kinetic 1288 study on ethanol production using Saccharomyces cerevisiae ITV-01 yeast isolated from sugar 1289 cane molasses. J Chem Technol Biotechnol. 85:1361-1367. doi:10.1002/jctb.2441.

1290 Ortiz-Veizán N, Daga-Quisbert J, Perez-Zabaleta M, Guevara-Martínez M, Larsson G, 1291 Quillaguamán J (2020) Improvements of poly(3-hydroxybutyrate) production in an air-lift reactor 1292 using simple production media. Bioresources and Bioprocessing, 7:1. doi: 10.1186/s40643-0201293 00308-8.

1294 Paula CBC, Paula-Elias FC, Rodrigues MN, Coelho LF, Oliveira NML, Almeida AF, Contiero J 1295 (2021) Polyhydroxyalkanoate Synthesis by Burkholderia glumae into a Sustainable Sugarcane 1296 Biorefinery Concept. Frontiers in Bioengineering and Biotechnology. doi: $1297 \quad$ 10.3389/fbioe.2020.631284.

1298 Pedro-Escher J, Maziviero GT, Fontanetti CS (2014) Mutagenic action of sugarcane vinasse in 1299 the Tradescantia pallida Test System. J Ecosys Econograph. doi:10.4172/2157-7625.1000145.

1300 Petrides, D (2015). Bioprocess Design and Economics. In Harrison RG, Todd PW, Rudge SR, \& 1301 Petrides D (Eds.), Bioseparations Science and Engineering (pp. 11-1-11-83). Oxford University 1302 Press.

1303 Poltronieri P, Kumar P (2017) Polyhydroxyalcanoates (PHAs) in Industrial Applications. In:

1304 Martínez L, Kharissova O, Kharisov B (eds) Handbook of Ecomaterials. Springer, Cham . doi: 1305 10.1007/978-3-319-48281-1_70-1.

1306 Posada JA, Naranjo JM, López JA, Higuita JC, Cardona CA (2011) Design and analysis of poly1307 3-hydroxybutyrate production processes from crude glycerol. Process Biochemistry 46:1. doi: 1308 10.1016/j.procbio.2010.09.003.

1309 Pramanik A, Mitra A, Arumugam M, Bhattacharyya A, Sadhukhan S, Ray A, Haldar S, 1310 Mukhopadhyay UK, Mukherjee $\mathrm{J}$ (2012) Utilization of vinasse for the production of 1311 polyhydroxybutyrate by Haloarchula marismortui. Folia Microbiol. 57:71-79. doi: 10.1007/s122231312 011-0092-3. 
1313 Quillaguamán J, Delgado O, Mattiasson B, Hatti-Kaul R (2006) Poly( $\beta$-hydroxybutyrate) 1314 production by a moderate halophile, Halomonas boliviensis LC1. Enzyme and Microbial 1315 Technology, 38:1. doi: 10.1016/j.enzmictec.2005.05.013.

1316 Quillaguamán J, Doan-Van T, Guzmán H, Guzmán D, Martín J, Everest A, Hatti-Kaul R (2008). 1317 Poly(3-hydroxybutyrate) production by Halomonas boliviensis in fed-batch culture. Applied 1318 Microbiology and Biotechnology, 78:2. doi: 10.1007/s00253-007-1297-x.

1319 Quillaguamán J, Hashim S, Bento F, Mattiasson B, Hatti-Kaul R (2005) Poly( $\beta$-hydroxybutyrate) 1320 production by a moderate halophile, Halomonas boliviensis LC1 using starch hydrolysate as 1321 substrate. Journal of Applied Microbiology, 99:1. doi: 10.1111/j.1365-2672.2005.02589.x.

1322 Quillaguamán J, Muñoz M, Mattiasson B, Hatti-Kaul R (2007) Optimizing conditions for poly( $\beta$ 1323 hydroxybutyrate) production by Halomonas boliviensis LC1 in batch culture with sucrose as 1324 carbon soucr. Appl Microbiol Biotechnol. 74:981-986. doi: 10.1007/s00253-006-0754-2.

1325 Rathi DN, Amir HG, Abed RMM, Kosugi A, Arai T, Sulaiman O, Hashim R, Sudesh K (2012) 1326 Polyhydroxyalkanoate biosynthesis and simplified polymer recovery by a novel moderately 1327 halophilic bacterium isolated from hypersaline microbial mats. Journal of Applied Microbiology. 1328 114:384-395. doi: 10.1111/jam.12083.

1329 Ribeiro AC, Novais RF, Bahia-Filho AFC (1983) Efeitos da vinhaça sobre a dispersão de argila 1330 de amostras de latossolos. Revista Ceres 30. 167:12-18.

1331 Riis V, Mai W (1988) Gas chromatography determination of poly- $\beta$-hydroxybutyric acid in 1332 microbial biomass-esther hydrochloric acid propanolisis. J Chromatogr. 445:285-289.

1333 Rivera-Terceros P, Tito-Claros E, Torrico S, Carballo S, Van-Thuoc D, Quillaguamán J (2015) 1334 Production of poly(3-hydroxybutyrate) by Halomonas boliviensis in na air-lift reactor. Dig Journal 1335 of Biological Research-Thessaloniki. doi: 10.1186/s40709-015-0031-6.

1336 Rocha RCS, Silva LF, Taciro MK, Pradella JGC (2008) Production of poly(3-hydroxybutyrate-co1337 3-hydroxyvalerate) $\mathrm{P}(3 \mathrm{HB}-\mathrm{co}-3 \mathrm{HV})$ with a broad range of $3 \mathrm{HV}$ content at high yields by 
1338 Burkholderia sacchari IPT 189. World. J. Microbiol. Biotechnol. 24:427-431. doi: 10.1007/s112741339 007-9480-x.

1340 Rodríguez-Contreras A, Koller M, Dias MMS, Calafell-Monfort M, Braunegg G, Marqués-Calvo 1341 MS (2015) Influence of glycerol on poly(3-hydroxybutyrate) production by Cupriavidus necator 1342 and Burkholderia sacchari. Dig Biochemical Engineering Journal. doi: 10.1016/j.bej.2014.11.007.

1343 Salles-Filho SL, Castro PFD, Bin A, Edquist C, Ferro AFP, Corder S (2017) Perspectives for the 1344 Brazilian bioethanol sector: The innovation driver. Energy Policy 108:70-77. 1345 doi:10.1016/j.enpol.2017.05.037.

1346 Sharma K, Srivastava AK, Sreekrishnan TR (2021) Model-based optimization of biopolymer 1347 production from glycerol. Chemical and Biochemical Engineering Quarterly. 1:65-80. doi: $1348 \quad 10.15255 / C A B E Q .2020 .1864$.

1349 Shiloach J, Fass R (2005) Growing E. coli to high cell density - a historical perspective on method 1350 development. Biotechnol Adv. 23:345-357. doi: 10.1016/j.biotechadv.2005.04.004.

1351 Soini J, Ukkonen K, Neubauer P (2008) High cell density media for Escherichia coli are generally 1352 designed for aerobic cultivation - consequences for large-scale bioprocesses and shake flasks 1353 cultures. Dig Microbial Cell Factories. doi: 10.1186/1475-2859-7-26.

1354 Soto MAA, Basso JB, Kiang CH, Genuchten MT (2015) Simulação de fluxo e transporte de íons 1355 de vinhaça através da vertente da formação Rio Claro. Águas Subterrâneas. 29;1621356 174. doi:10.14295/ras.v29i2.28239.

1357 Souza JKC, Mesquita FO, Dantas-Neto J, Souza MMA, Farias CHA, Mendes HC, Nunes RMA 1358 (2015) Fertirrigação com vinhaça na produção de cana-de-açúcar. Agropecuária Científica no 1359 Seminárida. 11:7-12.

1360 Sreedevi S, Unni KN, Sajith S, Priji P, Josh MS, Benjamin S (2015) Bioplastics: Advances in 1361 Polyhydroxybutyra Research. In: Advances in Polymer Science. doi:10.1007/12_2014_297. 
1362 Stanley A, Kumar HNP, Mutturi S, Vijayendra SVN (2017) Fed-Batch Strategies for Production of 1363 PHA Using a Native Isolate of Halomonas venusta KT832796 Strain. Appl Biochem Biotechnol. 1364 184:935-952. doi: 10.1007/s12010-017-2601-6.

1365 Stracke MP, Wbatuba BBR, Padilha G, Seibert RM, Schrekker HS (2018) Biodiesel Production

1366 Process: Valorization of the Crude Glycerol Constituents. Brazilian Journal of Development, $1367 \quad 4: 3401-3416$.

1368 Suhaili N, Cárdenas-Fernández M, Ward JM, Lye GJ (2018) Potential of sugar beet vinasse as a 1369 feedstock for biocatalyst production within an integrated biorefinery context. Journal of Chemical 1370 Technology and Biotechnology. 94:739-751. doi: 10.1002/jctb.5819.

1371 UNICA (2021) Histórico de produção e moagem. https://observatoriodacana.com.br/historico-de1372 producao-e-moagem.php?idMn=31\&tipoHistorico=2. Accessed 04 Jun 2021.

1373 Van-Thuoc D, Quillaguamán J, Mamo G, Mattiasson B (2007) Utilization of agricultural residues 1374 for poly(3-hydroxybutyrate) production by Halomonas boliviensis LC1. Dig Journal of Applied 1375 Microbiology. doi: 10.1111/j.1365-2672.2007.03553.x.

1376 Van-Wegen RJ, Ling Y, Middelberg APJ (1998) Industrial Production of Polyhydroxyalkanoates 1377 Using Escherichia Coll: An Economic Analysis. Chemical Engineering Research and Design 76:3. 1378 doi: $10.1205 / 026387698524848$.

1379 Vieira JPF, lenczak JL, Costa PS, Rossell CEV, Franco TT, Pradella JGC (2016) Single cell oil 1380 production integrated to a sugarcane-mill: Conceptual design, process specifications and 1381 economic analysis using molasses as raw material. Dig Industrial Crops and Products. doi: 1382 10.1016/j.indcrop.2016.05.046.

1383 Volova T, Demidenko A, Kiselev E, Baranovskiy S, Shishatskaya E, Zhila N (2018) 1384 Polyhydroxyalkanoate synthesis based on glycerol and implementation of the process under 1385 conditions of pilot production. Appl Microbiology and Biotechnology. 103:225-237. doi: $1386 \quad 10.1007 / \mathrm{s} 00253-018-9460-0$. 
1387 Wang J, Ma W, Yang J, Chen S, Wang X (2019) Increasing L-threonine production in Escherichia 1388 coli by overexpressing the gene cluster phaCAB. Journal of Industrial Microbiology \& 1389 Biotechnology. 46:1557-1568. doi: 10.1007/s10295-019-02215-0.

1390 Ying H, He X, Chen K, Ouyang P (2014) Optimization of Culture Conditions for Enhanced Lysine

1391 Production Using Engineered Escherichia coli. Appl Biochem Biotechnol. 172:3835-3843. doi: $1392 \quad 10.1007 / \mathrm{s} 12010-014-0820-7$.

1393 Yue H, Ling C, Yang T, Chen X, Chen Y, Deng H, Wu Q, Chen J, Chen GQ (2014) A seawater1394 based open and continuous process for polyhydroxyalkanoates production by recombinant 1395 Halomonas campaniensis LS21 grown in mixed substrates. Biotechnology for Biofuels, 7:1. doi: $1396 \quad 10.1186 / 1754-6834-7-108$.

1397 Zanfonato K, Schmidt M, Quines LK, Gai CS, Schmidell W, Aragão GMF (2018) Can vinasse be 1398 used as carbon source for poly(3-hydroxybutyrate) production by Cupriavidus necator DSM545? 1399 Brazilian Journal of Chemical Engineering. 35:901-908. doi: 10.1590/0104$1400 \quad 6632.20180353 s 20170265$.

1401 Zhao H, Fang Y, Wang X, Zhao L, Wang J, Li Y (2018) Increasing L-threonine production in 1402 Escherichia coli by engineering the glyoxylate shunt and the L-threonine biosynthesis pathway. 1403 Applied Microbiology and Biotechnology. 102:5505-5518. doi: 0.1007/s00253-018-9024-3. 
1412

1413

1414

1415

1416

1417

1418 
Table 1. In natura vinasse chemical composition (3.4ํㅜrix)

\begin{tabular}{|c|c|c|c|}
\hline & & Concentration & Unit \\
\hline \multirow[t]{2}{*}{ Organic acids } & Acetic acid & $0.3 \pm 0.01$ & $\mathrm{~g} \mathrm{~L}^{-1}$ \\
\hline & Lactic acid & $0.7 \pm 0.04$ & $\mathrm{~g} \mathrm{~L}^{-1}$ \\
\hline \multirow[t]{4}{*}{ Carbohydrates } & Sucrose & ND & $\mathrm{g} \mathrm{L}^{-1}$ \\
\hline & Glucose & $0.2 \pm 0.04$ & $g L^{-1}$ \\
\hline & Fructose & $0.6 \pm 0.02$ & $\mathrm{~g} \mathrm{~L}^{-1}$ \\
\hline & Glycerol & $10.0 \pm 0.1$ & $g L^{-1}$ \\
\hline \multirow[t]{4}{*}{ Salts } & Calcium $\left(\mathrm{Ca}^{2+}\right)$ & $1,586.6 \pm 315.3$ & $\mathrm{mg} \mathrm{L}^{-1}$ \\
\hline & Potassium $\left(\mathrm{K}^{+}\right)$ & $4,188.8 \pm 41.3$ & $\mathrm{mg} \mathrm{L}^{-1}$ \\
\hline & Ammonium $\left(\mathrm{NH}_{4}+\right)$ & $113.8 \pm 2.9$ & $\mathrm{mg} \mathrm{L}^{-1}$ \\
\hline & Sodium $\left(\mathrm{Na}^{+}\right)$ & $775.0 \pm 4.8$ & $\mathrm{mg} \mathrm{L}^{-1}$ \\
\hline \multirow[t]{20}{*}{ Amino acids } & L-alanine & $22.4 \pm 2.0$ & $\mathrm{mg} \mathrm{L}^{-1}$ \\
\hline & L-glycine & $6.7 \pm 0.4$ & $\mathrm{mg} \mathrm{L}^{-1}$ \\
\hline & L-valine & $12.2 \pm 0.5$ & $\mathrm{mg} \mathrm{L}^{-1}$ \\
\hline & L-leucine & $4.9 \pm 0.1$ & $\mathrm{mg} \mathrm{L}^{-1}$ \\
\hline & L-isoleucine & $5.3 \pm 0.4$ & $\mathrm{mg} \mathrm{L}^{-1}$ \\
\hline & L-threonine & $4.0 \pm 1.3$ & $\mathrm{mg} \mathrm{L}^{-1}$ \\
\hline & L-serine & $22.1 \pm 0.7$ & $\mathrm{mg} \mathrm{L}^{-1}$ \\
\hline & L-proline & $9.8 \pm 0.2$ & $\mathrm{mg} \mathrm{L}^{-1}$ \\
\hline & L-asparagine & $59.5 \pm 34.1$ & $\mathrm{mg} \mathrm{L}^{-1}$ \\
\hline & L-aspartate & $133.4 \pm 27.6$ & $\mathrm{mg} \mathrm{L}^{-1}$ \\
\hline & L-methionine & $3.0 \pm 0.2$ & $\mathrm{mg} \mathrm{L}^{-1}$ \\
\hline & L-glutamate & $5.0 \pm 0.03$ & $\mathrm{mg} \mathrm{L}^{-1}$ \\
\hline & L-phenilalanine & $3.9 \pm 0.2$ & $\mathrm{mg} \mathrm{L}^{-1}$ \\
\hline & L-glutamine & ND & $\mathrm{mg} \mathrm{L}^{-1}$ \\
\hline & L-ornithine & $1.8 \pm 0.5$ & $\mathrm{mg} \mathrm{L}^{-1}$ \\
\hline & L-lysine & $4.9 \pm 0.6$ & $\mathrm{mg} \mathrm{L}^{-1}$ \\
\hline & L-histidine & $3.8 \pm 0.1$ & $\mathrm{mg} \mathrm{L}^{-1}$ \\
\hline & L-tyrosine & $3.8 \pm 0.4$ & $\mathrm{mg} \mathrm{L}^{-1}$ \\
\hline & L-triptophan & ND & $\mathrm{mg} \mathrm{L}^{-1}$ \\
\hline & L-cystine & ND & $\mathrm{mg} \mathrm{L}^{-1}$ \\
\hline
\end{tabular}

ND: not detectable.

1422 Table 2. Culture medium composition for bioprocesses of PHB production in CSTR bioreactors. 


\begin{tabular}{llll}
\hline & \multicolumn{3}{c}{ Mineral medium MMB } \\
\cline { 2 - 3 } & $\begin{array}{l}\text { Rocha et al. } \\
(2008)\end{array}$ & $\begin{array}{l}\text { Final composition in } \\
\text { bioreactor * }\end{array}$ & $\begin{array}{l}\text { Vinasse } \\
7^{\circ} \text { Brix }\end{array}$ \\
\hline Carbon source $\left(\mathrm{g} \mathrm{L}^{-1}\right)^{\dagger}$ & 15.0 & 15.0 & $7.5^{+}$ \\
$\mathrm{KH}_{2} \mathrm{PO}_{4}\left(\mathrm{~g} \mathrm{~L}^{-1}\right)$ & 0.65 & 0.65 & - \\
$\left(\mathrm{NH}_{4}\right)_{2} \mathrm{SO}_{4}\left(\mathrm{~g} \mathrm{~L}^{-1}\right)$ & 3.6 & 3.6 & - \\
$\mathrm{MgSO}_{4} .7 \mathrm{H}_{2} \mathrm{O}\left(\mathrm{g} \mathrm{L}^{-1}\right)$ & 0.31 & 0.155 & - \\
$\mathrm{CaCl}_{2} .2 \mathrm{H}_{2} \mathrm{O}\left(\mathrm{g} \mathrm{L}^{-1}\right)$ & 0.01 & 0.005 & - \\
Ammonium ferric citrate $\left(\mathrm{g} \mathrm{L}^{-1}\right)$ & 0.15 & 0.075 & - \\
Trace elements solution $\left(\mathrm{mL} \mathrm{L}^{-1}\right)$ & 2.0 & 1.0 & - \\
Initial volume $(\mathrm{L})$ & - & 3.0 & 3.0 \\
\hline
\end{tabular}

* Halomonas sp. $\mathrm{HG} 03$ had $\mathrm{NaCl} 80.0 \mathrm{~g} \mathrm{~L}^{-1}$ added to MMB medium in the first batch.

${ }^{\dagger}$ Halomonas sp. HG03: sucrose as the main carbono source; $R$. eutropha L359PCJ: glycerol as carbon source

- For both bacteria, the volumetric dilution of $50 \%\left(\mathrm{v} \mathrm{v}^{-1}\right)$ of concentrated vinasse supplied $7.5 \mathrm{~g} \mathrm{~L}^{-}$ 1 of glycerol.

1423

1424

1425

1426

1427

1428

1429

1430

1431

1432

1433

1434

1435

1436

1437

1438 


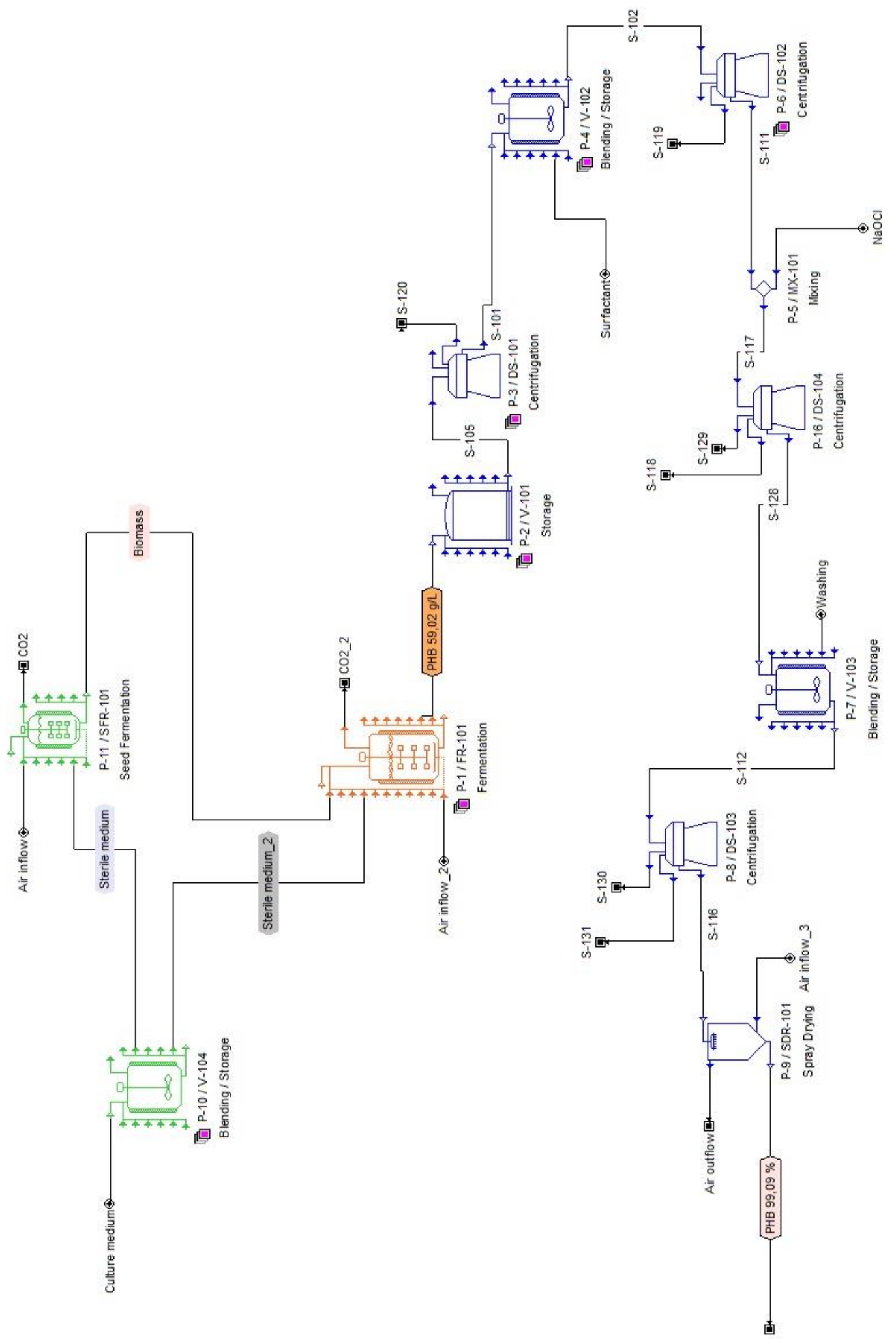

1439

1440 Figure 1. Bioprocess of PHB production by R. eutropha L359PCJ in SuperPro Designer v. 9.5. 
Table 3. Global stoichiometric equations used in base scenario SC1

\begin{tabular}{|c|c|c|c|}
\hline Section & Reaction & $\begin{array}{l}\text { Limiting } \\
\text { component }\end{array}$ & Global stoichiometric equation (mass coefficient) \\
\hline Upstream & $\mathrm{R} 1$ & Glycerol & $\begin{array}{l}1 \text { glycerol }+0.24\left(\mathrm{NH}_{4}\right)_{2} \mathrm{SO}_{4}+0.18 \mathrm{KH}_{2} \mathrm{PO}_{4}+0.021 \\
\mathrm{MgSO}_{4}+0.0007 \mathrm{CaCl}_{2}+0.01 \text { Ammoniacal iron citrate }+ \\
4 \times 10^{-5} \mathrm{H}_{3} \mathrm{BO}_{3}+3 \times 10^{-5} \mathrm{CoCl}_{2}+1.3 \times 10^{-5} \mathrm{ZnSO}_{4}+4 \times 10^{-6} \\
\mathrm{MnSO}_{4}+4 \times 10^{-6} \mathrm{Na}_{2} \mathrm{MoO}_{4}+3 \times 10^{-6} \mathrm{NiCl}_{2}+1.3 \times 10^{-6} \mathrm{CuSO}_{4} \\
=>\mathrm{Y}_{\mathrm{X} / \mathrm{S}^{+}}+\mathrm{YP}_{\mathrm{P} / \mathrm{S}}{ }^{+}\end{array}$ \\
\hline Bioprocess & $\mathrm{R} 2$ & Glycerol & $\begin{array}{l}1 \text { glycerol }+0.24\left(\mathrm{NH}_{4}\right)_{2} \mathrm{SO}_{4}+0.18 \mathrm{KH}_{2} \mathrm{PO}_{4}+0.021 \\
\mathrm{MgSO}_{4}+0.0007 \mathrm{CaCl}_{2}+0.01 \text { Ammoniacal iron citrate }+ \\
4 \times 10^{-5} \mathrm{H}_{3} \mathrm{BO}_{3}+3 \times 10^{-5} \mathrm{CoCl}_{2}+1.3 \times 10^{-5} \mathrm{ZnSO}_{4}+4 \times 10^{-6} \\
\mathrm{MnSO}_{4}+4 \times 10^{-6} \mathrm{Na}_{2} \mathrm{MoO}_{4}+3 \times 10^{-6} \mathrm{NiCl}_{2}+1.3 \times 10^{-6} \mathrm{CuSO}_{4} \\
=>\mathrm{YX}_{\mathrm{X} / \mathrm{S}} *+\mathrm{YP}_{\mathrm{P} / \mathrm{S}}^{*}\end{array}$ \\
\hline
\end{tabular}

${ }^{\dagger}$ Experimentally determined during growth phase. * Global yields experimentally determined for the whole process. 
Table 4. Technical-economical scenarios for evaluation of high cell density cultures and PHB productivities.

\begin{tabular}{ccc}
\hline Scenario & $\mathrm{X}_{\mathrm{f}-\mathrm{Si}}\left(\mathrm{g} \mathrm{L}^{-1}\right)$ & $\mu \mathrm{P}\left(\mathrm{g} \mathrm{gh}^{-1}\right)$ \\
\hline SC7 & 30 & optimistic \\
SC8 & 30 & realistic \\
SC9 & 30 & pessimistic \\
SC10 & 40 & optimistic \\
SC11 & 40 & realistic \\
SC12 & 40 & pessimistic \\
SC13 & 50 & optimistic \\
SC14 & 50 & realistic \\
SC15 & 50 & pessimistic \\
\hline
\end{tabular}

1464

1465

1466

1467

1468

1469

1470

1471

1472

1473

1474

1475

1476

1477

1478

1479

1480

1481

1482

1483

1484 


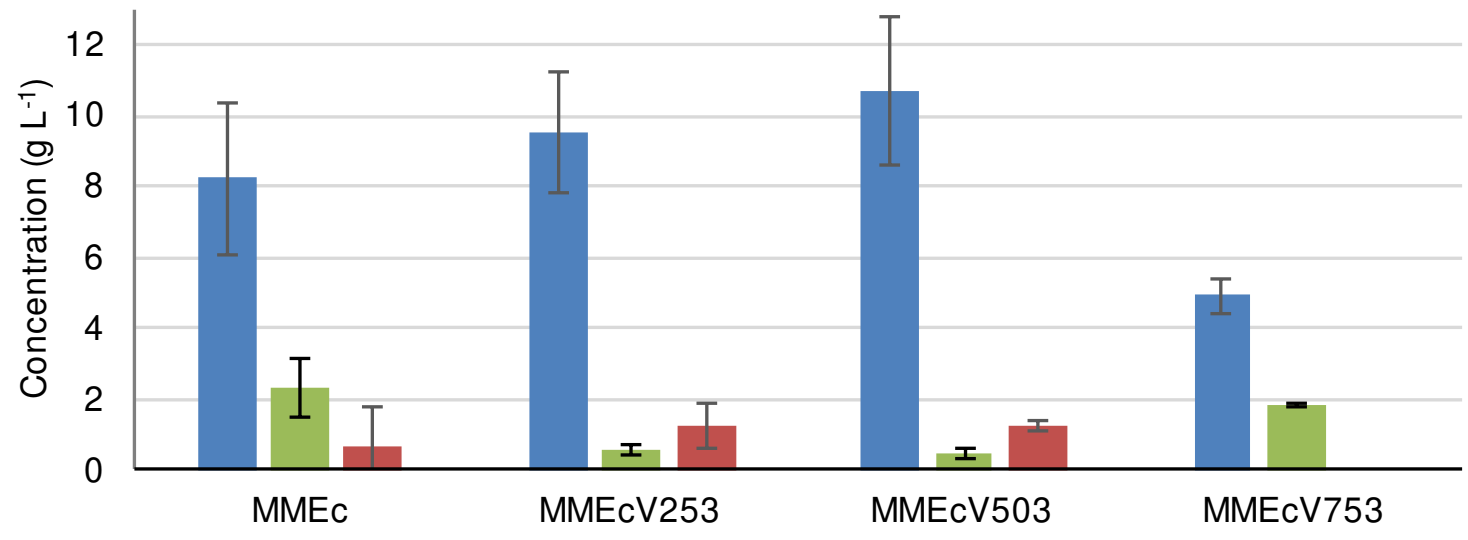

1485

$\square$ CDW Acetic acid $\quad$ L-threonine

1486

1487 Figure 2. CDW, L-threonine and acetic acid concentrations by E. coli THR14 in control and 1488 vinasse-based treatments after $24 \mathrm{~h}$ incubation in shake flasks.

1489

1490

1491

1492

1493

1494

1495

1496

1497

1498

1499

1500

1501

1502

1503

1504

1505

1506 
Table 5. Biomass and L-threonine yields from glucose by E. coli THR14

\begin{tabular}{lcc}
\hline & $Y_{x / S}\left(\mathrm{~g} \mathrm{~g}^{-1}\right)$ & $Y_{\mathrm{P} / \mathrm{S}}\left(\mathrm{g} \mathrm{g}^{-1}\right)$ \\
\hline $\mathrm{MM}_{E c}$ & $0.53 \pm 0.1$ & $0.03 \pm 0.05$ \\
$\mathrm{MM}_{E c}$ V253 & $0.44 \pm 0.04$ & $0.06 \pm 0.02$ \\
$\mathrm{MM}_{E c}$ V503 & $0.46 \pm 0.1$ & $0.05 \pm 0.01$ \\
$\mathrm{MM}_{E c}$ V753 & $0.51 \pm 0.04$ & NA \\
\hline
\end{tabular}

No statistical difference was found according to $F$ test $(p<0.05)$.

NA: not applicable.

1507

1508

1509

1510

1511

1512

1513

1514

1515

1516

1517

1518

1519

1520

1521

1522

1523

1524

1525

1526

1527

1528

1529

1530 


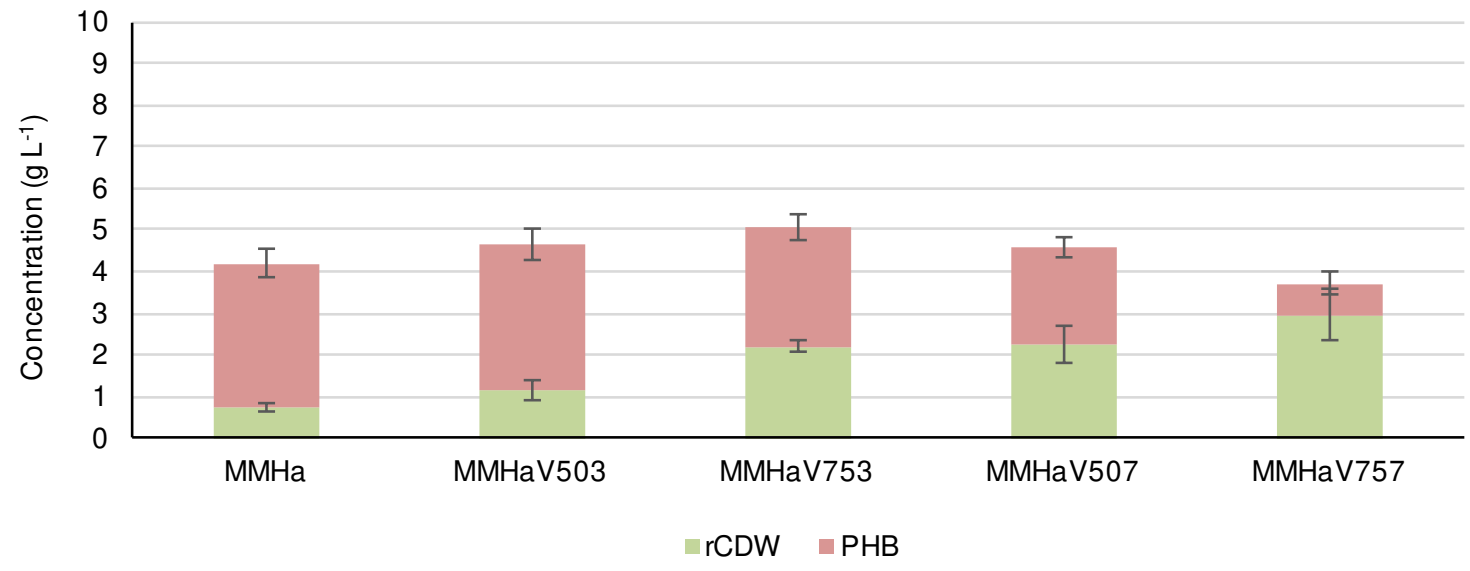

1531

1532

1533 Figure 3. Halomonas sp. HG03 cellular growth and PHB biosynthesis in mineral medium, in

1534 natura and concentrated vinasse-based treatments, after $48 \mathrm{~h}$ incubation.

1535

1536

1537

1538

1539

1540

1541

1542

1543

1544

1545

1546

1547

1548

1549

1550

1551

1552

1553 


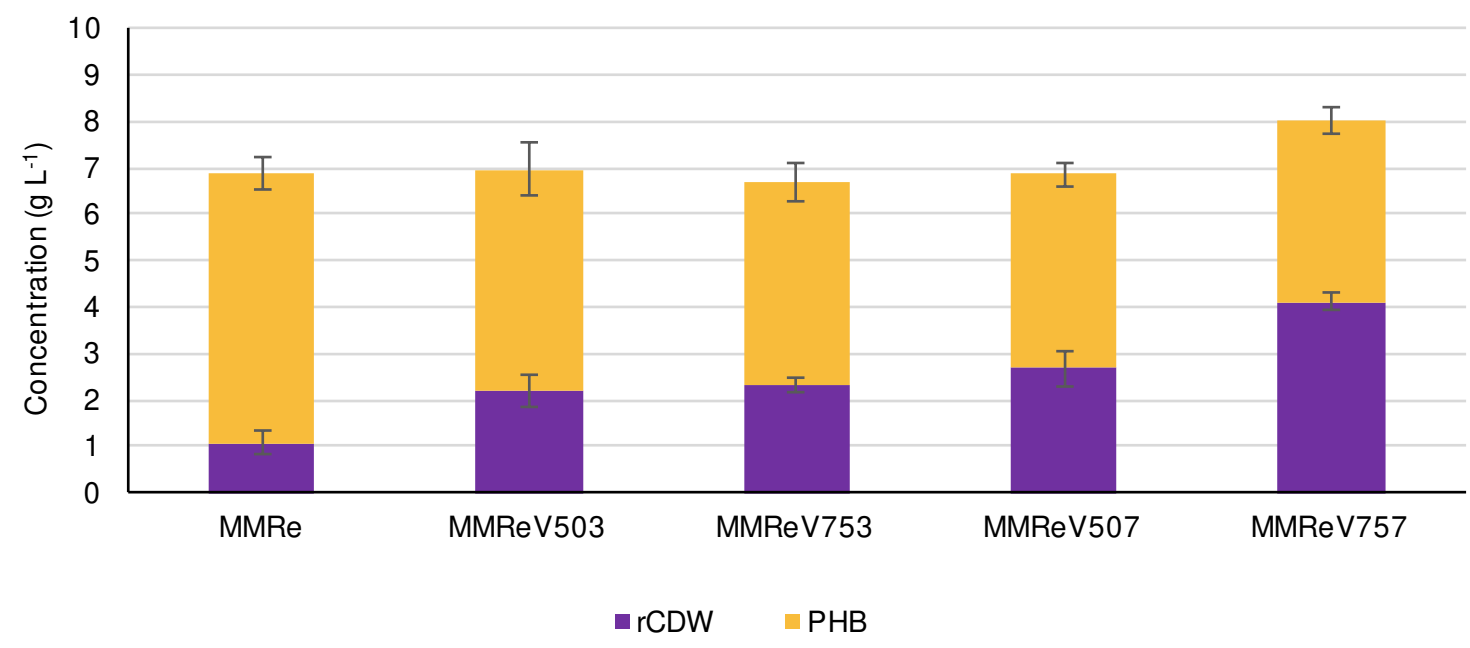

1554

1555 Figure 4. R. eutropha L359PCJ cellular growth and PHB biosynthesis in mineral medium, in 1556 natura and concentrated vinasse-based treatments, after $48 \mathrm{~h}$ incubation.

1557

1558

1559

1560

1561

1562

1563

1564

1565

1566

1567

1568

1569

1570

1571

1572

1573

1574

1575 
Table 6. Biomass and PHB yields from sucrose by Halomonas sp. HG03

\begin{tabular}{|c|c|c|}
\hline & $Y_{X / S}\left(g g^{-1}\right)$ & $Y_{P / S}\left(g g^{-1}\right)$ \\
\hline $\mathrm{MM}_{\mathrm{Ha}}$ & $0.07 \pm 0.01 c$ & $0.32 \pm 0.02 a$ \\
\hline $\mathrm{MM}_{\mathrm{Ha}} \mathrm{V} 503$ & $0.09 \pm 0.02 c$ & $0.27 \pm 0.04 b c$ \\
\hline $\mathrm{MM}_{\mathrm{Ha}} \mathrm{V} 753$ & $0.24 \pm 0.02 b$ & $0.31 \pm 0.04 a b$ \\
\hline $\mathrm{MM}_{\mathrm{Ha}} \mathrm{V} 507$ & $0.23 \pm 0.08 b$ & $0.23 \pm 0.02 c$ \\
\hline $\mathrm{MM}_{\mathrm{Ha}} \mathrm{V} 757$ & $0.36 \pm 0.08 a$ & $0.09 \pm 0.04 d$ \\
\hline
\end{tabular}

Letters abcd differ according to Tukey test with $5 \%$ of significance.

1576

1577

1578

1579

1580

1581

1582

1583

1584

1585

1586

1587

1588

1589

1590

1591

1592

1593

1594

1595

1596

1597

1598

1599 
Table 7. Biomass and PHB yields from glycerol by $R$. eutropha L359PCJ

\begin{tabular}{lcc}
\hline & $Y_{X / S}\left(\mathrm{~g} \mathrm{~g}^{-1}\right)$ & $Y_{P / S}\left(g^{-1}\right)$ \\
\hline$M_{R e}$ & $0.07 \pm 0.02 d$ & $0.39 \pm 0.02 a$ \\
$M_{R e} V 503$ & $0.16 \pm 0.03 c$ & $0.35 \pm 0.03 b$ \\
$M_{R e} V 753$ & $0.18 \pm 0.01 b c$ & $0.33 \pm 0.01 b$ \\
$M_{R e} V 507$ & $0.23 \pm 0.05 b$ & $0.34 \pm 0.03 b$ \\
$M_{R e} V 757$ & $0.31 \pm 0.02 a$ & $0.29 \pm 0.03 c$
\end{tabular}

Letters abcd differ according to Tukey test with $5 \%$ of significance.

1600

1601

1602

1603

1604

1605

1606

1607

1608

1609

1610

1611

1612

1613

1614

1615

1616

1617

1618

1619

1620

1621

1622

1623 


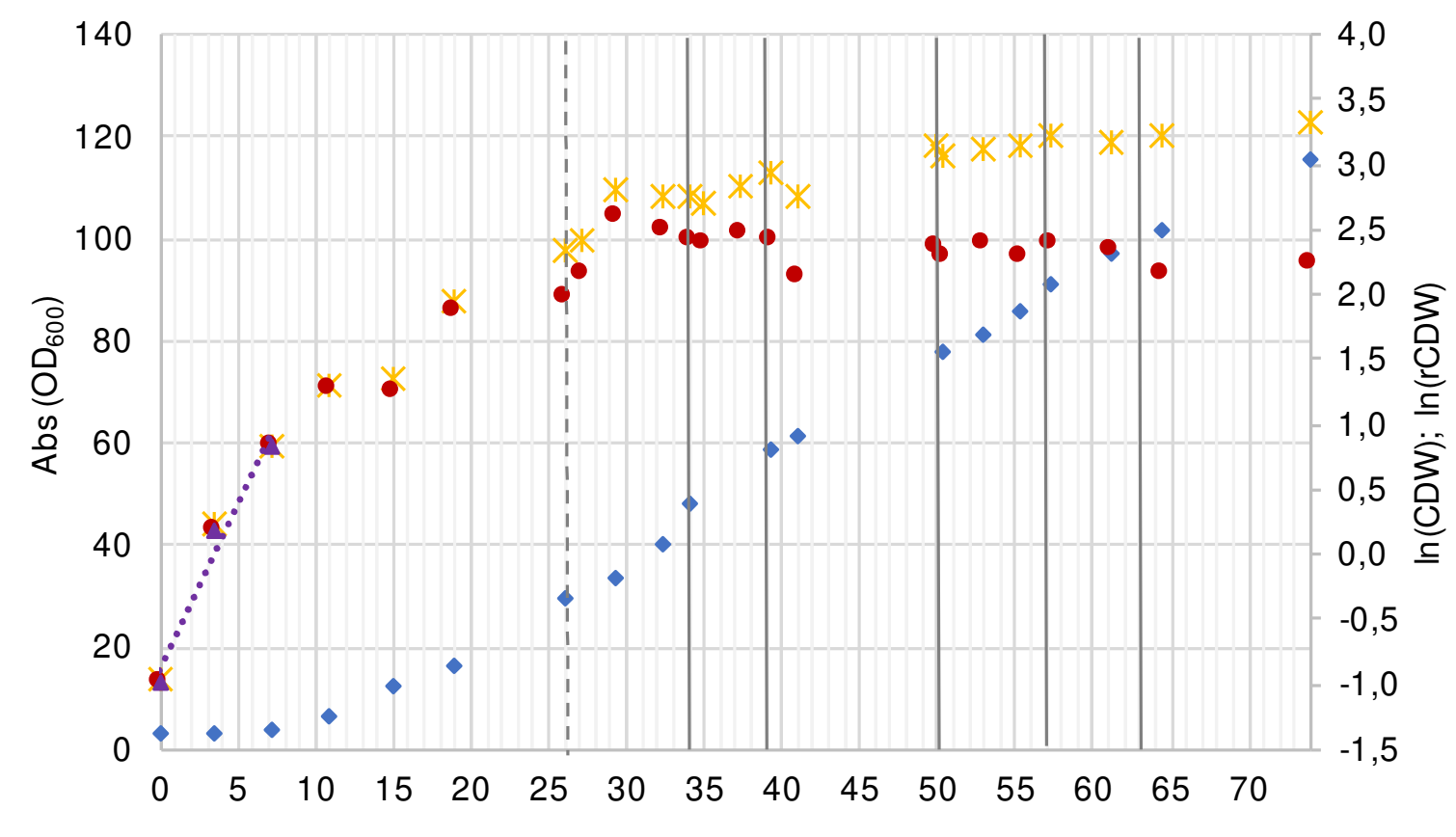

1624

(h)

1625 Figure 5. Cellular growth by $R$. eutropha L359PCJ in bioprocess operated by consecutive batches

1626 mode in bioreactor with concentrated vinasse-based medium. (-- -): start of the second batch. (

$1627-$ ): start of third to seventh batches. ( $(\mathbb{L}) \ln (\mathrm{CDW}) ;(\bullet) \ln (\mathrm{rCDW}) ;(\boldsymbol{\Delta}) \mu_{\max } \mathrm{h}^{-1} ;(\diamond)$ optical density

1628 (absorbance $600 \mathrm{~nm}$ ).

1629

1630

1631

1632

1633

1634

1635

1636

1637

1638

1639

1640

1641

1642 


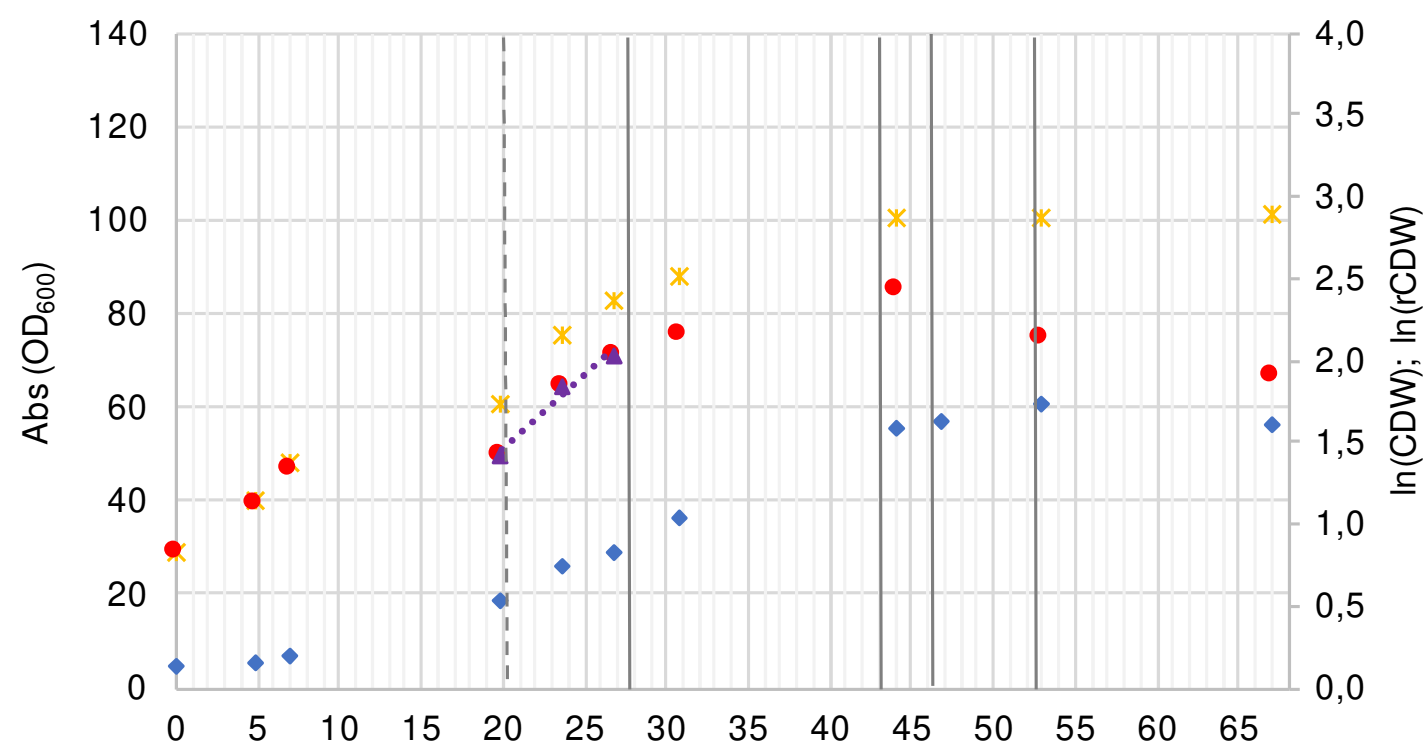

1645

(h)

1646 Figure 6. Cellular growth by Halomonas sp. HG03 in bioprocess operated by consecutive batches

1647 mode in bioreactor with concentrated vinasse-based medium. (- - ) : start of the second batch. (

$1648 \_$): start of third to sixth batches. ( $) \ln (\mathrm{CDW}) ;(\bullet) \ln (\mathrm{rCDW}) ;(\boldsymbol{\Delta}) \mu_{\max } \mathrm{h}^{-1} ;(\diamond)$ optical density 1649 (absorbance $600 \mathrm{~nm}$ ).

1650

1651

1652

1653

1654

1655

1656

1657

1658

1659

1660

1661

1662

1663 


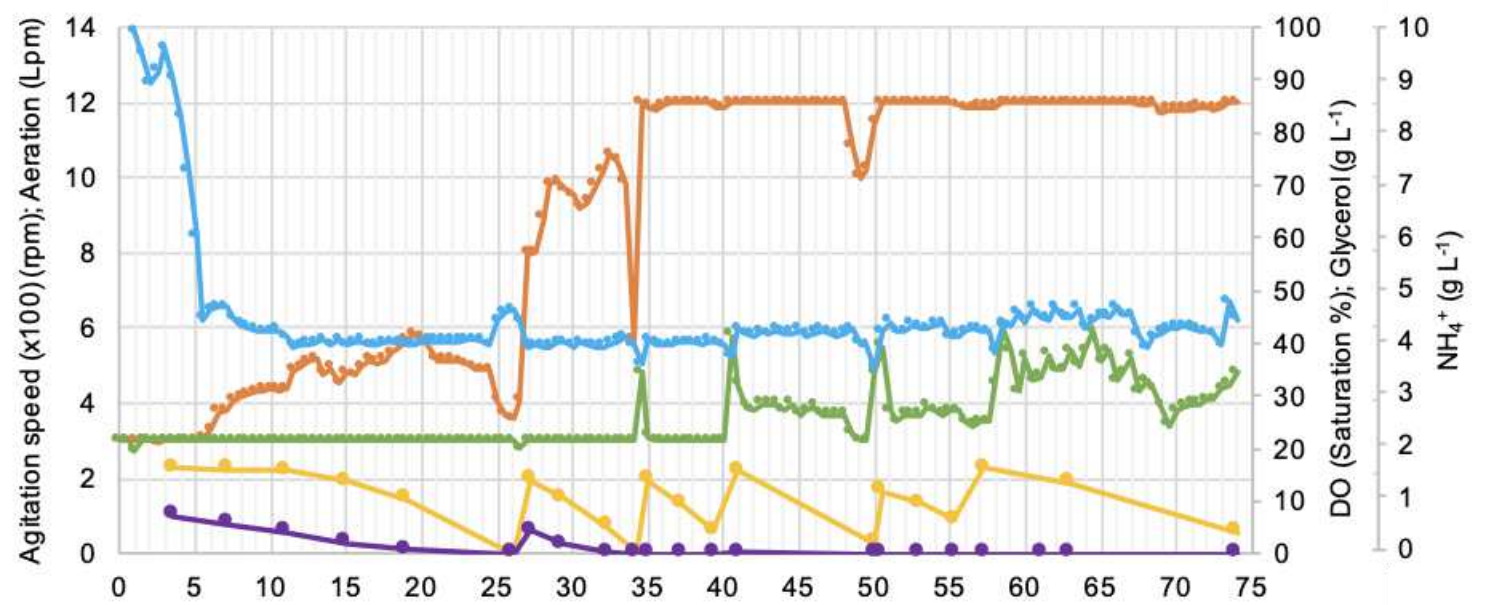

(h)

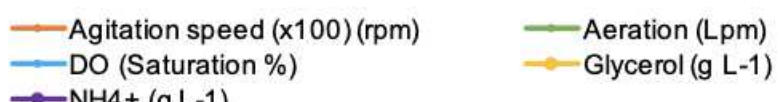

1665 Figure 7. R. eutropha L359PCJ cultivation in bioreactor with concentrated vinasse-based culture

1666 medium: monitoring of agitation speed, dissolved oxygen, aeration, glycerol and ammonium

1667 concentrations.

1668

1669

1670

1671

1672

1673

1674

1675

1676

1677

1678

1679

1680

1681

1682

1683

1684 


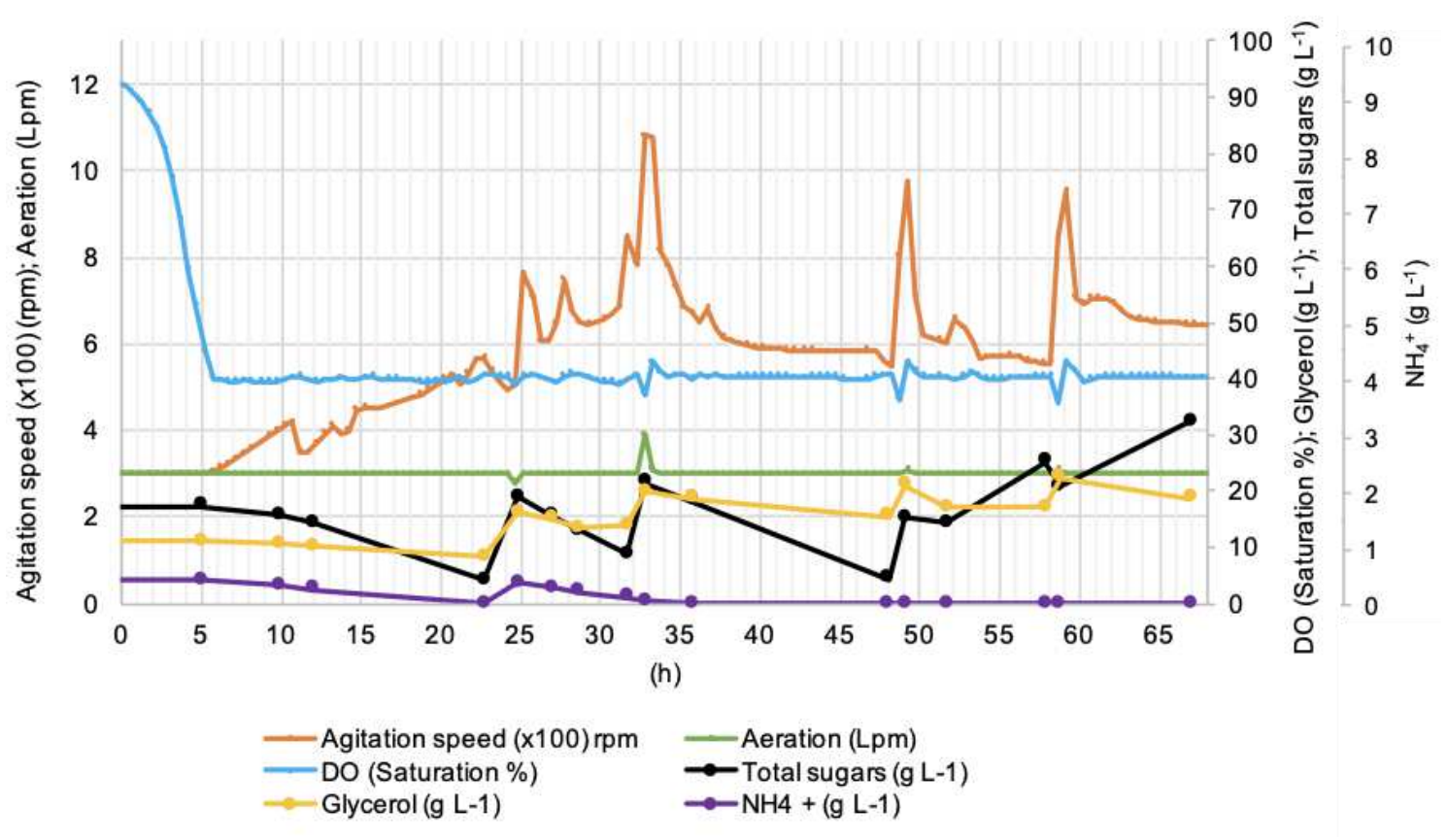

1686 Figure 8. Halomonas sp. HG03 cultivation in bioreactor with concentrated vinasse-based culture

1687 medium: monitoring of agitation speed, dissolved oxygen, aeration, glycerol and ammonium concentrations.

1689

1690

1691

1692

1693

1694

1695

1696

1697

1698

1699

1700

1701

1702

1703

1704 


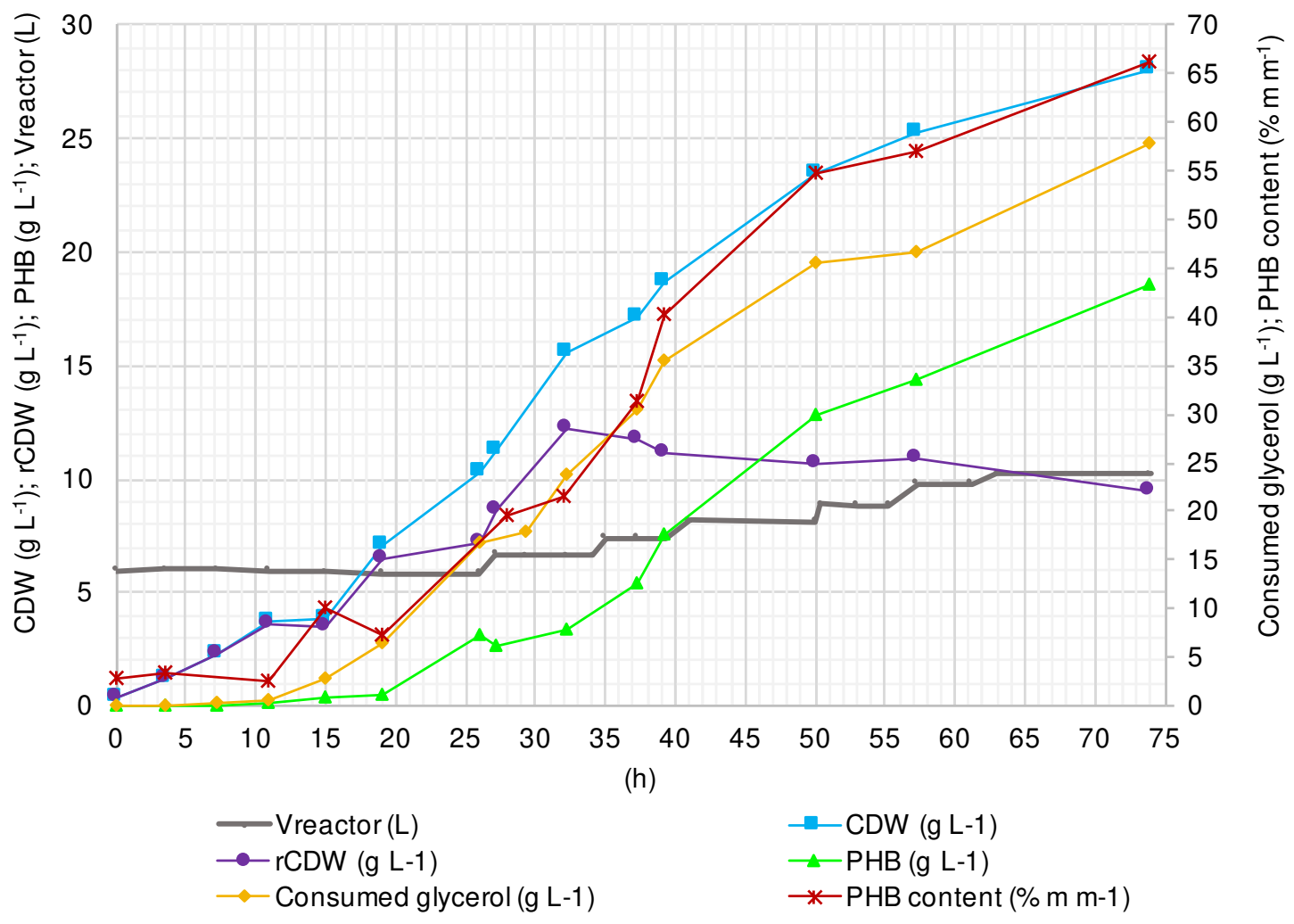

1706 Figure 9. R. eutropha L359PCJ cultivation in bioreactor with concentrated vinasse-based culture

1707 medium: volume variation, PHB content, CDW, rCDW, consumed glycerol and PHB 1708 concentrations.

1709

1710

1711

1712

1713

1714

1715

1716

1717

1718

1719

1720

1721

1722 


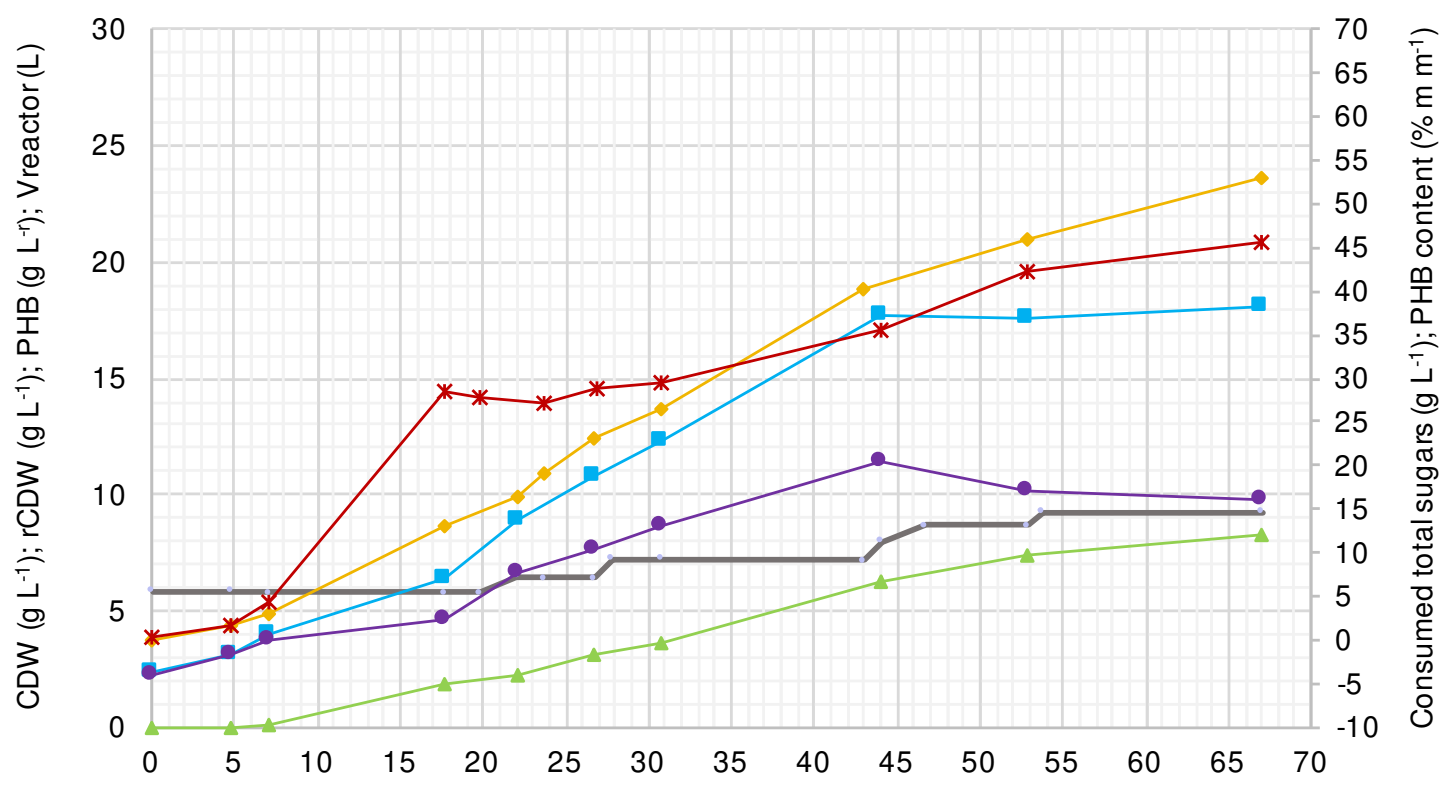

(h)

1724 Figure 10. Halomonas sp. HG03 cultivation in bioreactor with concentrated vinasse-based culture

1725 medium: volume variation, PHB content, CDW, rCDW, consumed total sugars and PHB 1726 concentrations.

1727

1728

1729

1730

1731

1732

1733

1734

1735

1736

1737

1738

1739

1740 
Table 8. Simulation parameters in base scenario SC1 - input, output data and settings in SuperPro Designer model.

\begin{tabular}{|c|c|c|}
\hline Unit procedure & Value & Unit \\
\hline \multicolumn{3}{|l|}{ Seed fermenter } \\
\hline $\mathrm{rCDW}_{0}$ & 0 & $g L^{-1}$ \\
\hline$Y_{x / S}$ & $0.52^{\ddagger}$ & $\mathrm{g} \mathrm{g}^{-1}$ \\
\hline $\mathrm{YP} / \mathrm{S}_{1}$ & $0.14^{\ddagger}$ & $\mathrm{g} \mathrm{g}^{-1}$ \\
\hline \multirow[t]{2}{*}{$\mathrm{rCDW}_{\mathrm{f}}$} & 0.565 * & ton batch ${ }^{-1}$ \\
\hline & 14.1 & $g L^{-1}$ \\
\hline \multirow[t]{2}{*}{$\mathrm{PHB}_{\mathrm{f}}$} & $0.152 *$ & ton batch ${ }^{-1}$ \\
\hline & 3.8 & $g L^{-1}$ \\
\hline Glycerol input & 1.09 * & ton batch ${ }^{-1}$ \\
\hline \multicolumn{3}{|l|}{ Production fermenter " } \\
\hline \multicolumn{3}{|l|}{ (Growth phase) } \\
\hline$\mu_{\max }$ & $0.255^{\ddagger}$ & $\mathrm{h}^{-1}$ \\
\hline $\mathrm{rCDW}_{0}$ & $0.3^{\ddagger}$ & $g L^{-1}$ \\
\hline $\mathrm{rCDW}_{\mathrm{f}}$ & 30 & $g L^{-1}$ \\
\hline PHB content & $21.4^{\ddagger}$ & $\% \mathrm{~m} \mathrm{~m}^{-1}$ \\
\hline PHB titer $_{f}$ & $8.2 \S$ & $g L^{-1}$ \\
\hline CDW & $38.2^{\S}$ & $g L^{-1}$ \\
\hline Time & $18^{\S}$ & $\mathrm{h}$ \\
\hline \multicolumn{3}{|c|}{ (PHB accumulation phase) } \\
\hline$\mu_{P}$ & $0.05^{\ddagger}$ & $h^{-1}$ \\
\hline \multirow[t]{2}{*}{$r C D W_{0}=r C D W_{f}$} & 54 * & ton batch ${ }^{-1}$ \\
\hline & 30 & $g L^{-1}$ \\
\hline PHB content 0 & $21.4^{\ddagger}$ & $\% \mathrm{~m} \mathrm{~m}^{-1}$ \\
\hline PHB content $f$ & $66.3^{\ddagger}$ & $\% \mathrm{~m} \mathrm{~m}^{-1}$ \\
\hline PHB titero & $8.2^{\S}$ & $g L^{-1}$ \\
\hline \multirow[t]{2}{*}{ PHB titer $_{f}$} & $59 \S$ & $g L^{-1}$ \\
\hline & 108 * & ton batch ${ }^{-1}$ \\
\hline $\mathrm{CDW}_{f}$ & $89 \S$ & $g L^{-1}$ \\
\hline Time & $33.8^{\S}$ & $\mathrm{h}$ \\
\hline \multicolumn{3}{|l|}{ (Global) } \\
\hline$Y_{X / S}\left(g^{-1}\right)$ & $0.16^{\ddagger}$ & $\mathrm{g} \mathrm{g}^{-1}$ \\
\hline$Y_{P / S}\left(g^{-1}\right)$ & $0.32^{\ddagger}$ & $\mathrm{g} \mathrm{g}^{-1}$ \\
\hline Productivity & $1.1 \S$ & $g \operatorname{Lh}^{-1}$ \\
\hline Time & $51.7 \S$ & $\mathrm{h}$ \\
\hline Glycerol input & $337.3 *$ & ton batch ${ }^{-1}$ \\
\hline
\end{tabular}

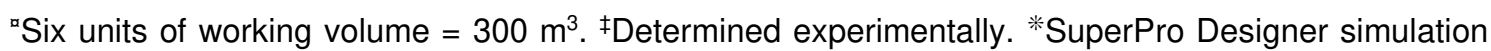
data. ${ }^{\S}$ Calculated using experimental data. 
Batch \#1 (Complete process)

P-10 / V-104 - Medium preparation and sterilization

P-11 / SFR-101 - Inoculum preparation

* P-1 / FR-101 - Bioprocess

* Bioreactor charging

* Reaction

P-2 / V-101 - Culture medium transfer out

P-3 / DS-101 - Centrifugation

P-4 / V-102 - Surfactant treatment

P-6 / DS-102 - Centrifugation

P-5 / MX-101 - Hypochlorite digestion

P-16 / DS-104 - Centrifugation

P-7 / V-103 - Washing

P-8 / DS-103 - Centrifugation

P-9 / SDR-101 - Spray-drying

Batch \#2 (Complete process)

P-10 / V-104 - Medium preparation and sterilization

P-11 / SFR-101 - Inoculum preparation

* P-1 / FR-101 - Bioprocess

Downstream_Batch \#2

Batch \#3 (Complete process)

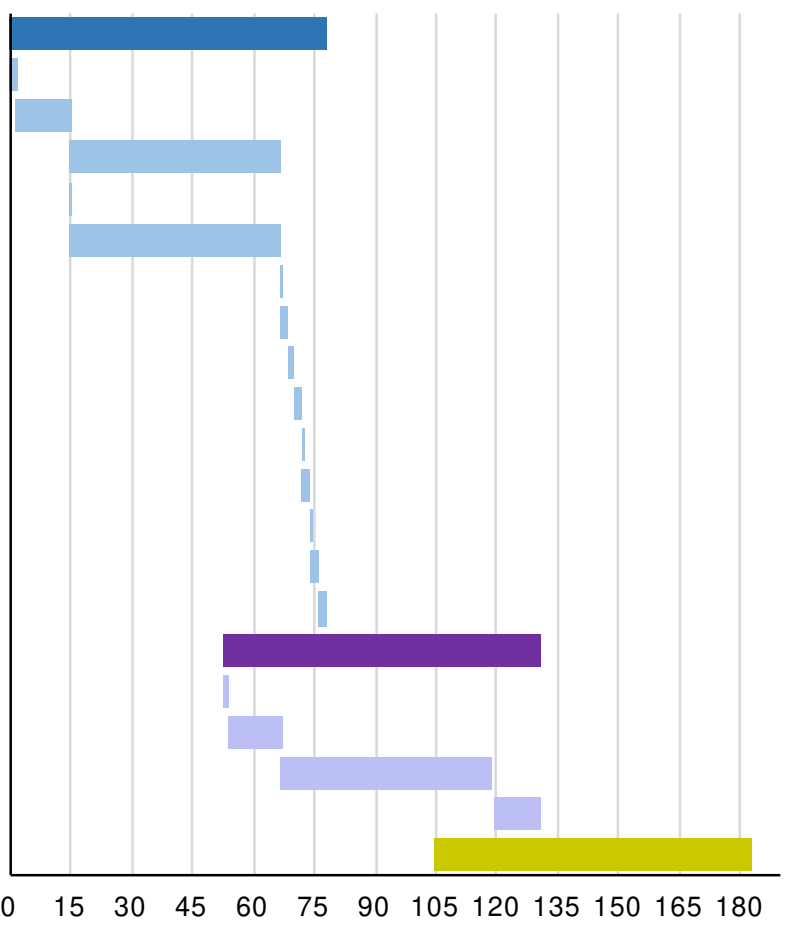

(h)

1742

1743 Figure 11. Gantt chart of base scenario SC1: Unit procedure (P-) / equipment - operation. (苂)

1744 Bottleneck unit procedure. (*) Operations in bottleneck unit procedure.

1745

1746

1747

1748

1749

1750

1751

1752

1753

1754

1755

1756

1757

1758

1759 
Table 9. Simulation parameters and output data - Base scenario SC1 (this study) and Leong et al. (2017).

\begin{tabular}{|c|c|c|}
\hline & Scenario SC1 & Leong et al. (2017) \\
\hline PHB productivity $\left(\mathrm{g} \mathrm{Lh}^{-1}\right)$ & $1.1 \S$ & 2.86 \\
\hline Operating hours year-1 $(h)$ & 5760 & 7920 \\
\hline Bioprocess time $(h)$ & $51.7 \S$ & 42 \\
\hline Purified PHB batch-1 (ton) & 93.9 & 56.3 \\
\hline Number of batches year-1 & 109 & 146 \\
\hline Units of production bioreactors & 6 & 3 \\
\hline PHB content $\left(\% \mathrm{~m} \mathrm{~m}^{-1}\right)$ & $66.3^{\ddagger}$ & 49 \\
\hline Glycerol batch $^{-1}$ (ton) & 307.5 & 190.3 \\
\hline Total annual production cost (US\$) & $63,991,002$ & $57,883,913$ \\
\hline Raw materials (\%) & 37.4 & 39.0 \\
\hline Glycerol (\%) & 23.1 & 27.6 \\
\hline Facility (\%) & 56.9 & 51.0 \\
\hline Labor (\%) & 3.6 & 8.0 \\
\hline Utilities (\%) & 1.5 & 2.0 \\
\hline Laboratory and others (\%) & 0.5 & $<1$ \\
\hline Glycerol price (US\$ ton-1) & 400 & 500 \\
\hline Annual production (PHB tons) & 10,000 & 9,000 \\
\hline Total investment (US\$) & $206,597,000$ & $170,658,000$ \\
\hline Direct fixed cost (US\$) & $193,501,000$ & $160,098,000$ \\
\hline Equipment purchase cost (US\$) & $32,281,250$ & $27,535,000$ \\
\hline Unit production cost (US\$ $\left.\mathrm{kg}_{\mathrm{PHB}^{-1}}\right)$ & 6.2 & 6.1 \\
\hline Return on investment (ROI) (\%) & 20,05 & 21.8 \\
\hline Internal rate of return (IRR) (\%) & 14.0 & 18.0 \\
\hline Net present value (NPV) (US\$) & $112,135,000$ & $117,213,000$ \\
\hline Payback (years) & 5,0 & 4.6 \\
\hline
\end{tabular}




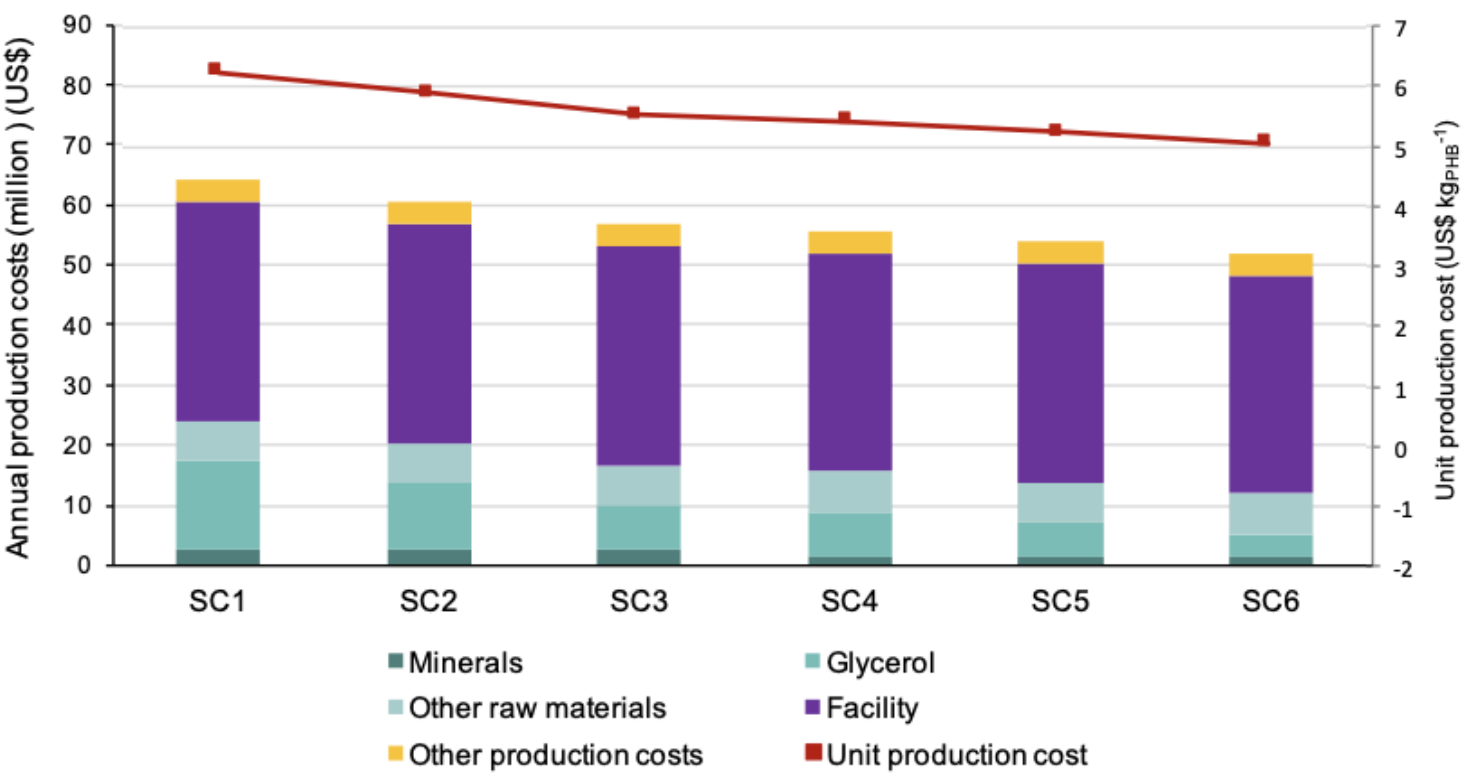

1764 Figure 12. Unit production costs and annual production costs discriminated by raw materials,

1765 facility and others in scenarios with mineral medium (SC1, SC2, SC3) and scenarios with

1766 concentrated vinasse as partial source of nutrients in culture medium (SC4, SC5, SC6).

1767

1768

1769

1770

1771

1772

1773

1774

1775

1776

1777

1778

1779

1780

1781

1782

1783 


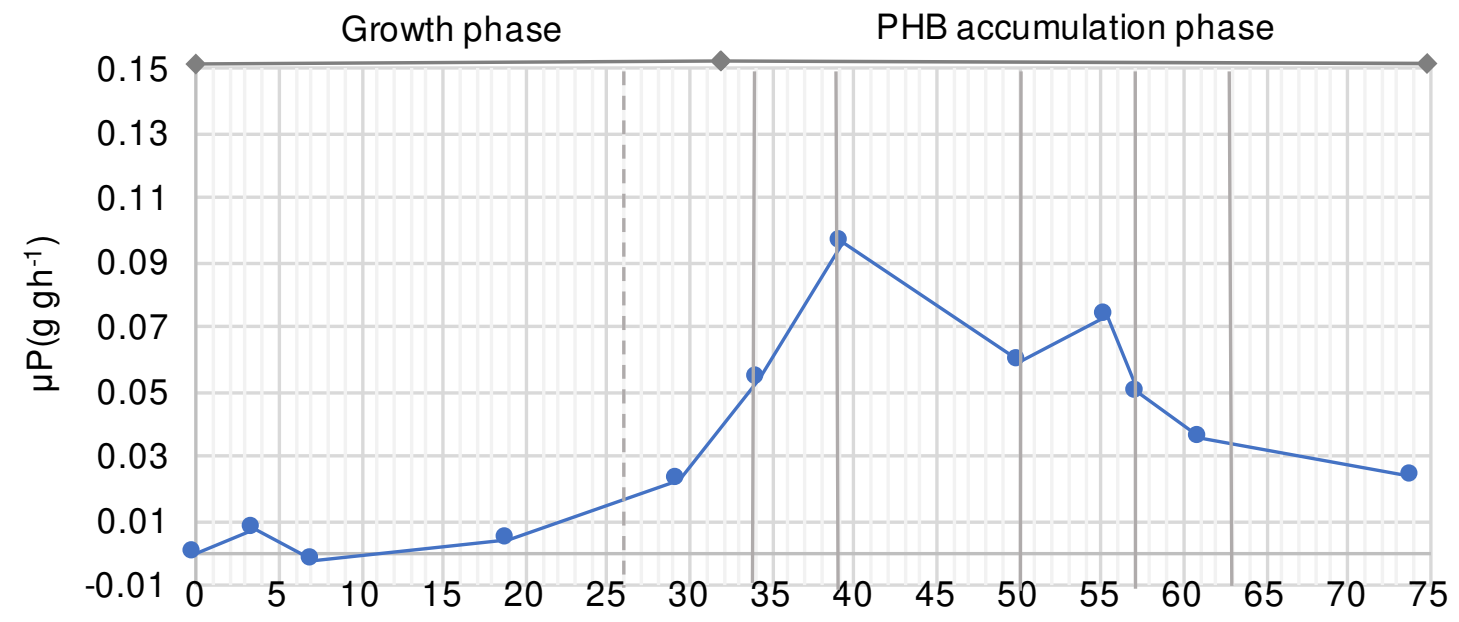

1784

(h)

1785 Figure 13. R. eutropha L359PCJ cultivation in bioreactor with concentrated vinasse-based culture

1786 medium: specific velocities of product biosynthesis $\left(\mu \mathrm{p} \mathrm{g} \mathrm{gh}^{-1}\right)$. (-- ): start of the second batch. ( $1787 \quad$ ): start of third to seventh batches.

1788

1789

1790

1791

1792

1793

1794

1795

1796

1797

1798

1799

1800

1801

1802

1803

1804

1805 
Table 10. Optimistic, realistic and pessimistic scenarios for simulation of productivities, cell density and PHB titers.

\begin{tabular}{cccccccc}
\hline Scenario & $\begin{array}{c}\mathrm{X}_{f-S i} \\
\left(\mathrm{~g} \mathrm{~L}^{-1}\right)\end{array}$ & $\begin{array}{c}\mu \mathrm{P} \\
\left(\mathrm{g} \mathrm{gh}^{-1}\right)\end{array}$ & $\mathrm{t}_{X-S i}(\mathrm{~h})$ & $\mathrm{t}_{P H B-S i}(\mathrm{~h})$ & $\begin{array}{c}\text { Total process } \\
\text { time }(\mathrm{h})\end{array}$ & $\begin{array}{c}\mathrm{P}_{f-S i} \\
\left(\mathrm{~g} \mathrm{~L}^{-1}\right)\end{array}$ & $\begin{array}{c}\mathrm{Pp}_{S i} \\
\left(\mathrm{~g} \mathrm{Lh}^{-1}\right)\end{array}$ \\
\hline SC70 & 30 & 0.07 & 18 & 23.4 & 40.8 & 59 & 1.4 \\
SC8 & 30 & 0.05 & 18 & 33.8 & 51.7 & 59 & 1.1 \\
SC9p & 30 & 0.02 & 18 & 70.4 & 88.2 & 59 & 0.7 \\
SC10 & 40 & 0.07 & 19 & 23.4 & 41.9 & 78.7 & 1.9 \\
SC11 & 40 & 0.05 & 19 & 33.8 & 52.8 & 78.7 & 1.5 \\
SC12 & 40 & 0.02 & 19 & 70.4 & 89.4 & 78.7 & 0.9 \\
SC13 & 50 & 0.07 & 20 & 23.4 & 42.8 & 98.4 & 2.3 \\
SC14 & 50 & 0.05 & 20 & 33.8 & 53.7 & 98.4 & 1.8 \\
SC15 & 50 & 0.02 & 20 & 70.4 & 90.3 & 98.4 & 1.1 \\
\hline
\end{tabular}

o: optimistic scenarios; ' r: realistic scenarios; : pessimistic scenarios.

1806

1807

1808

1809

1810

1811

1812

1813

1814

1815

1816

1817

1818

1819

1820

1821

1822

1823

1824 


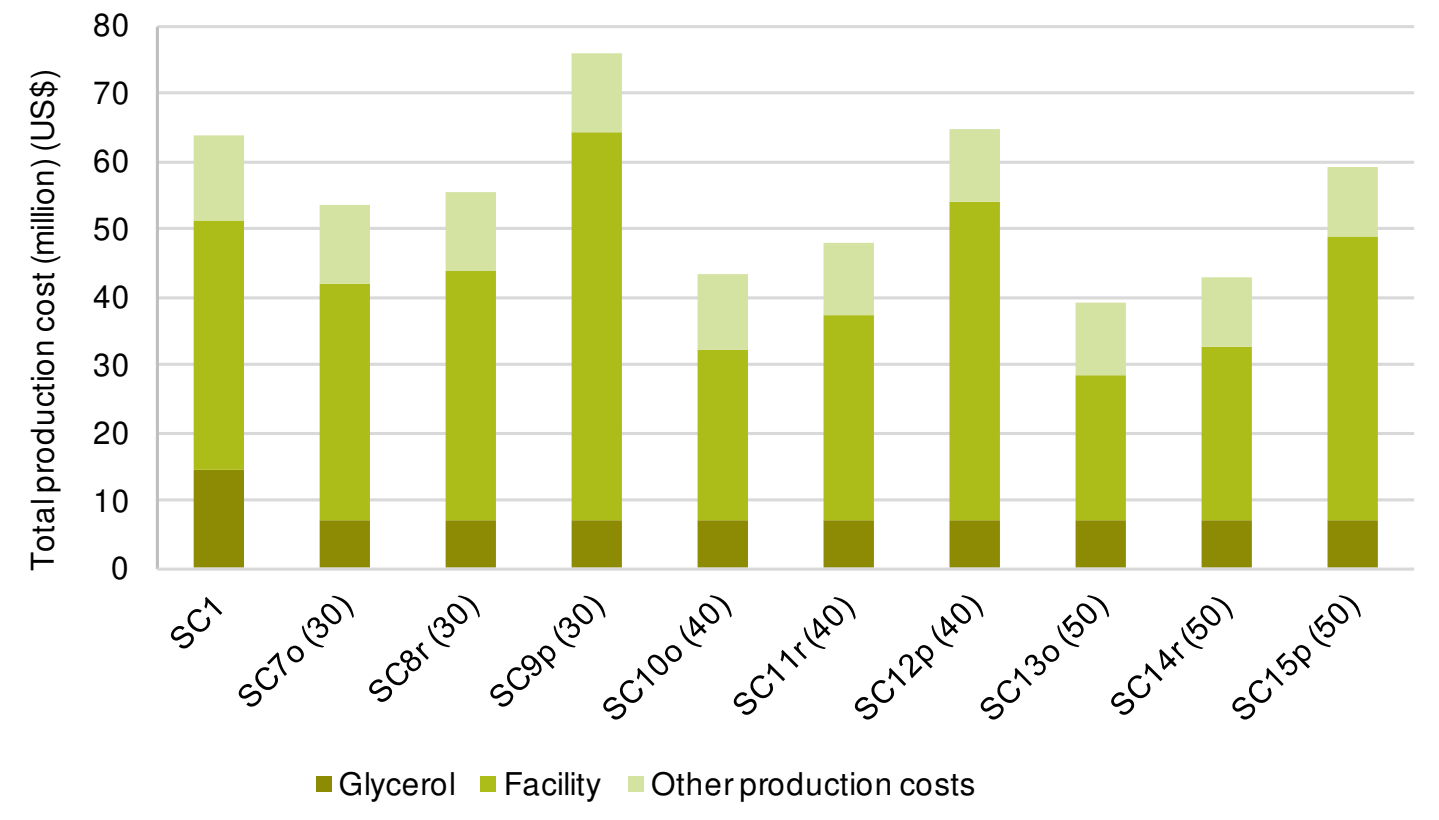

1825

Figure 14. Total annual production costs. (o) optimistic scenarios; $(r)$ realistic scenarios; $(p)$

1827 pessimistic scenarios; (30) $\mathrm{X}_{f-S i}=30 \mathrm{~g} \mathrm{~L}^{-1}$; 30) $\mathrm{X}_{f-S i}=40 \mathrm{~g} \mathrm{~L}^{-1}$; 30) $\mathrm{X}_{f-S i}=50 \mathrm{~g} \mathrm{~L}^{-1}$.

1828

1829

1830

1831

1832

1833

1834

1835

1836

1837

1838

1839

1840

1841

1842

1843

1844

1845 
A.

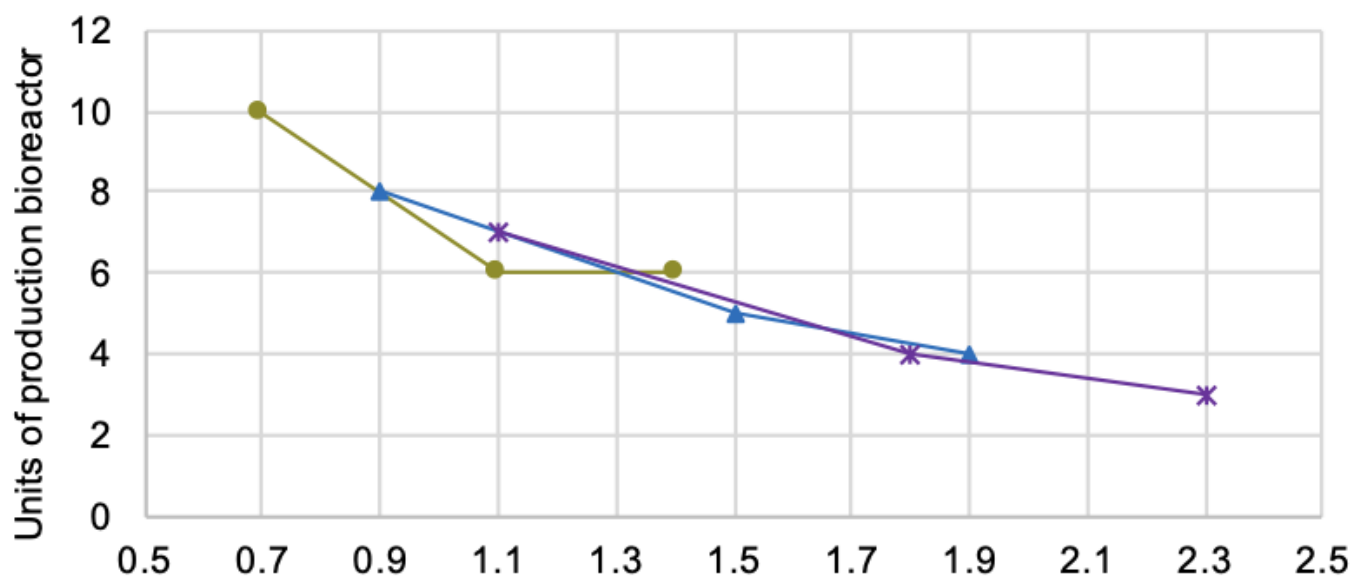

B.

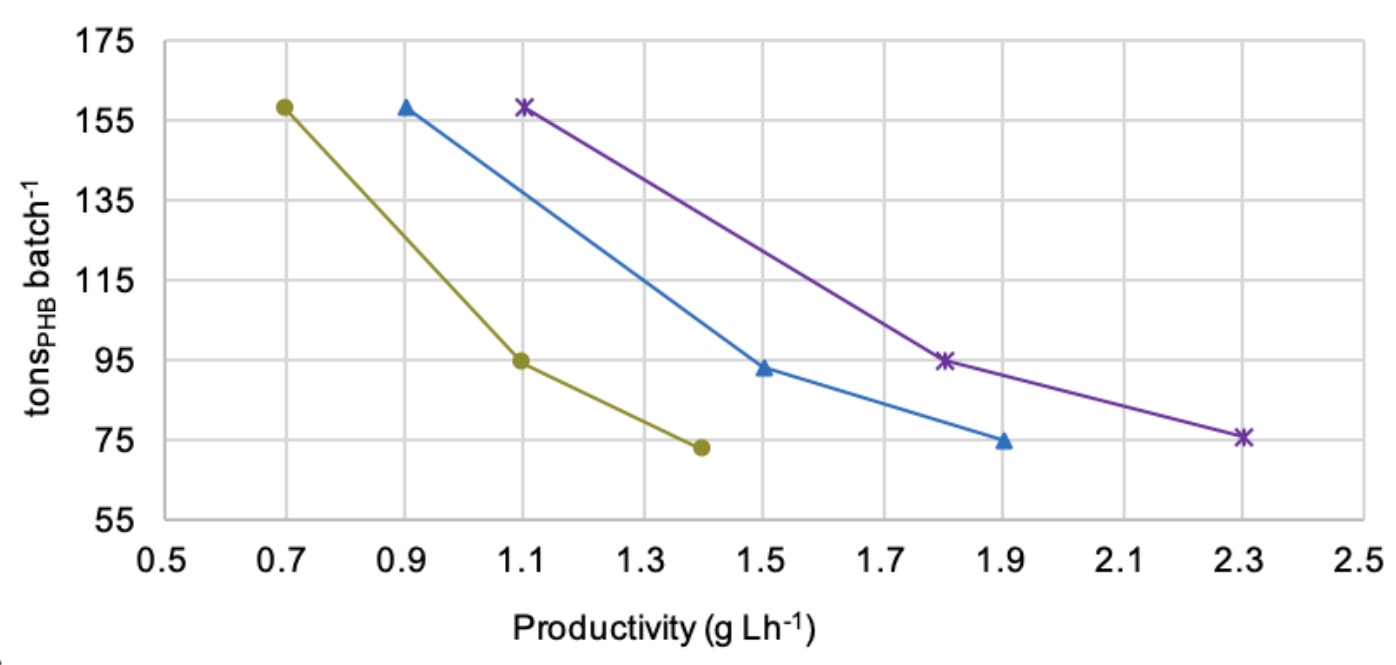

C.

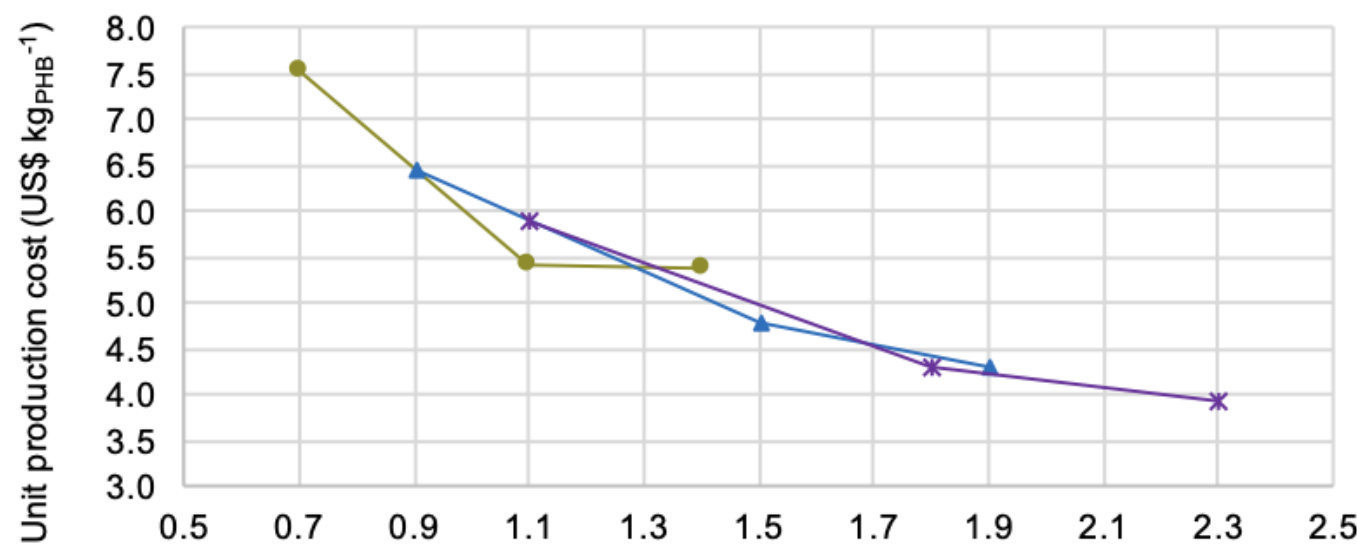

Productivity $\left(\mathrm{g} \mathrm{Lh}^{-1}\right)$

1847 Figure 15. Effect of productivity on production costs. A.Number of units of production bioreactor.

1848 B. PHB production as tons per batch. C. Unit production cost. 
Table 11. Unit production costs and profitability indicators in scenarios of optimistic, realistic and pessimistic productivities.

\begin{tabular}{|c|c|c|c|c|c|}
\hline Scenario & $\begin{array}{l}\text { Unit production cost } \\
\left(\text { US } \$ \mathrm{~kg}_{\mathrm{PHB}^{-1}}\right)\end{array}$ & $\begin{array}{l}\mathrm{ROI} \\
(\%)\end{array}$ & $\begin{array}{c}\text { Payback } \\
\text { (years) }\end{array}$ & IRR (\%) & $\begin{array}{l}\text { NPV (million) } \\
\text { (US\$) }\end{array}$ \\
\hline $\mathrm{SC}^{\circ}(30)$ & 5.4 & 23.2 & 4.3 & 17.0 & 152.3 \\
\hline SC8r (30) & 5.4 & 22.6 & 4.4 & 16.2 & 151.3 \\
\hline $\operatorname{SC9p}(30)$ & 7.5 & 13.6 & 7.3 & 6.8 & 15.1 \\
\hline $\operatorname{SC} 10^{\circ}(40)$ & 4.3 & 32.8 & 3.1 & 25.1 & 217.6 \\
\hline $\operatorname{SC} 11^{r}(40)$ & 4.8 & 27.2 & 3.7 & 20.6 & 186.0 \\
\hline $\mathrm{SC} 12^{\mathrm{p}}(40)$ & 6.5 & 17.0 & 5.9 & 10.7 & 80.5 \\
\hline $\operatorname{SC} 13^{\circ}(50)$ & 3.9 & 28.9 & 2.6 & 29.8 & 241.6 \\
\hline $\operatorname{SC} 14^{r}(50)$ & 4.3 & 32.6 & 3.1 & 24.9 & 217.2 \\
\hline $\mathrm{SC} 15^{\mathrm{p}}(50)$ & 5.9 & 19.5 & 5.2 & 13.2 & 115.1 \\
\hline
\end{tabular}

1849 


\section{Supplementary Files}

This is a list of supplementary files associated with this preprint. Click to download.

- graphicalabstract.png 